Review

\title{
Five-Membered Cyclic Carbonates: Versatility for Applications in Organic Synthesis, Pharmaceutical, and Materials Sciences
}

\author{
Patrick Rollin ${ }^{1, * \mathbb{D}}$, Liane K. Soares ${ }^{2}$, Angelita M. Barcellos ${ }^{2}{ }^{\circ}$, Daniela R. Araujo ${ }^{2}$, Eder J. Lenardão ${ }^{2}(\mathbb{D}$, Raquel \\ G. Jacob ${ }^{2}$ and Gelson Perin ${ }^{2, * \mathbb{D}}$ \\ 1 Université d'Orléans et CNRS, Institut de Chimie Organique et Analytique, UMR 7311, BP 6759, \\ F-45067 Orléans, France \\ 2 Laboratório de Síntese Orgânica Limpa LASOL, Centro de Ciências Químicas, Farmacêuticas e de Alimentos \\ CCQFA, Universidade Federal de Pelotas UFPel, P.O. Box 354, Pelotas 96010-900, RS, Brazil; \\ lianekrolowsoares@yahoo.com.br (L.K.S.); angelita.barcellos@gmail.com (A.M.B.); \\ daniela.roodriguues@gmail.com (D.R.A.); elenardao@uol.com.br (E.J.L.); raquelgjacob@yahoo.com.br (R.G.J.) \\ * Correspondence: patrick.rollin@univ-orleans.fr (P.R.); gelson_perin@ufpel.edu.br (G.P.); \\ Tel./Fax: +55-53-3275-7533 (G.P.)
}

check for updates

Citation: Rollin, P.; Soares, L.K.; Barcellos, A.M.; Araujo, D.R.; Lenardão, E.J.; Jacob, R.G.; Perin, G. Five-Membered Cyclic Carbonates: Versatility for Applications in Organic Synthesis, Pharmaceutical, and Materials Sciences. Appl. Sci. 2021, 11, 5024. https://doi.org/10.3390/ app11115024

Academic Editor: Marta

Erminia Alberto

Received: 30 April 2021

Accepted: 27 May 2021

Published: 29 May 2021

Publisher's Note: MDPI stays neutral with regard to jurisdictional claims in published maps and institutional affiliations.

Copyright: (c) 2021 by the authors. Licensee MDPI, Basel, Switzerland. This article is an open access article distributed under the terms and conditions of the Creative Commons Attribution (CC BY) license (https:// creativecommons.org/licenses/by/ $4.0 /)$.

\begin{abstract}
This review presents the recent advances involving several applications of five-membered cyclic carbonates and derivatives. With more than 150 references, it covers the period from 2012 to 2020, with special emphasis on the use of five-membered cyclic carbonates as building blocks for organic synthesis and material elaboration. We demonstrate the application of cyclic carbonates in several important chemical transformations, such as decarboxylation, hydrogenation, and transesterification reactions, among others. The presence of cyclic carbonates in molecules with high biological potential is also displayed, together with the importance of these compounds in the preparation of materials such as urethanes, polyurethanes, and flame retardants.
\end{abstract}

Keywords: cyclic carbonates; glycerol; green chemistry

\section{Introduction}

Organic carbonates are important synthetic intermediates in a number of reactions [1,2]. They are characterized by presenting a carbonyl group flanked by two oxygen atoms and may be linear or cyclic. Five-membered cyclic carbonates can be obtained through the combination of $\mathrm{CO}_{2}$ with diols and epoxides [3-6] or by conversion of glycerol into glycerol carbonate and derivatives (Figure 1) [7].<smiles>OCC(O)C1CCCC1</smiles>

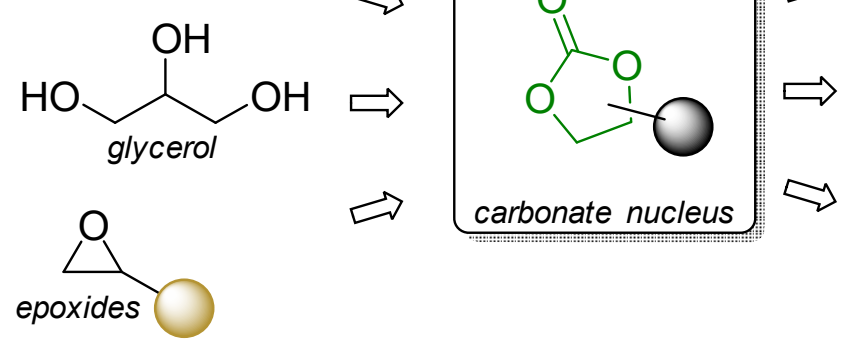

\section{bioactive molecules \\ potential application as materials}

Figure 1. Versatility of five-membered cyclic carbonates.

Among the above-mentioned substrates, glycerol derivatives are particularly important starting materials, which have been widely exploited for different applications, such as their potent antiwear action when added to fuels [8]. For example, glycerol carbonate 
(GC) 1a was used as a monomer in the synthesis of hyperbranched aliphatic polyethers [9] and polyurethanes [10].

The versatility of GC-derived five-membered cyclic carbonates as synthons in organic synthesis was explored by Rollin and co-workers [11-14]. However, their extensive reactivity was reviewed only recently [15-21]. Therefore, being interested in the chemical versatility of the carbonate moiety, we provide here an updated review of the recent advances involving different applications of five-membered cyclic carbonates and derivatives in organic synthesis.

For an optimized discussion, this review presents papers published between 2012 and 2020, organized in three sections, according to the potential application of the synthesized compounds in chemistry, biology, and material science studies.

\section{Applications in Chemistry}

\subsection{Decarboxylation of Cyclic Carbonates}

The decarboxylation reaction of glycerol carbonate (GC) 1a with concomitant generation of $\mathrm{CO}_{2}$ is a typical method used to obtain the 1,2-anhydroglycerol derivative denominated glycidol, which has a variety of industrial uses, such as in surface coatings, as a gelation agent in solid propellants, as a stabilizer for natural oils and vinyl polymers, and as a demulsifier (emulsion breaker). Glycidol is also used as an intermediate in the synthesis of esters and amines and it can be of high-value in the production of epoxy resins, polyurethanes, and in the controlled etherification of glycerol to form polyglycerols [22,23].

At the industrial level, glycidol can be produced through oxidation of allyl alcohol using hydrogen peroxide in the presence of a titanium silicate catalyst [24]. However, all conventional processes used to prepare glycidol generate undesirable byproducts; therefore, producing glycidol from glycerol derivatives stands as an interesting alternative to minimize the generation of waste.

Kim, Lee, and co-workers [25] performed the decarboxylation of GC 1a to glycidol 2a using various ionic liquids (ILs) as catalysts $(0.5 \mathrm{~mol} \%)$ at $175^{\circ} \mathrm{C}$ under reduced pressure $(2.67 \mathrm{kPa})$ for $30 \mathrm{~min}$, releasing $\mathrm{CO}_{2}$ as the only co-product (Scheme 1). After studying the catalytic efficiency of anions (with a range of sodium salts) and cations (with a range of metallic chlorides), the authors discovered that both the yield and selectivity in producing glycidol 2a could be improved by using ILs. The best results were attained using [bmim] nitrate and iodide (59-73\% yields), due to the strong interaction of the anion of the IL with 1a and the weak interaction with $2 \mathbf{a}$. The effects of the $N$-cations were less pronounced, while $[\mathrm{bdmim}] \mathrm{NO}_{3},[\mathrm{bmim}] \mathrm{NO}_{3},\left[\mathrm{Bu}_{4} \mathrm{~N}\right] \mathrm{NO}_{3}$, and $[\mathrm{MPPyr}] \mathrm{NO}_{3}$ all proved similarly satisfactory for the production of $2 \mathrm{a}$. The addition of Lewis acid $\mathrm{Zn}\left(\mathrm{NO}_{3}\right)_{2}$ to the reaction medium caused an increase in the glycidol yield, which was attributed to the weakening of the hydrogen-bonding interactions between the nitrate anion of $[\mathrm{bmim}] \mathrm{NO}_{3}$ and the hydroxyl groups of $\mathbf{1 a}$ and $\mathbf{2 a}$.

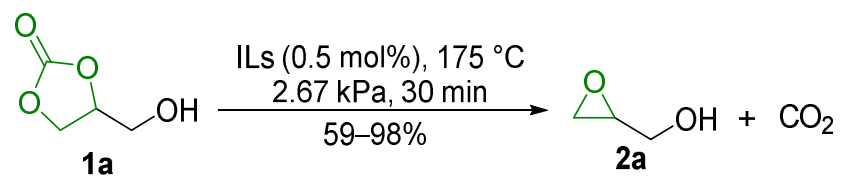

Scheme 1. The decarboxylation of GC 1a to glycidol 2a.

In a continuous process, a solvent was used to minimize the contact between the IL and glycidol while simultaneously removing $\mathbf{2 a}$ as soon as it formed. The use of high-boiling solvents, such as glycol dimethyl ether, dibenzyl ether, and dibutyl phthalate, increased the yield (83-98\%) and selectivity in both batch and continuous reactions. The mechanism of the decarboxylation of $\mathbf{1 a}$ was theoretically investigated under [EMIm] $\mathrm{NO}_{3}$ catalysis and computational calculations showed that the decarboxylation of 1a to $2 \mathbf{a}$ to proceeded in two steps: (1) nitrate-assisted ring-opening of 1a, followed by formation of a 3-membered ring; (2) proton-transfer from $\mathrm{HNO}_{3}$ to an oxygen atom of the carbonate group, along with 
the simultaneous loss of $\mathrm{CO}_{2}$. It is worth mentioning that $\mathrm{Li}$ and co-workers [26] recently developed a similar protocol for synthesizing epoxybutane from 1,2-butanediol by using the ionic liquid 1-butyl-3-methylimidazolium bromide in batch or continuous processes.

With a view to getting away from conventional heating, the conversion of $1 \mathbf{a}$ to $\mathbf{2 a}$ was studied through alternative methodologies: solvent-free thermal activation at 150 ${ }^{\circ} \mathrm{C}$ over $23 \mathrm{~h}$ (about $35 \%$ conversion yield), ultrasound activation at ca. $60{ }^{\circ} \mathrm{C}(44-48 \%$ conversion yield), and microwave activation in liquid phase at $150{ }^{\circ} \mathrm{C}$ over $30 \mathrm{~min}(48-71 \%$ conversion yield). In all cases, the authors used a ZSM-5 zeolite or a zinc oxide-supported nanoscaled cobalt oxide (RT-10CoZn, $5 \mathrm{wt} \%$ ) as catalysts (Scheme 2) [27]. In thermal activation, the ZSM-5 zeolite showed $100 \%$ selectivity for $\mathbf{2 a}$, while it did not exceed $60 \%$ with RT-10CoZn. In ultrasonic activation, RT-10CoZn showed 100\% selectivity for $2 a$, whereas in microwave activation, RT-10CoZn reaches $71 \%$ conversion yield to $2 \mathbf{a}$ with total selectivity, indicating that this catalyst delivers the best performance in the shortest reaction time (30 min vs. $6-7 \mathrm{~h}$ under ultrasonic activation and $23 \mathrm{~h}$ under thermal activation). The hypothetical mechanism is based on the polymerization of $1 \mathrm{a}$ to poly-(glyceryl-1,2carbonate), which then forms $\mathbf{2 a}$ through $\mathrm{CO}_{2}$ release. The reuse of both heterogeneous catalysts was not mentioned.

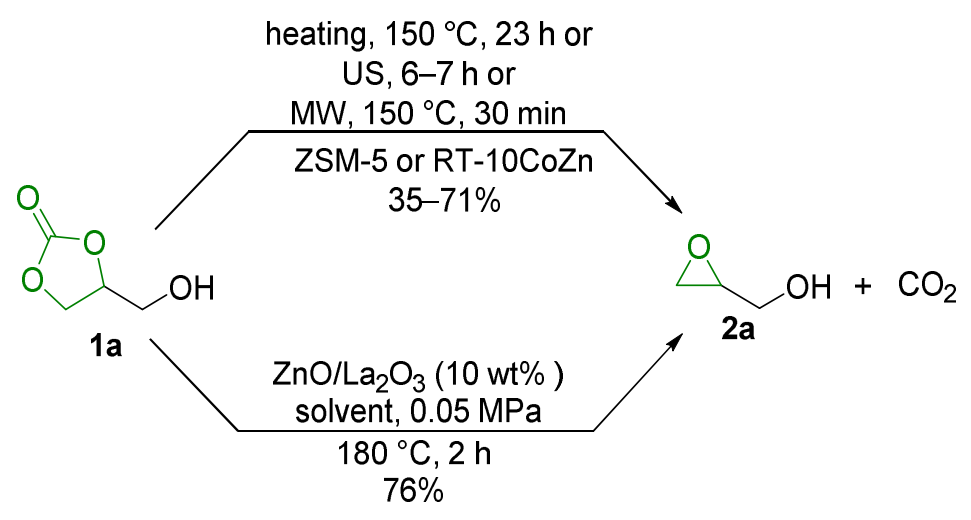

Scheme 2. Decarboxylation reactions using US, $\mathrm{MW}$ and $\mathrm{ZnO} / \mathrm{La}_{2} \mathrm{O}_{3}$.

Lee and co-workers [28] studied the use of a binary zinc-lanthanum catalytic system $\left(\mathrm{ZnO} / \mathrm{La}_{2} \mathrm{O}_{3} ; \mathrm{Zn}: \mathrm{La}\right.$ ratio $\left.=1: 9\right)$ in the decarboxylative process. When $10 \mathrm{wt} \%$ of the mixed oxides was employed in the reaction, $2 \mathrm{a}$ was obtained with $76 \%$ yield after $2 \mathrm{~h}$ reaction under reduced pressure $(0.05 \mathrm{MPa})$ in a nonspecific solvent below $180^{\circ} \mathrm{C}$ (Scheme 2$)$. The evaluation of the catalytic activity showed that an increase in the La molar ratio correlates with a yield increase of $\mathbf{2 a}$, due to equilibrium between acidic and basic sites on the surface of the catalyst. However, when the reaction was performed in the presence of $\mathrm{La}_{2} \mathrm{O}_{3}$ alone, 2a was obtained with $47 \%$ yield only.

Mahajani and co-workers [29] produced 2a by using the same $\mathrm{ZnO} / \mathrm{La}_{2} \mathrm{O}_{3}$ system, albeit with a molar ratio for $\mathrm{Zn} / \mathrm{La}$ of 4:1. In this work, the performance of the catalyst was studied up to four re-uses (about $64-97 \%$ conversion) and a decrease of activity was noted after each cycle, because of the adsorption of carbonaceous side products on the catalytic basic sites. This problem was minimized by calcination of the catalyst to restore its activity. As the major objective of the authors was to synthesize 1a by dimethyl carbonate transesterification with glycerol, no additional studies were carried out to increase the catalyst's activity in preparing $\mathbf{2 a}$.

Hyunjoo Lee and co-workers [30] described a one-pot consecutive glycidol synthesis method from glycerol, whereby carbonylation of glycerol 3a with urea first takes place under high pressure using a homogeneous zinc catalyst to produce GC 1a. Subsequently, decarboxylation is used to obtain the desired 2a product (Scheme 3). This second reaction proceeds in acetonitrile in the presence of zinc acetate to give glycidol 2a with $67 \%$ yield after $1.5 \mathrm{~h}$. According to the authors, the high catalytic activity of $\mathrm{Zn}(\mathrm{OAc})_{2}$ can be attributed to the formation of the intermediate species $\left[\mathrm{Zn}\left(\mathrm{NH}_{3}\right)_{\mathbf{x}}(\mathrm{OAc})_{2}\right]$. 


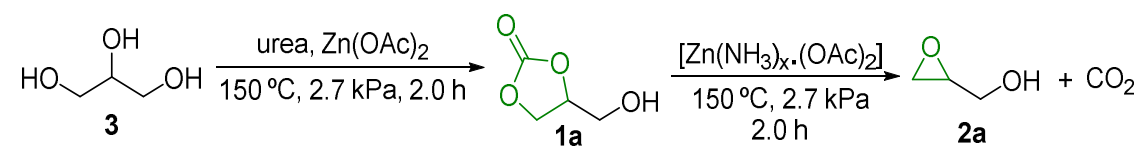

Scheme 3. One-pot consecutive glycidol synthesis method from glycerol.

An original decarboxylation process involving GC 1 was described by Falivene and coworkers [31] through an organocatalytic coupling reaction between the bromolactide 4 and carbonates 1, in the presence of the heterocyclic carbene 1,3-bis(2,4,6-trimethylphenyl)imidazol-2-ylidene (IMes), resulting in the formation of chiral keto-diesters 5 (Scheme 4 ). The reaction was found to proceed at $100{ }^{\circ} \mathrm{C}$ in times ranging from $13 \mathrm{~h}$ to $15 \mathrm{~h}$, delivering the desired products in high yields (72-93\%).

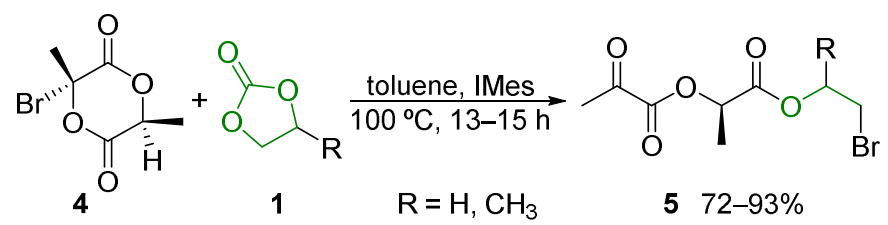

Scheme 4. Organocatalytic coupling reaction between the bromolactide 4 and carbonates $\mathbf{1}$.

More recently, the use of palladium catalysis for the decarboxylation of GC 1a was reported [32,33]. Kleij and co-workers [32] described the synthesis of ethers via a Pd-catalyzed reaction of carbonates 6 with phenols 7 in THF in the presence of cesium carbonate $\left(\mathrm{Cs}_{2} \mathrm{CO}_{3}\right)$ and phosphoramidite or phosphine ligands (Scheme 5). The authors observed that the choice of the ligand influences the regioselectivity of the reaction. Thus, by changing the ligands it was possible to direct the reaction to prepare either branched- $\mathbf{8}$ or linear allylic aryl ethers 8 . Reacting the cyclic carbonates at $0{ }^{\circ} \mathrm{C}$ for $36 \mathrm{~h}$ led to aryl ethers 8 , while running the same reaction at room temperature for $12 \mathrm{~h}$ mainly provided 9 . The products were obtained in moderate to excellent yields (49-98\%) and with considerable enantio-induction. In a closely related work, Guo and co-workers [33] developed an efficient protocol to construct densely functionalized quaternary carbons with the concomitant formation of a new $C s p^{3}-C s p^{3}$ bond through decarboxylation of carbonate 6 . The reaction was carried out in DMF at room temperature for $12 \mathrm{~h}$, using palladium catalysis with the $\mathbf{L} 2$ ligand and resulted in the formation of branched aldehydes 10 (32-91\%) and substituted acroleins 11 $(26-84 \%)$.
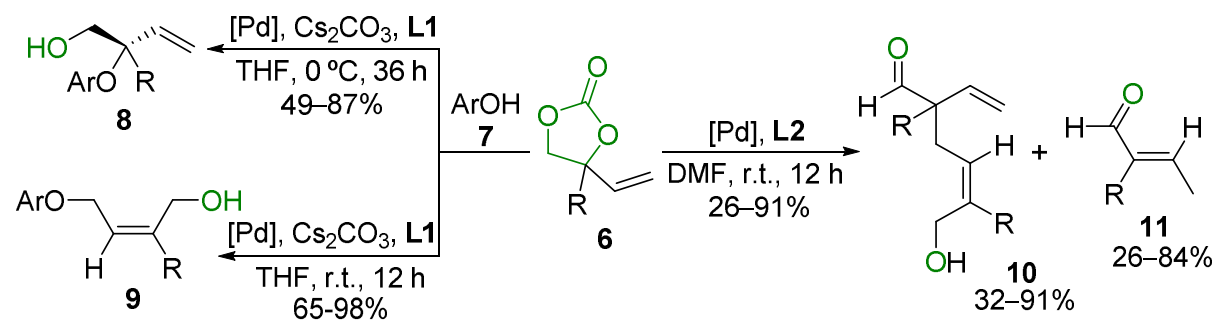

$R=$ aryl, furyl, naphthyl, alkyl<smiles>CCOP(Oc1ccc2ccccc2c1-c1cccc2ccccc12)N(C(C)C)C(C)C</smiles>

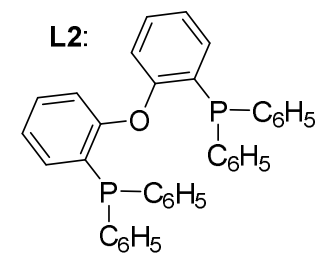

Scheme 5. Synthesis of ethers via a Pd-catalyzed reaction of carbonates 6 with phenols 7.

\subsection{Hydrogenation Reaction}

Catalytic hydrogenation of organic carbonates is of synthetic interest as an environmentally benign approach to fundamental synthetic building blocks, such as alcohols and diols [34,35]. In 2012, Han and co-workers [36] developed a process to obtain ethylene 
glycol and methanol via catalytic hydrogenation of cyclic carbonates by using (PNP)Ru ${ }^{\mathrm{II}}$ pincer complexes as catalysts (Scheme 6). In this work, ethylene glycol was prepared through insertion of $\mathrm{CO}_{2}$ into epoxides (omega process), as an option for the recycling of $\mathrm{CO}_{2}$. This catalytic process allowed them to obtain a variety of ethylene glycols (EGs) 12 with $96-99 \%$ yields, with co-production of methanol (up to $99 \%$ yield) from different cyclic carbonates 1. The reactions proceeded over $4-10 \mathrm{~h}$ in THF at $140{ }^{\circ} \mathrm{C}$ under $50 \mathrm{~atm}$ of $\mathrm{H}_{2}$ and in the presence of catalytic amounts of the $\mathrm{Ru}^{\mathrm{II}}$ complex I $(0.02-0.10 \mathrm{~mol} \%)$ and ${ }^{t} \mathrm{BuOK}$ (1.0 equivalent relative to the catalyst) in a $125 \mathrm{~mL}$ autoclave. It is noteworthy that when using GC 1a protected with a methyl or a benzyl group, the corresponding EGs 12 were obtained with $99 \%$ and $97 \%$ yields, respectively, after $4 \mathrm{~h}$. Additionally, it was observed that sterically hindered cyclic carbonates 1 required longer reaction times or higher amounts of the catalyst. The protocol was successfully applied to a six-membered ring carbonate, giving the respective diol after $2 \mathrm{~h}$ of reaction. Moreover, the protocol was used in the depolymerization of poly(propylene carbonate) (PPC), resulting in propane-1,2-diol and methanol after $24 \mathrm{~h}$, both with $99 \%$ conversion.

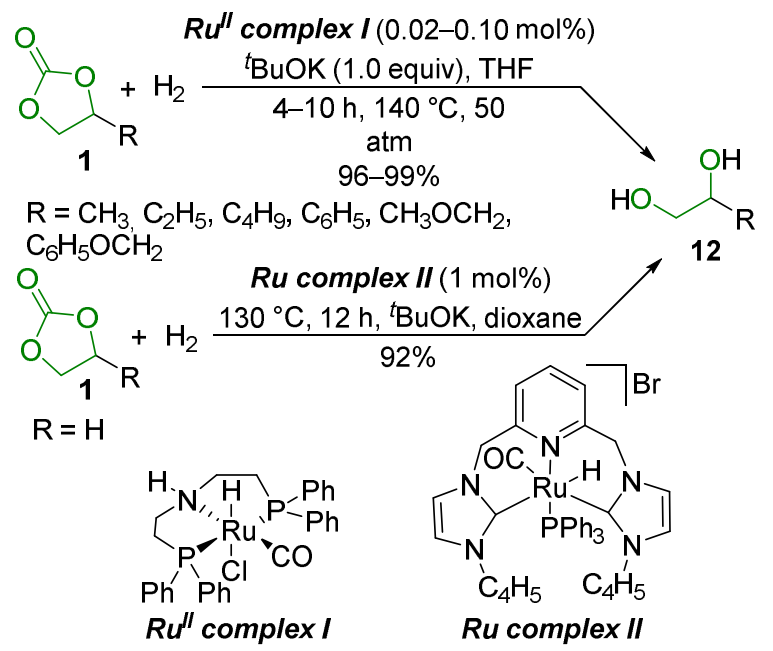

Scheme 6. Catalytic hydrogenation of cyclic carbonates by using (PNP)Ru ${ }^{\mathrm{II}}$ pincer complexes as catalysts.

Similarly, the Ru-lutidine-bridged $\mathrm{N}$-heterocyclic carbene complex (Ru complex II) was used as a catalyst in the hydrogenation of ethylene carbonate $1 c(R=H)$ (Scheme 6) [37]. In this work, glycol and methanol were obtained with $92 \%$ and $42 \%$ yields, with $99 \%$ conversion of the carbonate under $5 \mathrm{MPa}$ of $\mathrm{H}_{2}$ over $12 \mathrm{~h}$ at $130{ }^{\circ} \mathrm{C}$. A $\mathrm{N}$-butyl-substituted CNC-pincer ligand and $\mathrm{RuHCl}(\mathrm{CO})\left(\mathrm{PPh}_{3}\right)_{3}$ were applied to prepare the $\mathrm{Ru}-\mathrm{NHC}$ complex, formed in situ in the presence of ${ }^{t} \mathrm{BuOK}(10 \mathrm{~mol} \%)$ as a base. From the optimization studies, the authors concluded that the high catalytic activity might be ascribed to the metal-ligand cooperation through aromatization-dearomatization of the lutidine framework. Furthermore, air and moisture-stable Ru-based complexes were applied for indirect conversion of $\mathrm{CO}_{2}$.

In the same line, the pincer pyridine-bridged $N$-heterocyclic carbene-ruthenium complex (Ru complex III) exhibited high catalytic activity in the hydrogenation of cyclic carbonates 13 (Scheme 7) [38]. When carried out in THF in the presence of $\mathrm{K}_{3} \mathrm{PO}_{4}$ and $\mathrm{H}_{2}(50 \mathrm{~atm})$ at $140{ }^{\circ} \mathrm{C}$, with a catalyst loading of $0.5 \mathrm{~mol} \%$, the reaction provided nearly quantitative yields of the corresponding diol $\mathbf{1 2}$ and methanol. Even when using a catalytic amount of a weak base and a low catalyst loading, a range of substrates with varying steric congestion underwent the transformation. 

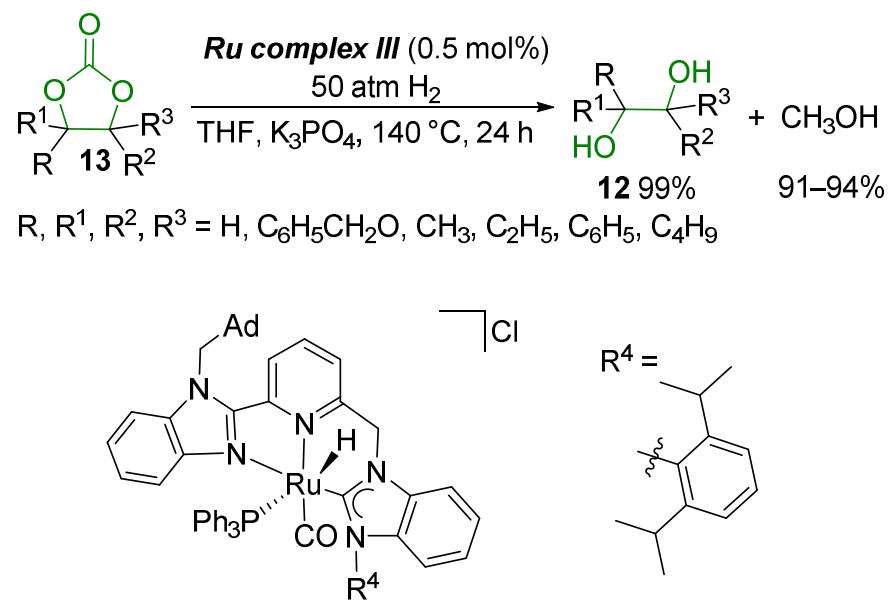

Ru complex III

Scheme 7. Hydrogenation of ethylene carbonate 1c.

The production of diols and methanol was reported by using copper-silica nanocomposite catalysts with a uniform $\mathrm{Cu}$ dispersion, prepared using a precipitation-gel method $\left(\mathrm{Cu}-\mathrm{SiO}_{2}-\mathrm{PG}\right)$ (Scheme 8) [39]. This system promoted hydrogenation of cyclic carbonates 1 (87-97\% conversion), providing methanol and diols 12 at conversion rates of $29-98 \%$ in both batch and fixed-bed continuous flow reactors, under relatively mild conditions. All the cyclic carbonates involved gave the respective diols in high yield, with the exception of GC 1a, which provided glycerol with $29 \%$ yield only.

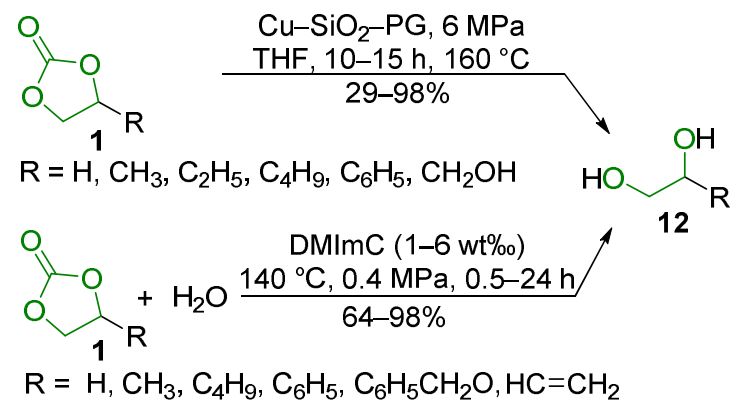

Scheme 8. Hydrogenation of cyclic carbonates 1, providing methanol and diols 12.

A catalytic process using a basic zwitterionic salt as an alternative to inorganic bases was employed to synthesize glycols through hydrolysis of cyclic carbonates [40]. Six examples of glycols 12 were prepared with $64-98 \%$ yields by using $1-6 \mathrm{wt} \%$ zwitterionic 1,3-dimethylimidazolium-2-carboxylate (DMImC), cyclic carbonate $1 / \mathrm{H}_{2} \mathrm{O}=1: 1.5$ (molar ratio), at $140{ }^{\circ} \mathrm{C}$ and under $0.4 \mathrm{MPa}$ for $30 \mathrm{~min}$ to $6 \mathrm{~h}$ (Scheme 8). A reaction time of $24 \mathrm{~h}$ was required to convert 4-phenyl-1,3-dioxolan-2-one $\mathbf{1 b}$ into the corresponding vicinal diol 12a with $90 \%$ yield. The catalyst DMImC was recovered and re-used six times at $140{ }^{\circ} \mathrm{C}$, $0.4 \mathrm{MPa}$ for $30 \mathrm{~min}$, keeping good selectivity and high yield.

Based on the experimental results, NMR spectroscopy, and theoretical calculations, a possible catalytic cycle was suggested (Scheme 9). Generated by formation of the conjugated acid $\mathrm{DMImCH}$, the hydroxide ion promotes opening of the cyclic carbonate $\mathbf{1 b}$, forming the intermediate I, which is converted to II by intramolecular hydrogen transfer. Then, II is converted into a possible imidazolium alkylcarbonate salt III or IV by reaction with DMImCH. Subsequent elimination of DMImC and production of II occurs. The reaction of II with $\mathrm{OH}^{-}$affords $\mathbf{V}$ with $\mathrm{CO}_{2}$ and $\mathrm{H}_{2} \mathrm{O}$ release to the reaction medium. Finally, a proton from DMImCH is captured by $\mathbf{V}$, producing the desired glycol 12a while regenerating the catalyst for a new cycle. 


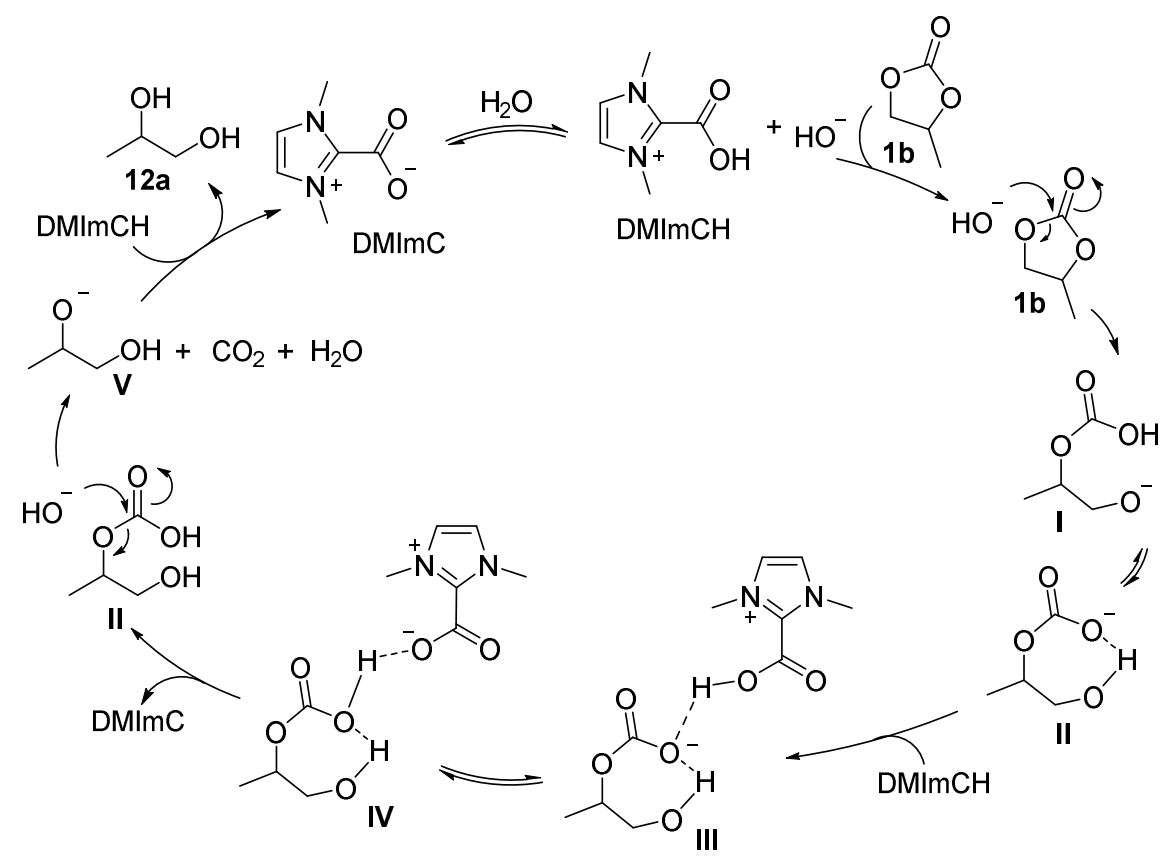

Scheme 9. Glycols synthesis through hydrolysis of cyclic carbonates.

The indirect hydrogenation of $\mathrm{CO}_{2}$ via the ethylene carbonate intermediate $1 \mathrm{c}$ to produce ethylene glycol $\mathbf{1 2 b}$ and methanol was proposed by using mesoporous silica (KIT6, MCM-41, and SBA-15) as the support for copper-based catalysts (Scheme 10, condition a) [41]. This attractive approach showed 100\% conversion of carbonate 1c, yielding $94.7 \%$ of diol $\mathbf{1 2 b}$ and $62.3 \%$ of $\mathrm{CH}_{3} \mathrm{OH}$ 7a in only $4 \mathrm{~h}$ reaction time over $\mathrm{Cu} / \mathrm{SBA}-15$ under the optimal conditions. This copper-based catalyst exhibited superior catalytic activity with turnover numbers of 22.0 and $11.4\left(\mathrm{~mol} \mathrm{~mol}^{-1}\right)$ towards diol and methanol, respectively. It is noteworthy that the higher catalytic performance was due to the synergic effect between the $\mathrm{Cu}^{0}$ and $\mathrm{Cu}^{+}$species that co-exist on the surface of the catalysts and also to a larger metallic surface area on SBA-15 when compared with KIT- 6 and MCM-41. Additionally, the thermodynamic calculation showed the ethylene glycol hydrogenation to be exothermic $\left(\Delta_{\mathrm{r}} H^{\theta}{ }_{m}=-71.59 \mathrm{~kJ} \mathrm{~mol}^{-1}\right)$ and thermodynamically favorable $\left(\Delta_{\mathrm{r}} G^{\theta}{ }_{m}=-25.62 \mathrm{~kJ} \mathrm{~mol}^{-1}\right)$.

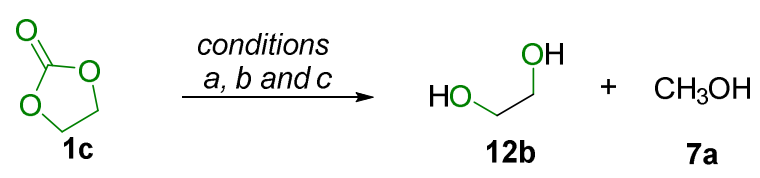

\section{conditions:}

a) Cu/SBA-15 (10 wt\%), $4 \mathrm{~h}, 200^{\circ} \mathrm{C}, 5 \mathrm{MPa} \mathrm{H}$, THF, conversion of

$100 \% ; \mathbf{1 2} \mathbf{b}: \mathbf{7 a}=94.7: 62.3$

b) $10 \% \mathrm{Cu} / \mathrm{SiO}_{2}-\mathrm{AE}\left(20 \mathrm{wt} \%\right.$ ), THF, $5 \mathrm{MPa} \mathrm{H}_{2}, 180^{\circ} \mathrm{C}, 15 \mathrm{~h}$

conversion of $100 \% ; 12 \mathbf{b}: \mathbf{7 a}=70.8: 98.0$

c) 3.0-CuSi-NAM, 1,4 -dioxane, $180^{\circ} \mathrm{C}, 3 \mathrm{MPa}\left(\mathrm{H}_{2} / \mathrm{EC}=200\right)$,

LHSV $=0.6 \mathrm{~h}^{-1}$. conversion of $99 \% ; 12 \mathbf{b}: 7 \mathbf{a}=97: 50$

Scheme 10. The indirect hydrogenation of $\mathrm{CO}_{2}$ via the ethylene carbonate intermediate $1 \mathrm{c}$ to produce ethylene glycol 12b and methanol 7a.

In another study, the same authors reported the selective hydrogenation of ethylene carbonate $1 \mathrm{c}$ with $100 \%$ of conversion over $\mathrm{Cu} / \mathrm{SiO}_{2}$ catalysts, prepared using the ammonia evaporation method, with silica sol as the silica source (Scheme 10, condition b) [42]. The $10 \% \mathrm{Cu} / \mathrm{SiO}_{2}-\mathrm{AE}$ catalyst with moderate copper loading exhibited better catalytic activity to co-produce methanol $7 \mathbf{a}$ with $70.8 \%$ yield and EG $12 \mathrm{c}$ at $98.0 \%$ yield. After catalyst characterization, the authors disclosed the synergic effects of $\mathrm{Cu}^{0}$ and $\mathrm{Cu}^{+}$species in this reaction; while $\mathrm{Cu}^{0}$ species promoted $\mathrm{H}_{2}$ dissociation, $\mathrm{Cu}^{+}$species were adsorbed on the 
carbonyl group of EC. Moreover, in catalyst reusability experiments, the $10 \% \mathrm{Cu} / \mathrm{SiO}_{2}-\mathrm{AE}$ catalyst showed agglomeration of $\mathrm{Cu}$ and $\mathrm{Cu}_{2} \mathrm{O}$ particles, which were responsible for the gradually decreasing activity after consecutive recycling runs.

Similarly, nanoarray $\mathrm{Cu} / \mathrm{SiO}_{2}$ catalysts embedded in monolithic channels (CuSi-NAM) were applied in hydrogenation reactions (Scheme 10, condition c) [43]. Monolithic $\mathrm{Cu}$ based catalysts exhibited high activity in the conversion of ethylene carbonate 1c (99\%) into EG 12c and methanol 7a selectivity, with yields of $97 \%$ and $50 \%$, respectively.

The most frequently used methods to produce diols are described above, which involve catalytic hydrogenation or hydrolysis of cyclic carbonates using organic solvents. Fu and co-workers recently published a new procedure for the conversion of cyclic carbonates 1 to diols 12 in overheated water, without an external catalyst or additive (Scheme 11) [44]. The reaction of ethylene carbonate proceeded smoothly to give the desired glycol in high yield (99\%) along with $\mathrm{CO}_{2}$ as a byproduct. The reaction was studied at different temperatures $\left(100{ }^{\circ} \mathrm{C}\right.$ to $\left.250^{\circ} \mathrm{C}\right)$ with water filling of $25 \%$ for $2 \mathrm{~h}$. In general, a higher temperature was better in promoting the reaction and the methodology was extended to methyl- and ethyl-substituted ethylene carbonates. With these substrates, $10 \mathrm{~h}$ was needed to provide the corresponding diols with $59 \%$ and $62 \%$ yield, respectively.

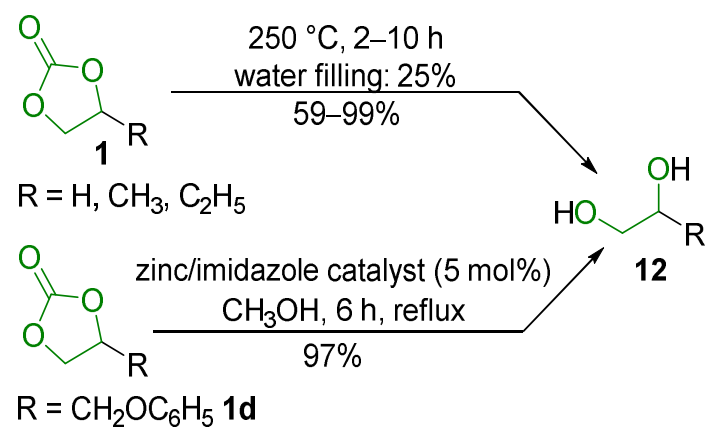

Scheme 11. Catalytic hydrogenation or hydrolysis of cyclic carbonates using organic solvents.

The same diols can be obtained from cyclic carbonates via a deprotection reaction. In this sense, the new heterogeneous zinc/imidazole catalyst was evaluated in various reactions such as transesterification and transcarbonation [45]. A small amount of the suitable zinc/imidazole catalyst immobilized on polystyrene resin proved effective to prepare 3-phenoxypropane-1,2-diol 12 from 4-(phenoxymethyl)-1,3-dioxolan-2-one $\mathbf{1 d}$ after $6 \mathrm{~h}$ in refluxing methanol (Scheme 11).

An extension of the deprotection reaction was recently described by Perin and coworkers [46], whereby 4-chalcogenomethyl-1,3-dioxolan-2-ones 1 were synthesized from GC 1a (Section 2.4), then converted into diols 12 by using potassium carbonate in PEG-400 for $12 \mathrm{~h}$ at $25^{\circ} \mathrm{C}$ (Scheme 12). Six vicinal diols bearing an arylsulfanyl or arylselenanyl moiety were obtained in excellent yields.

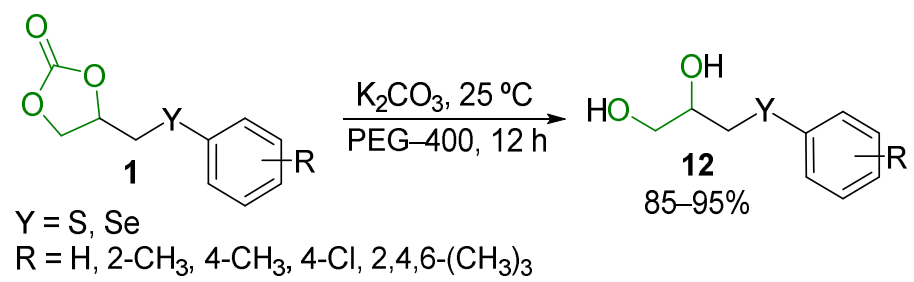

Scheme 12. Synthesis of diols 12 from 4-chalcogenomethyl-1,3-dioxalan-2-ones 1.

Pongrácz and Kollár described the asymmetric hydroformylation of racemic 4-vinyl1,3-dioxolan-2-one 1e to prepare the aldehyde 1f (Scheme 13) [47]. The authors reported the chemoselective and regiospecific formation of $\mathbf{1} f$ by using the "pre-formed" $\mathrm{PtCl}_{2}$ (diphosphine) and tin(II) chloride catalyst and (2S,4S)-2,4-bis(diphenylphosphinopentane) [(S,S)-BDPP)] 
as an enantiopure diphosphine ligand. The platinum-containing catalytic systems provided nearly complete conversion of compound $1 \mathrm{e}$ after 3,19 , and $72 \mathrm{~h}$ at 100,60 , and $40{ }^{\circ} \mathrm{C}$, respectively. In addition, a hydrogenated product $1 \mathrm{~g}$ was formed, even under optimal conditions. In this work, the kinetic resolution of the aldehyde indicated that (S)-(1f) was preferably formed in the temperature range of $40-100{ }^{\circ} \mathrm{C}$.

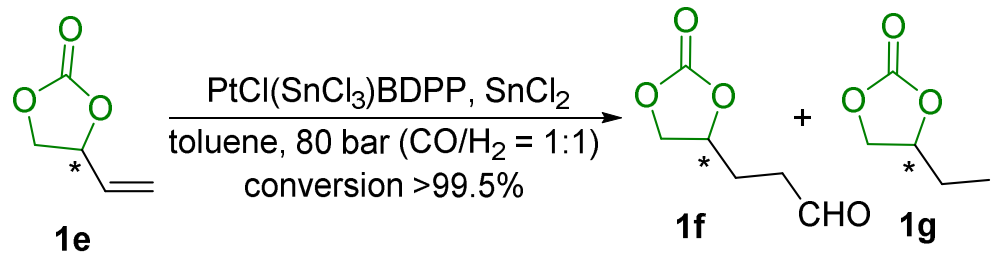

Scheme 13. Hydroformylation of racemic 4-vinyl-1,3-dioxolan-2-one 1e to prepare the aldehyde 1f.

Werner and co-workers reported on the first use of an earth-abundant metal complex as a catalyst for the transfer hydrogenation of carbonate 14, opening an indirect route for the reduction of $\mathrm{CO}_{2}$ to methanol (Scheme 14) [48]. An advantage of this method, according to the authors, is the use of isopropanol as a hydrogen source, avoiding the use of flammable hydrogen under high pressures. Using a metal-based catalyst, it was possible to perform the transfer hydrogenation of GC 1a selectively, using the PNP pincer-type iron complex $\mathrm{C}_{17} \mathrm{H}_{38} \mathrm{BrFeNOP}_{2} 15$. This reaction occurred at $140{ }^{\circ} \mathrm{C}$ over 6 to $24 \mathrm{~h}$, obtaining the respective diols 12 and $\mathrm{MeOH}$ as products with $51-97 \%$ and 39-92\% yield, respectively.
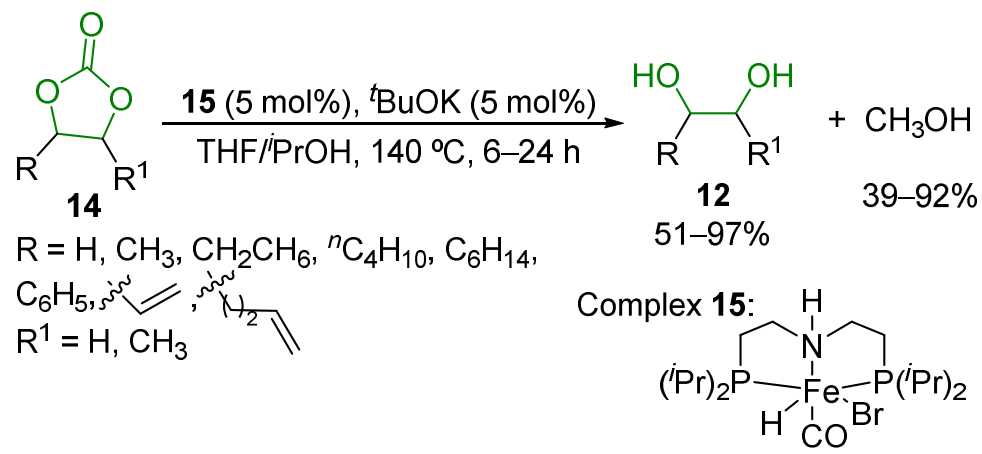

Scheme 14. Metal complex as a catalyst for the transfer hydrogenation of carbonate $\mathbf{1 4 .}$

\subsection{Transesterification of Cyclic Carbonates}

The transesterification of cyclic carbonates, especially ethylene carbonate $1 c$, to give non cyclic carbonates has attracted much attention, due to their role as building blocks for the production of chemical intermediates in the polymer industry [49].

Hahm and co-workers [50] reported the synthesis of dimethyl carbonate 16a via transesterification of ethylene carbonate 1c using an excess of methanol (1:15) over $4 \mathrm{~h}$ with ionic liquid catalysts supported on the mesoporous cellular foam (MCF) (Scheme 15). In this work, 4-diazobicyclo[2.2.2]octane (DABCO) provided the highest yield of dimethyl carbonate 16a (84\%), while the heterogeneous catalyst [DABCO]OH@MCF gave around $77 \%$ yield for the expected product. The ionic-liquid-supported catalyst was re-used four times with only $8 \%$ decrease of $\mathbf{1 6 a}$ yield. At higher temperatures (up to $150{ }^{\circ} \mathrm{C}$ ), decomposition of ethylene carbonate 1c or degradation of the immobilized species was observed, causing a decrease in 16a yield. Furthermore, the chemically immobilized [DABCO]OH@MCF catalyst proved to be more stable than the physically impregnated $\mathrm{DABCO} / \mathrm{MCF}$. 


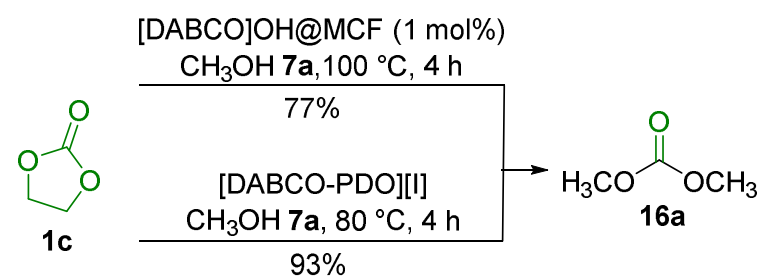

Scheme 15. Synthesis of dimethyl carbonate 16a via transesterification of ethylene carbonate 1c.

In a closely related study, Saptal and Bhanage [51] developed the synthesis of a series of bifunctional, DABCO-based, hydroxyl-functionalized ILs, which were applied in the conversion of carbon dioxide into valuable chemicals, such as cyclic carbonates, the transesterification of which was also considered. Here, transesterification of ethylene carbonate $\mathbf{1 c}$ with methanol to prepare dimethyl carbonate 16a proceeded at a moderate temperature in the presence of different ionic liquids. The [DABCO-PDO][I], functionalized with propane diol functional groups, gave the highest conversion rate and yield for dimethyl carbonate 16a, with $93 \%$ yield after $4 \mathrm{~h}$ at $80{ }^{\circ} \mathrm{C}$ (Scheme 15). One major advantage of this protocol is that no transition metal, solvent, or additive is used.

\subsection{Substitution Reaction}

Cyclic carbonates can be used to prepare new organochalcogen derivatives. The interest in compounds containing sulfur, selenium, and tellurium atoms has been continuously increasing, due to their potential applications as synthons for the synthesis of heterocycles [52], in cross-coupling reactions [53,54], and in asymmetric synthesis [55,56]. Those compounds have applications in materials science [57-59], and as key intermediates in the synthesis of natural products [60-62].

Perin and co-workers [63] recently reported the synthesis of 4-arylsulfanylmethyl1,3-dioxolan-2-ones under microwave irradiation (MW) using an environmentally benign $\mathrm{KF} / \mathrm{Al}_{2} \mathrm{O}_{3} / \mathrm{PEG}-400$ system [64]. By applying $\mathrm{KF} / \mathrm{Al}_{2} \mathrm{O}_{3}$ as an efficient heterogeneous base, 3-O-tosyl glycerol 1,2-carbonate 1h (TGC) reacted with alkyl, aryl, or heteroaryl thiols $\mathbf{1 7}$ to provide good yields of the corresponding sulfanylated carbonates $\mathbf{1}$ after short times of MW irradiation at $60^{\circ} \mathrm{C}$. This green methodology was extended to thiophenols bearing either electron-donating $\left(\mathrm{CH}_{3}\right)$ or electron-withdrawing groups $(\mathrm{Cl}$ and $\mathrm{F})$ in the para- and ortho-positions, to provide with good yields the respective 4-arylthio-1,2-glycerol carbonates. However, when the strong electron-donating amino group was present in the ortho-position (2-aminobenzenethiol), only $65 \%$ yield of the desired product was obtained, due to the disfavoring proton abstraction from the thiol (Scheme 16). The conversion was extended, albeit in lower yields, to 2-mercaptobenzothiazolyl and dodecyl derivatives.

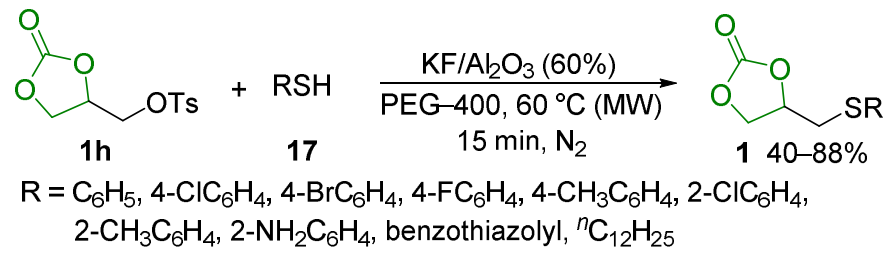

Scheme 16. Synthesis of 4-arylsulfanylmethyl-1,3-dioxolan-2-ones 1 under MW.

The possibility of developing a selective method for the synthesis of 1,3-bis-arylthiopropan-2-ols 18 by incorporation of two thiol units was explored (Scheme 17). By reacting a second equivalent of thiol 17 under $15 \mathrm{~h}$ conventional heating at $90^{\circ} \mathrm{C}$, the corresponding disubstituted products $\mathbf{1 8}$ were obtained in good to excellent yields. When conducted at 90 ${ }^{\circ} \mathrm{C}$ for $3 \mathrm{~h}$ in a microwave reactor (irradiation power of $200 \mathrm{~W}$ ), the same compounds 18 were isolated in slightly lower yields [63]. 


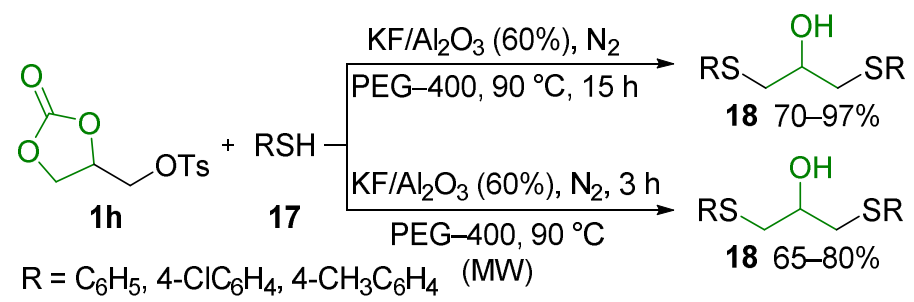

Scheme 17. Synthesis of 1,3-bis-arylthiopropan-2-ols 18 by incorporation of two thiol.

The same year, Perin's group reported the selective synthesis under stoichiometric control of 4-chalcogenomethyl-1,3-dioxolan-2-ones and 1,3-bis(organylchalcogenyl)propan2-ols [46]. To obtain the GC-derived chalcogenoethers 1, diaryl diselenides $\mathbf{1 9}$ or disulfides 20 (0.6 equivalent) were first reduced using $\mathrm{NaBH}_{4} / \mathrm{PEG}-400$ under inert atmosphere, before the addition of TGC $\mathbf{1 h}$ (Scheme 18). A library of eleven compounds $\mathbf{1}$ was prepared with 55-92\% yield after $2 \mathrm{~h}$ reaction at $50{ }^{\circ} \mathrm{C}$. The protocol was extended to aliphatic diselenides, and when dibutyl diselenide was used, the corresponding selenide was isolated with $74 \%$ yield. In general, diaryl disulfides lead to better yields when compared to the seleno-analogues.<smiles>O=C1OCC(C[O+])O1</smiles>
$1 \mathrm{~h}$ $\mathrm{Y}=\mathrm{S}, \mathrm{Se}$ $\mathrm{R}=\mathrm{C}_{6} \mathrm{H}_{5}, 4-\mathrm{ClC}_{6} \mathrm{H}_{4}, 2-\mathrm{ClC}_{6} \mathrm{H}_{4}, 4-\mathrm{FC}_{6} \mathrm{H}_{4}, 4-\mathrm{CH}_{3} \mathrm{C}_{6} \mathrm{H}_{4}$, 4- $\mathrm{CH}_{3} \mathrm{OC}_{6} \mathrm{H}_{4}, 2-\mathrm{CH}_{3} \mathrm{C}_{6} \mathrm{H}_{4}, 2,4,6-\left(\mathrm{CH}_{3}\right)_{3} \mathrm{C}_{6} \mathrm{H}_{2}, \mathrm{C}_{4} \mathrm{H}_{9}$

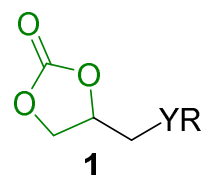

$55-92 \%$

Scheme 18. Selective synthesis under stoichiometric control of chalcogenoethers 1 .

During the optimization process, it was observed that increasing the amount of diaryl diselenides 19 or disulfides 20 to 1.2 equivalent led to ring-opening of the carbonate unit of 1h over $1 \mathrm{~h}$, resulting in symmetrical and unsymmetrical 1,3-bis(organochalcogenyl)propan2-ols 18 in moderate to excellent yields (Scheme 19). The reaction works well when either electron-donating or electron-withdrawing groups are present in the aromatic unit $\mathrm{R}$. It is worth noting that when using dimesityl diselenide in the synthesis of symmetrical compounds 18, $3 \mathrm{~h}$ reaction was needed to reach $94 \%$ yield of the expected product. Moreover when using 1,2-bis(2-chlorophenyl)disulfide in the synthesis of unsymmetrical compounds $\mathbf{1 8}^{\prime}$, the respective product was isolated with $40 \%$ yield after $1 \mathrm{~h}$ reaction.

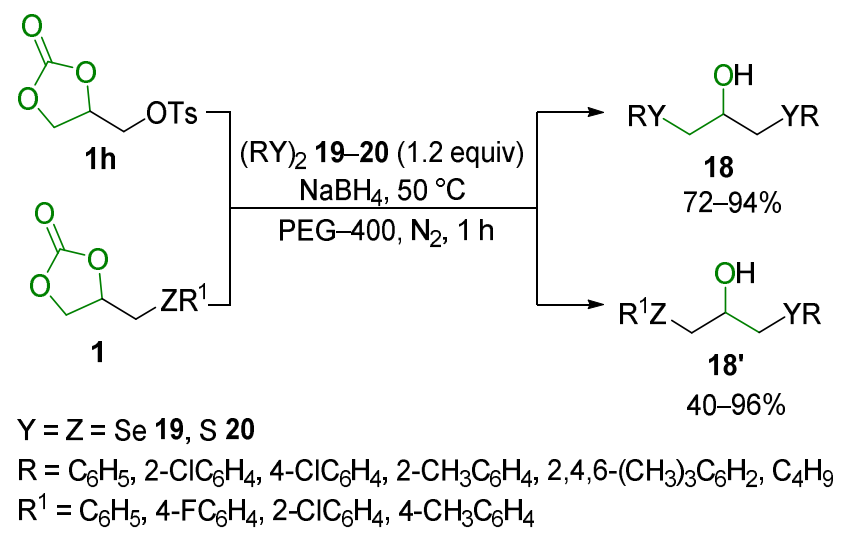

Scheme 19. Synthesis of symmetrical and unsymmetrical 3-bis(organochalcogenyl)propan-2-ols.

The stereoselective construction of cyclic carbonate systems is another attractive line of studies that has been explored. In this sense, racemic vinyl-substituted cyclic carbonates 6 are important substrates for copper-mediated $S_{N} 2$ reactions to access useful hydroxyl 
functionalities 9 and 21 in a single step (Table 1, entries 1-3) [65], or for combining a palladium catalytic system and a boron reagent to obtain chiral alcohols 12 and ethers 8 (Table 1, entries 4-6) [66].

Miralles and co-workers [65] explored the allyl-boryl coupling of a series of substituted vinyl cyclic carbonates 6 with $\mathrm{B}_{2}$ pin $_{2} 22$ in the presence of $\mathrm{CuCl}, \mathrm{Cs}_{2} \mathrm{CO}_{3}$, and the $N$-heterocyclic carbene ligand L1 (Table 1, Figure 2). Several E-configured borylated products 9 were obtained with 33-65\% yields within $16 \mathrm{~h}$ at room temperature (Table 1, entry 1). When performed in the absence of ligand and with a higher amount of base, the allyl_alkyl coupling reaction with diborylmethane 23 generated compound 9 with $48-82 \%$ yields (Table 1, entry 2). Under similar conditions but using 1,2-bis(di-tertbutylphosphinomethyl)benzene $\mathbf{L} 2$ (Figure 2) as the ligand, the selective allyl-boryl coupling of vinyl cyclic carbonates 6 with $B_{2}$ pin $_{2} 22$ led to the corresponding $(Z)$-stereoisomers, which were converted with $37-55 \%$ yields into the boracycles 20 (Table 1, entry 3) [65]. Finally, the versatility of $(E)$-allylic and homoallylic borylated products 9 was demonstrated through the in situ copper-catalyzed $\mathrm{S}_{\mathrm{N}} 2^{\prime}$ allyl-boryl and allyl-alkyl couplings, followed by oxidative work-up. Thus, (E)-configured but-2-ene-1,4-diols and pent-2-ene-1,5-diols were isolated with $27-59 \%$ and $42-58 \%$ yields, respectively.

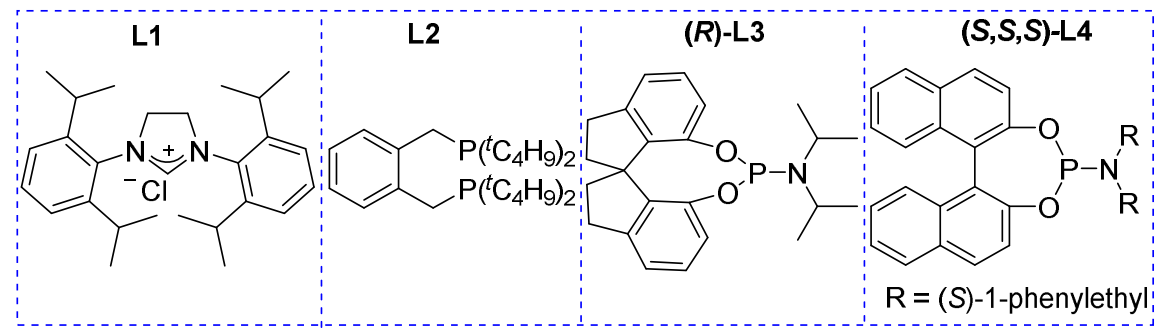

Figure 2. Scope of the ligands employed in the synthesis of compounds 8, 9, 12, and 21.

In the presence of a synergistic catalytic system formed by an in situ generated chiral palladium complex and a boron reagent, the asymmetric allylic substitution of racemic vinyl cyclic carbonates 6 with water and hydroxyl reagents provided a series of tertiary alcohols and ethers $\mathbf{8}$ in high yields (Table 1) [66]. The synthesis of tertiary alcohols $\mathbf{1 2}$ was performed by using a system containing phenylboronic acid $24, \mathrm{Pd}_{2}(\mathrm{dba})_{3} \cdot \mathrm{CHCl}_{3}, \mathrm{Zhou}^{\prime} \mathrm{s}$ ligand $[(R)$-L3] (Figure 2$)$, and water (10 equivalent). The corresponding products were obtained with $82-98 \%$ yields (80-98\% ee) after $16 \mathrm{~h}$ at $40{ }^{\circ} \mathrm{C}$ in THF (Table 1, entry 4 ). By changing to Feringa's ligand (S,S,S)-L4 (Figure 2) and to triethylborane $\mathbf{2 5}$ as the boron reagent, the alcohols 12 were isolated with $61-87 \%$ yields and high enantioselectivity (80$98 \%$ ee) (Table 1, entry 5). An enantioselective allylic etherification process was developed, involving reaction of hydroxyl reagents with racemic vinyl cyclic carbonates 6 in the presence of $(R)$-L3 and triethylborane 25 to provide the desired ethers 8 (56-97\% yields; $37-98 \%$ ee) (Table 1, entry 6). 
Table 1. Synthesis of alcohols and ethers compounds from cyclic carbonate 6.

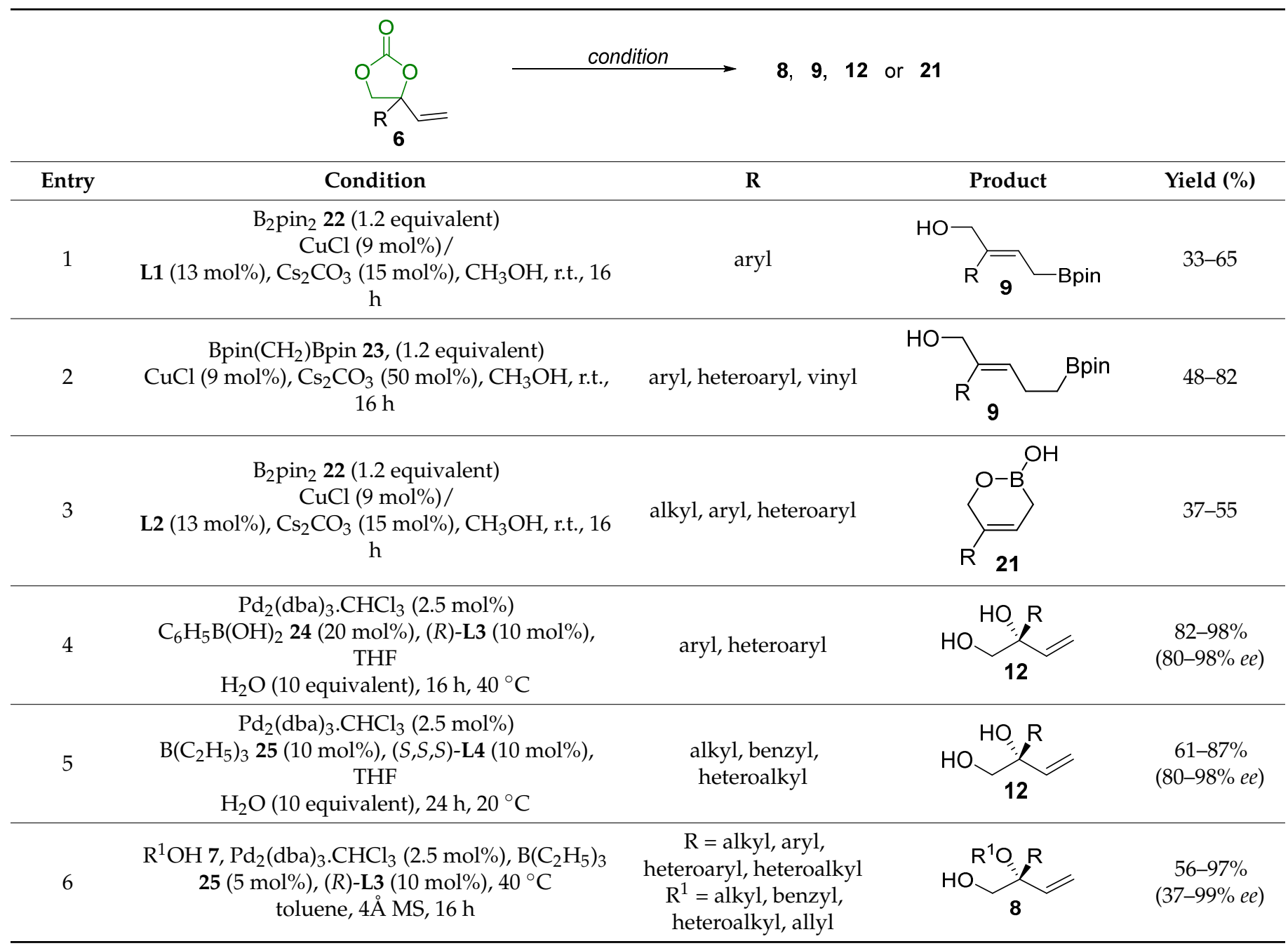

\subsection{Metal-Catalyzed Miscellaneous Reactions}

In recent years, the introduction of transition metal catalysis into diverse reactions has provided profitable results in organic chemistry. The most typical examples involve the use of palladium [67-71], platinum [72-74], rhodium [75-77], and magnesium [78] complexes. In addition, many studies have involved GC or vinylated carbonates as starting materials in coupling reactions to generate polymers and other important compounds.

Targeting the synthesis of new glyceryl carbonate ethers through coupling reactions, Sauthier, Visseaux, and co-workers reported the telomerization between GC 1a and 1,3butadiene 26 ( 2 equivalent) in the presence of a catalytic system containing palladium bis(acetylacetonate), triphenylphosphine, and triethylamine as a base [79]. The reactions were performed over $17 \mathrm{~h}$ at temperatures ranging from -15 to $80^{\circ} \mathrm{C}$, giving the expected octadienylglyceryl carbonate $\mathbf{1 i}$ with $85 \%$ yield (Scheme 20, step 1). Compound $\mathbf{1} \mathbf{i}$ was subsequently hydrogenated under $\mathrm{Pd} / \mathrm{C}$ catalysis to the corresponding octyl ether $\mathbf{1 j}$ (Scheme 20, step 2). The unsaturated glycerol carbonate ether $1 \mathbf{i}$ was co-polymerized with $\varepsilon$-caprolactone 27 in the presence of a neodymium initiator $\left[\mathrm{Nd}\left(2,6 \text {-tert } \mathrm{Bu}_{2} \mathrm{OC}_{6} \mathrm{H}_{3}\right)_{3}\right]$ to form the polymeric derivative $\mathbf{2 8}$ with $15-82 \%$ yields (Scheme 20, step 3). This polymerbearing carbonate unit presents good thermomechanical properties. 


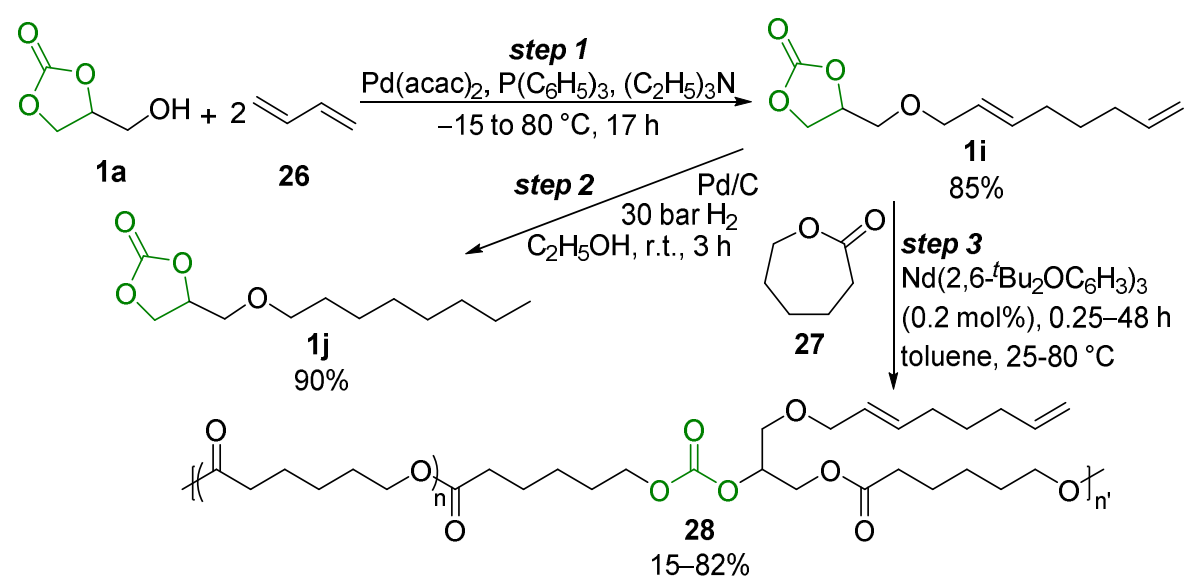

Scheme 20. Telomerization between GC 1a and 1,3-butadiene 26.

Several studies showing the efficiency of the palladium catalysis in the allylic cycloaddition of vinylated carbonates 6 have been published [80-84]. For example, Zhang and co-workers [80] demonstrated the interesting Pd-catalyzed decarboxylative heterocyclization of [60]fullerene for the preparation of novel vinyl-substituted [60]fullerene-fused tetrahydrofurans, pyrans, or quinolines. In 2018, through a cooperative $\mathrm{N}$-heterocyclic carbene (NHC) organocatalysis and palladium catalysis, Singha and co-workers [81] performed enantioselective [5+2] annulations of enals $\mathbf{1 1}$ with vinylated carbonates $\mathbf{6}$ (VECs) for the synthesis of lactone 29. The reaction was performed over 10-12 h at room temperature in toluene solution in the presence of a cooperative $\mathrm{N}$-heterocyclic carbene (NHC)/Pd catalytic system, along with (R)-Tol-BINAP L1 as a ligand and N-methylpiperidine. A library of twenty-six examples was obtained with 30-99\% yields and $92-99 \%$ ee (Scheme 21).

Lan, Zhao, and co-workers [82] also used a $\mathrm{Pd}_{2}(\mathrm{dba})_{3}$-containing system for the synthesis of nine-membered cyclic compounds 30 , starting from azadienes 31 and VECs 6 . In the presence of ligand $\mathbf{L 2}(5 \mathrm{~mol} \%)$, this formal [5+4] cycloaddition led to the enantioselective preparation of twenty-four new heterocyclic compounds 30 with $70-95 \%$ yields (80-92\% ee) (Scheme 21).

In order to obtain $\mathrm{CF}_{3}$-substituted tetrahydrobenzoxazonines 32, Shibata and coworkers [85] reacted VECs 6 and trifluoromethyl benzoxazinone 33 in refluxing dichloroethane in the presence of tetrakis(triphenylphosphine)-palladium(0). Using this catalytic system, various nine-membered heterocyclic compounds 32 were isolated with 33-91\% yields.

In 2016, the catalytic and stereoselective formation of (Z)-1,4-but-2-enediols 9 was reported through decarboxylative hydration of VECs 6 in the presence of water as a nucleophile [86]. The reaction was performed in $\mathrm{DMF} / \mathrm{H}_{2} \mathrm{O}$ at room temperature, using a catalytic Pd precursor, $\mathrm{Pd} / \mathrm{bis}$ (sulfoxide) and a bidentate phosphine ligand. The expected unsaturated 1,4-diols 9 were obtained with 50-98\% yields with >99:1 Z-stereoselectivity (Scheme 22). While different groups such as aryl, naphthyl, and heteroaryl were efficiently incorporated into diols 9, it is important to highlight that some specific substitutions, e.g., $o$-haloaryl or 3-pyridyl, required forced conditions with higher temperatures and larger amounts of Pd-catalyst ( $5 \mathrm{~mol} \%$ ) and phosphine ligand $(10 \mathrm{~mol} \%)$ in order to reach preparative yields. In order to illustrate the good reactivity of the (Z)-1,4-but-2-enediols $\mathbf{8}$, some chemical modifications were made, such as $m$-CPBA oxidation to the epoxide $\mathbf{2} \mathbf{b}$, high-yield conversion into the cyclic orthoester 34 , and copper-catalyzed chemoselective oxidocyclization to the isomeric lactones $\mathbf{3 5 a}$ and $\mathbf{3 5 b}$ (Scheme 23). 


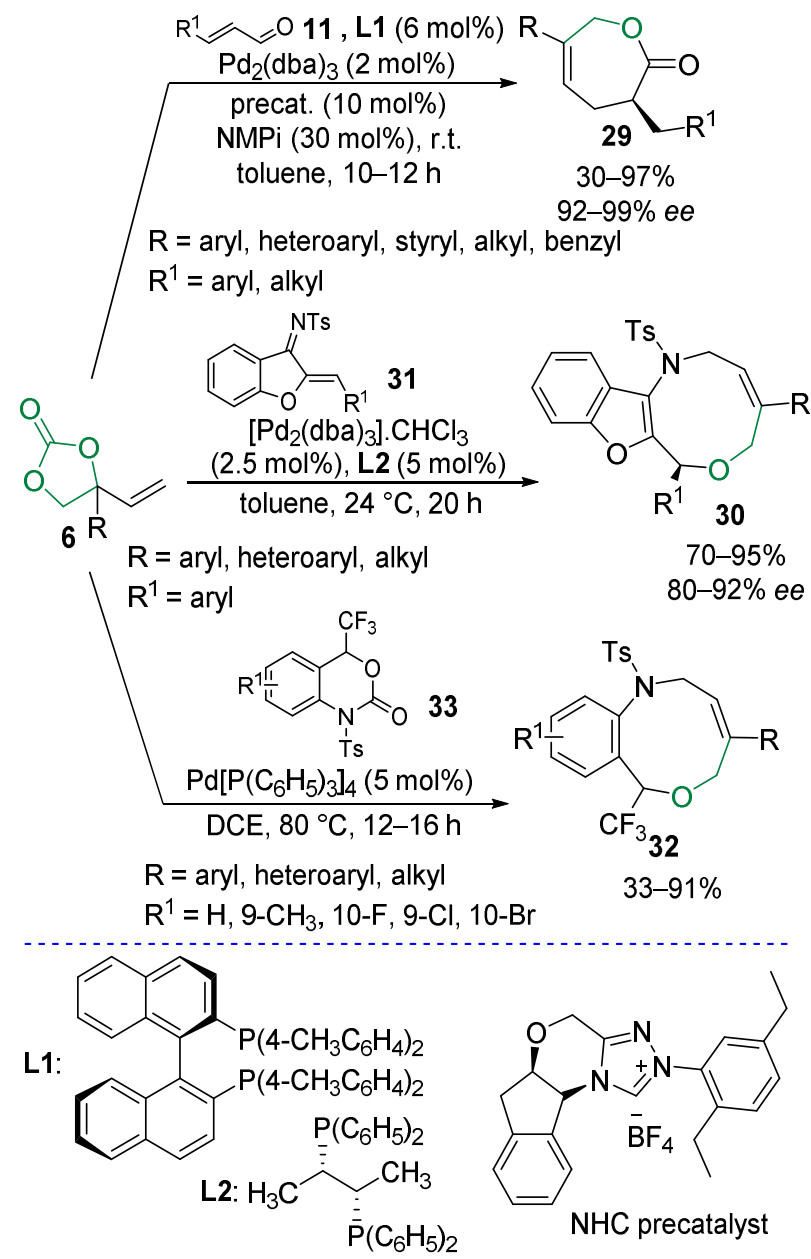

Scheme 21. Synthesis of nine-membered cyclic compounds 30, starting from azadienes 31 and VECs 6

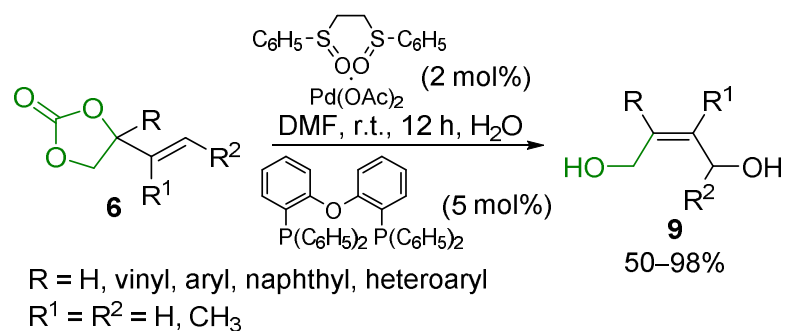

Scheme 22. Decarboxylative hydration of VECs 6. 


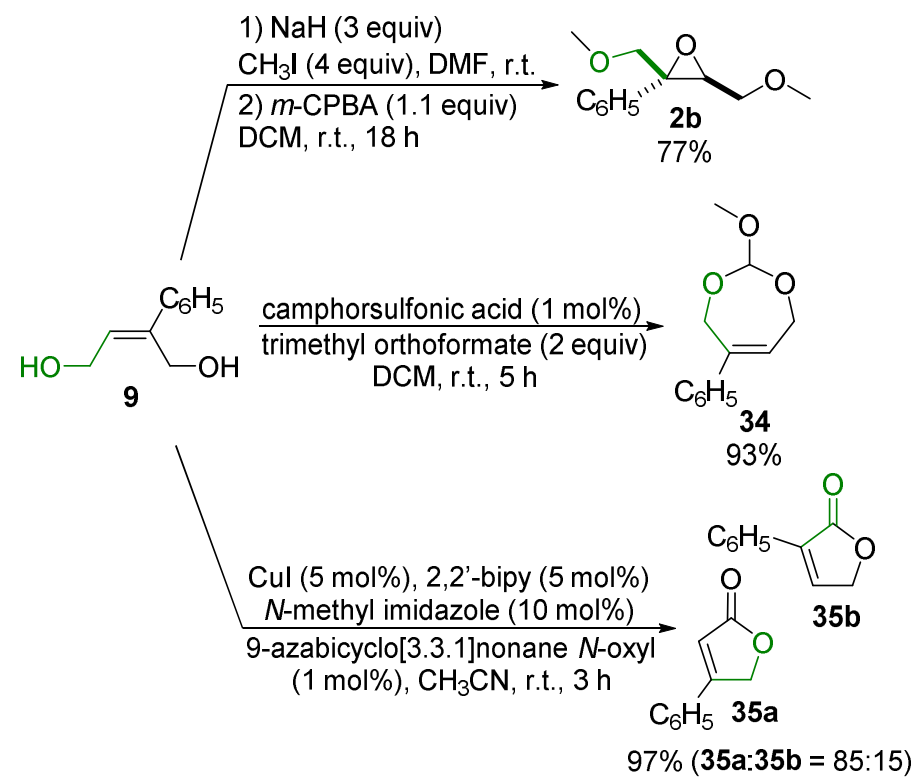

Scheme 23. Oxidation to the epoxide $2 b$, high-yield conversion into the cyclic orthoester 34 , and chemoselective oxidocyclization to the isomeric lactones $\mathbf{3 5 a}$ and $\mathbf{3 5} \mathbf{b}$.

Racemic VECs 6 were used for the stereoselective $O$ - or C-allylation of phenols and $\mathrm{N}$-allylation of 2-hydroxypyridines by use of $1-5 \mathrm{~mol} \%$ of $\left[\mathrm{Rh}(\mathrm{cod}) \mathrm{Cl}_{2}\right.$ and $2-10 \mathrm{~mol} \%$ of a chiral diphosphine as the ligand [(R,R)-QuinoxP*; $(S, S)$-DIOP or $(R, R)$-TBDM-SLIOP] [87]. Performed in dichloroethane or toluene over $24-48 \mathrm{~h}$ at temperatures ranging from r.t. to $80^{\circ} \mathrm{C}$, the reaction allowed exploration of an ample range of substrates, with yields exceeding $70 \%$ in most cases (see Figure 3 for selected examples). In this extensive study, carbonate 1e was converted into compound 39a (94\% yield; $97 \%$ ee) by asymmetric $O$ allylation of 4-bromophenol $7 \mathbf{b}$ (Scheme 24).

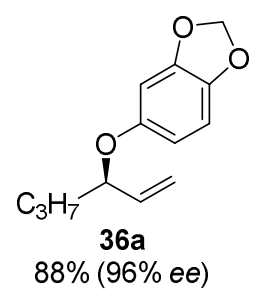<smiles>C=C[C@H](c1ccccc1)c1c(O)ccc2ccccc12</smiles><smiles>C=C[C@H](C(C)C)n1cc(Cl)ccc1=O</smiles>

Figure 3. Products of $O-, \mathrm{C}$ - and $\mathrm{N}$-allylation $36 \mathbf{a}, 37 \mathbf{a}$ and $38 \mathbf{a}$, respectively.

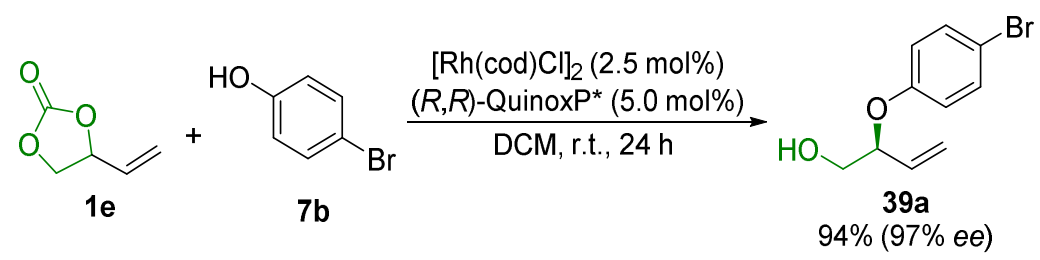

Scheme 24. Conversion of carbonate $1 \mathbf{e}$ by asymmetric $O$-allylation of 4-bromophenol $\mathbf{7 b}$.

Rueping and co-workers [88] described the alkaline earth metal-catalyzed reduction of cyclic and linear organic carbonates using a readily available magnesium catalyst (Scheme 25). These mild reaction conditions provided an indirect route for the conversion of $\mathrm{CO}_{2}$ into valuable alcohols. By using a low catalyst loading and avoiding ligands, a broad scope of compounds 40 was prepared via the selective hydroboration with HBPin 41, all with excellent yields. Specifically, cyclic carbonates 1 bearing substituents such as phenyl, methyl, hexyl, ${ }^{t} \mathrm{Bu}$, as well as glycerol derivatives, were efficiently reduced with excellent yields, ranging from $88 \%$ to $95 \%$ within $3 \mathrm{~h}$. 


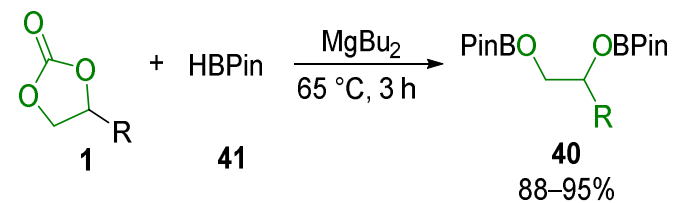

$\mathrm{R}=\mathrm{C}_{6} \mathrm{H}_{5}, \mathrm{H}, \mathrm{CH}_{3}, \mathrm{C}_{2} \mathrm{H}_{5}, \mathrm{C}_{6} \mathrm{H}_{13},{ }^{t} \mathrm{C}_{4} \mathrm{H}_{9}, \mathrm{CH}_{2} \mathrm{OH}, \mathrm{CH}_{2} \mathrm{OCH}_{3}$, $\mathrm{CH}_{2} \mathrm{OCH}_{2} \mathrm{C}_{6} \mathrm{H}_{5}, \mathrm{CH}_{2} \mathrm{CH}_{2}$

Scheme 25. The alkaline earth metal-catalyzed reduction of cyclic and linear organic carbonates.

With a view to promoting $\mathrm{C}-\mathrm{H}$ olefination of arenes and heteroarenes $\mathbf{4 2}$ by rhodium catalysis, $\mathrm{Xu}$, Zhang, and co-workers [89] explored the use of dichloro(pentamethylcyclopentadienyl)rhodium(III) dimer $\left\{\left[\mathrm{Cp}^{*} \mathrm{RhCl}_{2}\right]_{2}\right\}$ as a catalyst with copper(II) acetate as the oxidant and additional silver hexafluoroantimonate. By using VEC 1e, a series of $o$-olefinated benzamides such as 43 (Scheme 26) were obtained (49-94\% yields).

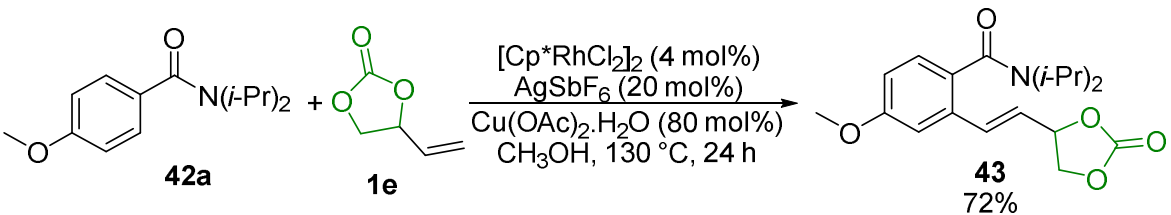

Scheme 26. C-H olefination of arenes and heteroarenes 42 by rhodium catalysis.

The authors also developed olefination of arylpyridines and indoles with 30-91\% yield using unactivated aliphatic olefins under the same conditions, albeit using pivalic acid as a promoter. A selection of the prepared compounds is shown in Figure 4.<smiles>COc1ccc(C/C=C/c2cccc(/C=C/Cc3ccc(Oc4ccccc4)cc3)c2-c2ccccn2)cc1</smiles>

Figure 4. Selected compounds prepared by $\mathrm{Xu}$, Zhang, and co-workers [89].

Under manganese catalysis, VEC 1e was employed to functionalize aryl compounds bearing electron donor groups to obtain the hydroxybutenylated derivatives $47 \mathbf{a}-\mathbf{c}$ [90]. The manganese complex $\left[\mathrm{MnBr}(\mathrm{CO})_{5}\right]$ was used in the presence of sodium acetate over $5 \mathrm{~h}$ reaction time, allowing the synthesis of twelve allylic alcohols with moderate to excellent yields (54-97\%) (Scheme 27).
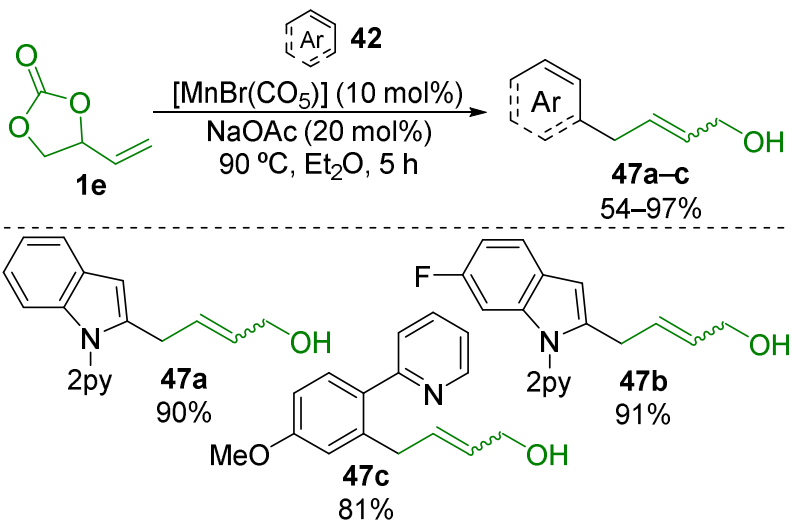

Scheme 27. Synthesis of twelve allylic alcohols. 
With a view to synthesizing spiroketals, orthoesters, and orthocarbonates, Lacour and co-workers [91] resorted to ruthenium catalysis, thanks to the combined use of the salt $\left[\mathrm{CpRu}\left(\mathrm{CH}_{3} \mathrm{CN}\right)_{3}\right]\left[\mathrm{BAr}_{\mathrm{F}}\right](2.5 \mathrm{~mol} \%)$ and 1,10-phenanthroline $(2.5 \mathrm{~mol} \%)$. For the synthesis of orthocarbonates 48 (27-72\% yields), decomposition of $\alpha$-diazo- $\beta$-ketoesters 49 (3.0 equivalent) in the presence of 1 was performed in dichloromethane for 3 days at $60{ }^{\circ} \mathrm{C}$ (Scheme 28). The lower reactivity of cyclic carbonates 1 when compared to cyclic ketones and lactones (3-24 h) led the authors to suggest the occurrence of a stronger complexation of the catalyst $[\mathrm{CpRu}(\mathrm{phen})]\left[\mathrm{BAr}_{\mathrm{F}}\right]$ with 1 , which would slow down the catalytic cycle due to the slower release of the complex $[\mathrm{CpRu}(\mathrm{phen})]\left[\mathrm{BAr}_{\mathrm{F}}\right]$. Moreover, compared to ketones, cyclic carbonates display reduced nucleophilicity in the capture of the transient electrophilic carbene.

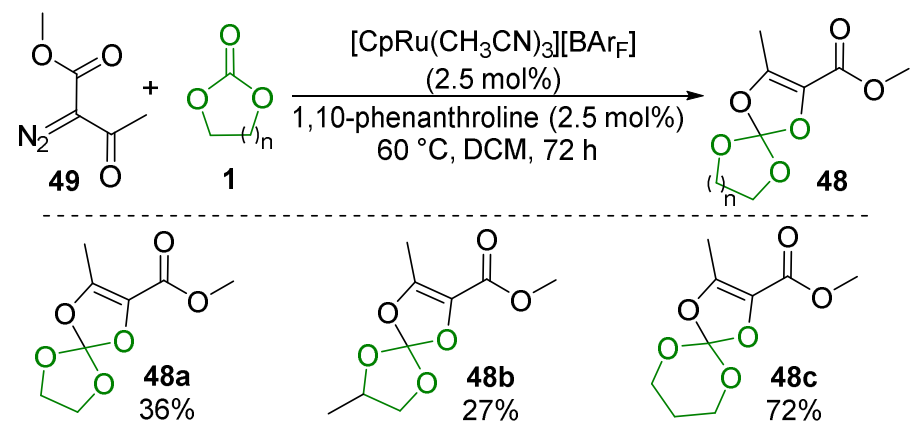

Scheme 28. Ruthenium catalysis for the synthesis of orthocarbonates 48 .

Another example of ruthenium catalysis was described by Guillaume, Carpentier, and co-workers [92] to obtain $\alpha$ - and $\alpha, \omega$-telechelic cyclocarbonate polycyclooctenes 50 and 51, macromolecules having two reactive end groups that are able to react selectively with other molecules to create new bonds [93]. The high-yielding reaction between cyclooctene 52 and VEC 1e or acryloyl derivative 1k was promoted by a Grubbs 2nd generation ruthenium catalyst in THF at $40{ }^{\circ} \mathrm{C}$ (Scheme 29). However, the authors did not define the polymerization degrees. The polymers characterized by ${ }^{1} \mathrm{H}$ NMR are important as a starting backbone for the preparation of new materials for applications in different fronts, such as surfactants or NIPUs.

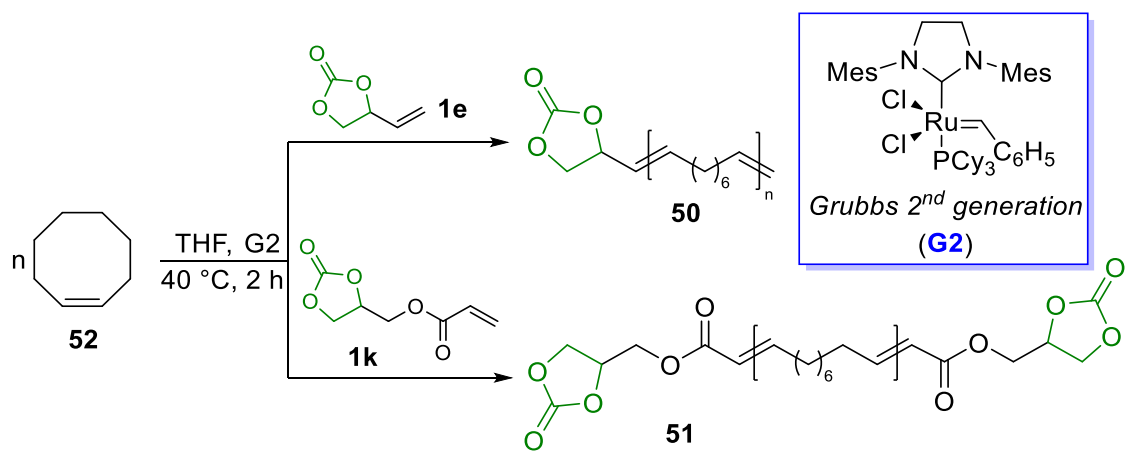

Scheme 29. Synthesis of $\alpha$ - and $\alpha, \omega$-telechelic cyclocarbonate polycyclooctenes 50 and $\mathbf{5 1 .}$

Silylating agents are broadly used to insert different functional groups on the surfaces of organic or inorganic materials. In this line, the synthesis of functionalized symmetrical and unsymmetrical disilazanes was reported with excellent yields (81-95\%) by using the Karstedt catalyst $\mathrm{Pt}_{2}\left[\left(\mathrm{CH}_{2}=\mathrm{CHSi}\left(\mathrm{CH}_{3}\right)_{2}\right)_{2} \mathrm{O}\right]_{3}$ [94]. Kucinski and co-workers reported the reaction between olefins and the 1,1,3,3-tetramethyldisilazane 53 in toluene at $60-110{ }^{\circ} \mathrm{C}$ over 3-24 h (Scheme 30). Among the olefins involved, when VEC 1e was reacted with 53, the bifunctional unsymmetrical disilazane 54 was obtained with $85 \%$ yield after only $5 \mathrm{~h}$, thus showing the relevant tolerance of the cyclic carbonate unit. 


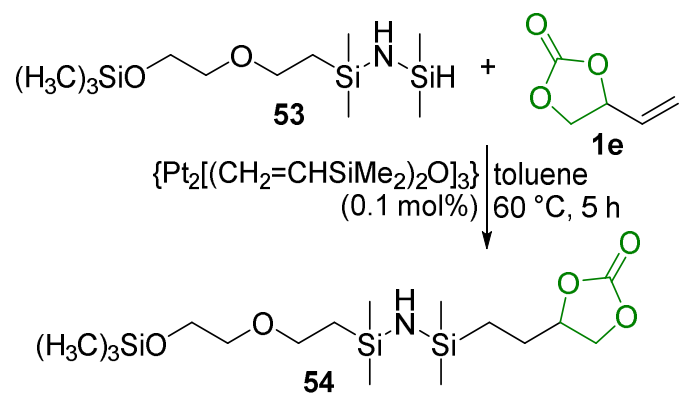

Scheme 30. Synthesis of bifunctional unsymmetrical disilazane 54.

To perform the C-H allylation of indoles by insertion of VEC 1e, Yu and co-workers [95] described the use of mechanochemistry, cobalt(III) catalyst $\left[\mathrm{Cp}^{*} \mathrm{Co}(\mathrm{MeCN})_{3}\right]\left[\mathrm{SbF}_{6}\right]_{2}$, silver acetate, and silica gel (Scheme 31). This reaction allowed the functionalization of fifteen indole derivatives with $1 \mathbf{e}$ under solvent-free conditions, delivering the desired products 55 in modest to high yields (28-98\%). It is worth highlighting that the reactions were run for only $2 \mathrm{~h}$ using a ball mill ( $800 \mathrm{rpm}$ ), which characterizes this method as an environmentally friendly protocol.

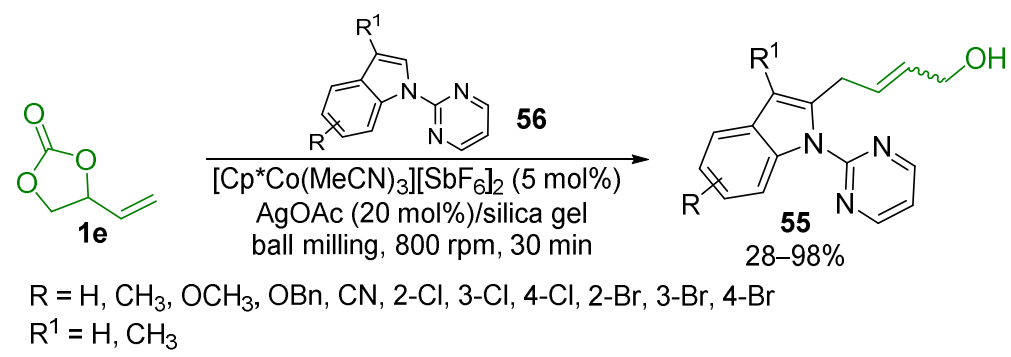

Scheme 31. C-H Allylation of indoles using VEC.

In 2012, Bensemhoun and Condon [96] reported the first creation of carbon-carbon bonds with glycerol 1,2-carbonate (Scheme 32). They proposed conjugate addition reactions of activated glycerol 1,2-carbonate derivatives 1 onto electron-deficient olefins 57 based on an electrochemical process using nickel complexes as catalysts in conjunction with a consumable anode. Halogen (I, Br) or pseudohalide $\left(\mathrm{N}_{3}, \mathrm{OTs}\right)$ derivatives $\mathbf{1}$ and certain electron-deficient olefins $\mathbf{5 7}$ such as methyl vinyl ketone, butyl acrylate, and acrylonitrile were used as substrates and the reactions were conducted in an undivided cell fitted with a nickel grid as the cathode and an iron rod as the anode. The first step of the reaction was a short pre-electrolysis process at room temperature; after $15 \mathrm{~min}$, the starting materials and $\mathrm{NiBr}_{2} \cdot 3 \mathrm{H}_{2} \mathrm{O}$ were added to the system for the electrolysis at $76{ }^{\circ} \mathrm{C}$ under a constant 0.2 A current, until full consumption of the GC. The regioselective conjugate addition was effective and provided the new carbonates in good yields. This sacrificial anode-based electroreductive process is compatible with the presence of the carbonate function. A comparison of product yields using DMF or propylene carbonate (PC) as a green solvent gave good results in both cases.

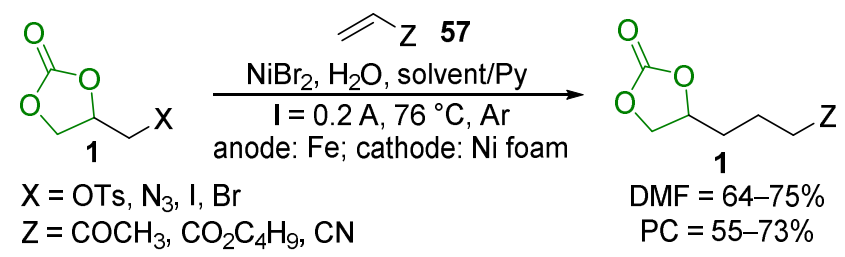

Scheme 32. Conjugate addition reactions of activated glycerol 1,2-carbonate derivatives 1 onto electron-deficient olefins 57. 
In 2020, Glorius and co-workers [97] described the synthesis of $\alpha, \beta$-disubstituted $\gamma$-butyrolactones 58 through cooperative iridium catalysis and $N$-heterocyclic carbene organocatalysis (Scheme 33). Considering the importance and prevalence of $\gamma$-butyrolactones in biologically active natural products, in this study the authors prepared several compounds 58 with moderate to excellent yields, with control of the relative and absolute configuration of the two formed stereocenters, using an enantio- and diastereodivergent [3+2] annulation reaction. These lactones were prepared from VEC $1 \mathbf{e}$ and trans-cinnamaldehydes 59 using a solution of $\left[\operatorname{Ir}(\mathrm{COD}) \mathrm{Cl}_{2}(2 \mathrm{~mol} \%), \mathrm{Et}_{3} \mathrm{~N}, \mathbf{L} 4(8 \mathrm{~mol} \%)\right.$, and $4 \mathrm{C}(10 \mathrm{~mol} \%)$ in toluene $(0.1 \mathrm{M})$ under Ar for $48-96 \mathrm{~h}$. This combination of catalysts was responsible for the effectiveness and selectivity, with the Ir- $\pi$-allyl intermediates seeming well suited for nucleophilic addition of the NHC-enolate, giving the desired compounds. An extended study involving two chiral catalysts allowed selective access to all four possible stereoisomers of the $\gamma$-butyrolactone products. The usefulness of this strategy was illustrated in the synthesis of the naturally occurring lignan (-)-hinokinin.

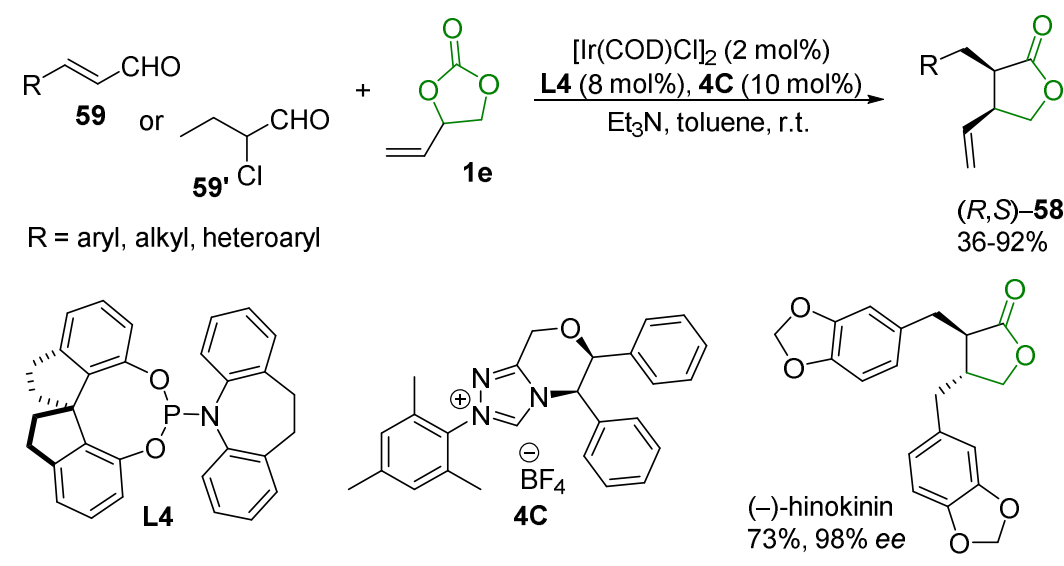

Scheme 33. Synthesis of $\alpha, \beta$-disubstituted $\gamma$-butyrolactones 58 .

\subsection{Other Reactions}

Due to their favorable nutritional properties, 1,3-diglycerides, i.e., 1,3-sn-diacylglycerols 3a, are popular in the food industry. Interestingly, these diglycerides may be synthetized by an efficient and benign two-step, one-pot process, without any solvent (Scheme 34) [98]. A practical method used fatty acid anhydrides 60 and GC 1a under DABCO catalysis to produce the industrially relevant diglycerides $3 a$ with good yields and high purity. Long-chain anhydrides $\mathbf{6 0}$ of lauric, myristic, palmitic, and stearic acids $\mathbf{6 1}$ led in all cases to the esterified carbonates, which were isolated in similar yields after $7 \mathrm{~h}$ reaction. Two plausible mechanisms were suggested for their transformation into 3a. First, the liberated fatty acid $\mathbf{6 1}$ reacts with DABCO to form an ammonium salt. The carboxylate anion can subsequently attack either the alkylene carbon (route 1) or the carbonyl group of the esterified carbonates (route 2), providing the desired 3a. The formation of the product was monitored by observing the liberation of $\mathrm{CO}_{2}$ and the disappearance of the carbonate IR band of the esterified carbonates. 


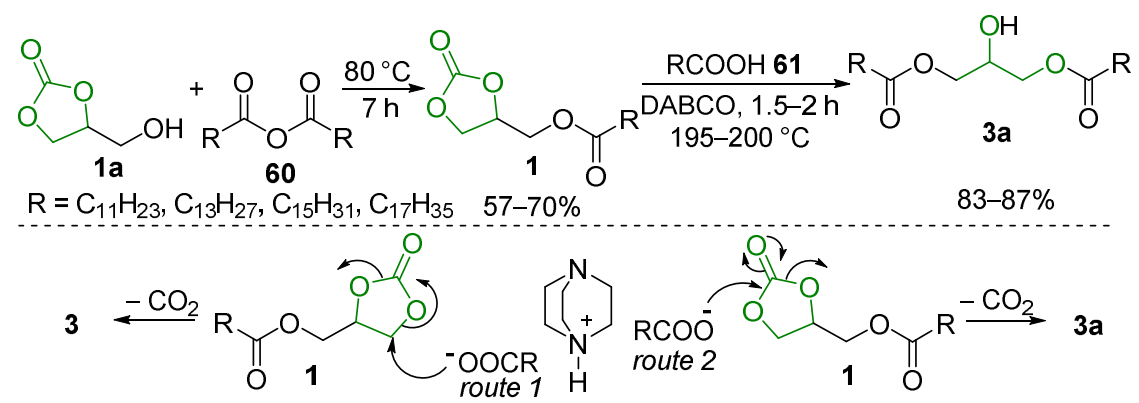

Scheme 34. Synthesis of diglycerides 3a from fatty acid anhydrides 60 and GC 1a under DABCO catalysis.

Poly(ionic liquid)s (PILs) represent an emerging interdisciplinary topic due to their potential applications in chemistry, physics, materials science, and electrochemistry $[99,100]$. In this sense, the application of nonporous PIL beads with swelling properties as catalysts for the reaction of ethylene carbonate with aniline was proposed by Zhang and co-workers (Scheme 35) [101]. After preparation of cross-linked poly(ionic liquid)s by direct radical copolymerization of $\mathrm{N}$-vinyl imidazolium ionic liquids with sodium acrylate, the authors used them in the conversion of various carbonates. Due to its swelling ability, P[VBIM][AA] presents catalytic activities similar to the homogeneous ionic liquid monomers. However, cyclic carbonates with a low dielectric constant, such as propylene- and 1,2-butylene carbonate, showed different swelling abilities, thus decreasing the catalytic activity and providing the corresponding oxazolidones 62 in lower yields (50\% and $2 \%$ ) than with ethylene carbonate $\mathbf{1}(99 \%)$.

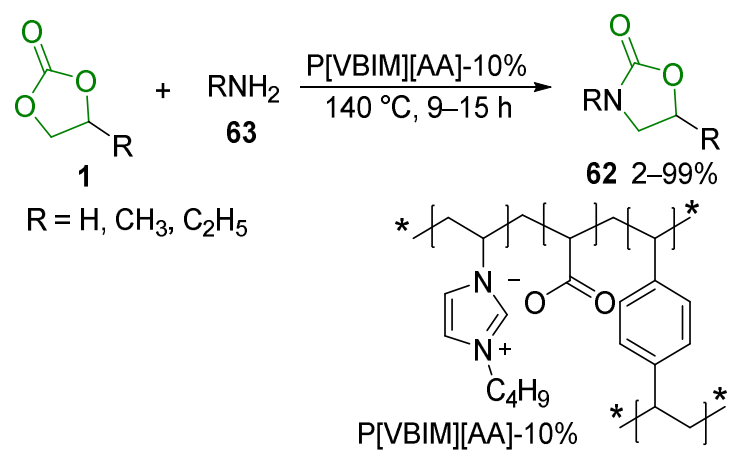

Scheme 35. Synthesis of oxazolidones 62 using P[VBIM][AA].

With a view to avoiding purification steps, Truscello and co-workers [102] reported the one-pot synthesis of glycols $\mathbf{1 2}$ via in situ formation of glycerol carbonate 1a in the absence of any solvent. By reacting different phenols 7 with glycerol 3 ( 3 equivalent) and diethyl carbonate 16b (1.4 equivalent) under $\mathrm{K}_{2} \mathrm{CO}_{3}$ catalysis, glycols 12 were obtained with 72 $82 \%$ yields (NMR evaluation) under conventional conditions (Scheme 36). 1-Naphthol was also successfully converted into the corresponding diol with $74 \%$ yield after $18 \mathrm{~h}$.

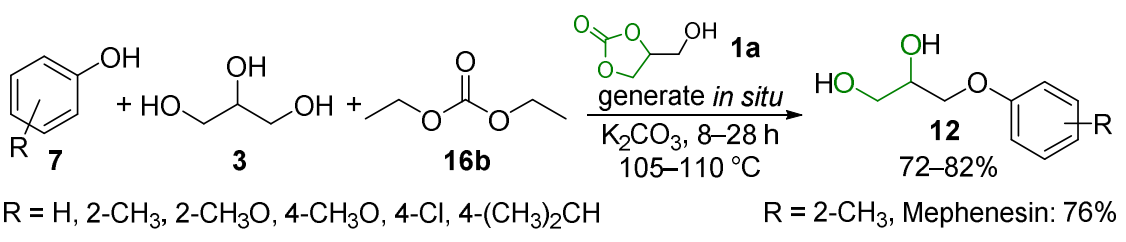

Scheme 36. One-pot synthesis of glycols 12.

The proposed method allowed seven aryloxypropanediols to be obtained, three of which were pharmaceutically important products, namely guaiphenesin, mephenesin, 
and chlorphenesin (Figure 5). To check the recyclability of excess glycerol and of the catalyst after the first run, mephenesin was extracted with toluene, then 1 equivalent of $o$-cresol, 1.4 equivalent of glycerol, and 1.4 equivalent of diethyl carbonate were added to the recovered residue. The resulting mixture was then stirred at $105-110^{\circ} \mathrm{C}$ over $28 \mathrm{~h}$. Although mephenesin could be obtained with good yields (76-80\%) after three consecutive runs, the study of the re-use of the glycerol and base was not further developed.<smiles>COc1ccccc1OCC(O)CO</smiles><smiles>Cc1ccccc1OCC(O)CO</smiles><smiles>OCC(O)COc1ccc(Cl)cc1</smiles>
muscle relaxant and antifungal

Figure 5. Structure of pharmaceutically important products.

A tetrabutylammonium-fluoride-mediated hydroxyalkylation process for phenols 7 with carbonate 1c was developed to access different aryl $\beta$-hydroxyethyl ethers 64 [103]. In this process, the corresponding products were obtained with $88-98 \%$ yields by using TBAF. $3 \mathrm{H}_{2} \mathrm{O}(1 \mathrm{~mol} \%)$ in DMF as the solvent at $170{ }^{\circ} \mathrm{C}$, under $\mathrm{N}_{2}$ atmosphere over $13 \mathrm{~min}$ to $21 \mathrm{~h}$ of reaction (Scheme 37). Different substituted phenols were employed and good yields were obtained. The authors also extended this protocol to gram-scale and flow synthesis of multiflorol 64e, with $90 \%$ isolated yield.

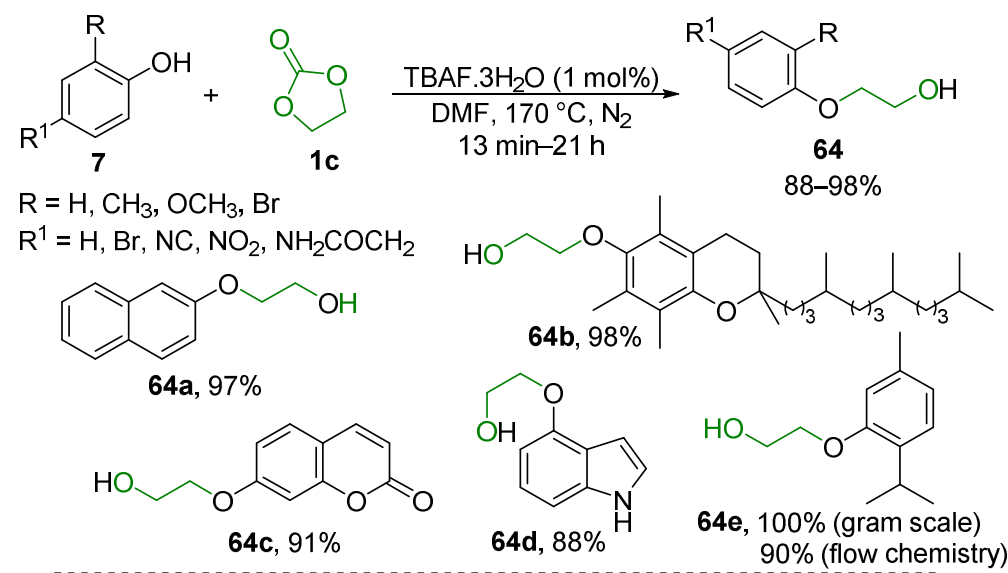

With 2.4 or 3.6 equiv of ethylene carbonate $1 \mathrm{c}$ :<smiles>CC(C)(C)Oc1cc(OCO)cc(OCO)c1</smiles>

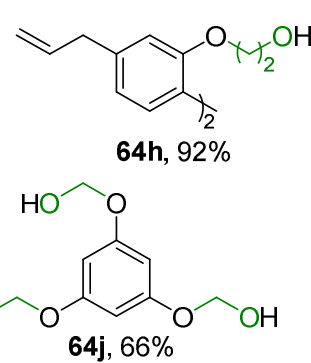

Scheme 37. Obtaining different aryl $\beta$-hydroxyethyl ethers 64 .

Olsén and co-workers [104] reported the synthesis of densely functionalized carbamates 65 and $65^{\prime}$ through ring-opening of cyclic carbonates 14 . The highlight of this study was the fact that unprotected $\alpha$-amino acids, such as glycine $66 \mathbf{a}$, were used in aqueous medium to provide a variety of new alkenes, carboxylic acids, thiols, and alcohols linked to a central carbamate motif (Scheme 38). The reactions were performed over $2 \mathrm{~h}$ at room temperature in the presence of triethylamine (2 equivalent). Optimization studies showed the necessity of 4 equivalent of the amino acid $\mathbf{6 6}$ to achieve opening of the cyclic carbonate 
ring. On reaction of the cyclic carbonates 14 with glycine $66 a$, the corresponding carbamates 65 and $65^{\prime}$ were obtained with $75-91 \%$ yields, while different amino acids $66 \mathbf{b}$, containing one stereocenter, led to carbamates $65^{\prime \prime}$ a-d with $94-97 \%$ conversion and $20-70 \%$ yields (NMR evaluation).
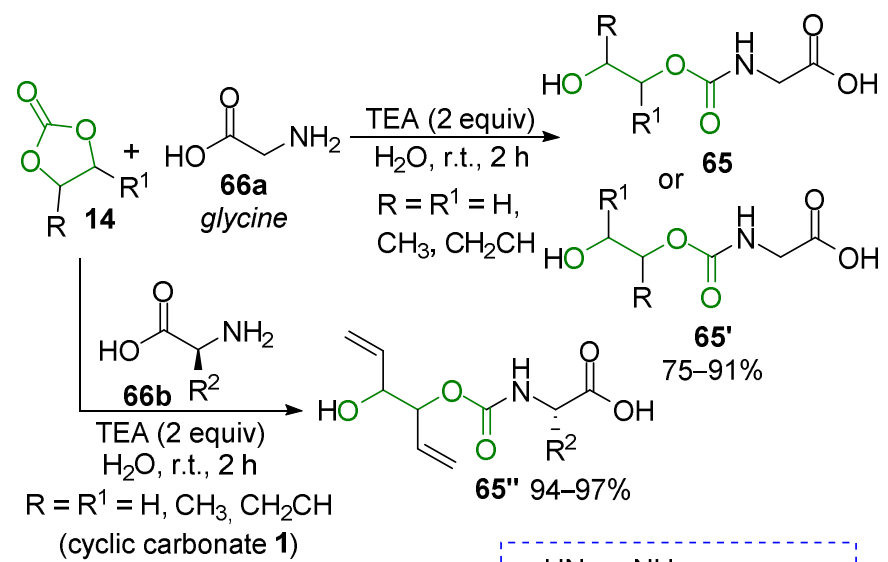

$\mathrm{R}^{2}=\mathrm{HOCH}_{2}(65 \mathrm{a} ", 70 \%)$

$\mathrm{HSCH}_{2}(65 \mathrm{~b} ", 51 \%)$

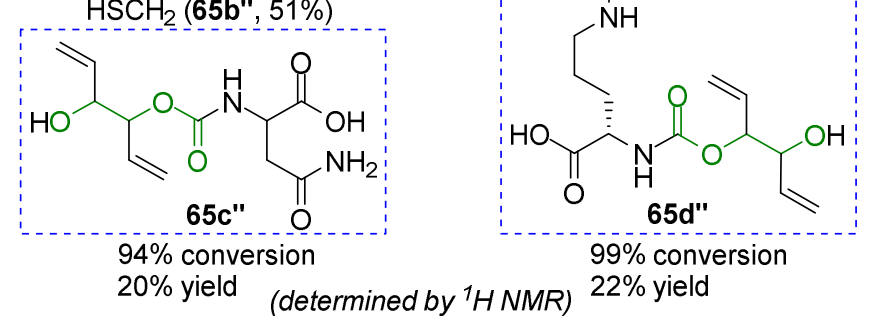

Scheme 38. Synthesis of densely functionalized carbamates.

Recently, Luo and co-workers [105] reported the asymmetric allylic alkylation of $\alpha$ branched $\beta$-ketocarbonyls, using an arene-coordinating chiral primary amine as a dual aminocatalyst and ligand. Different ketoesters 67 were reacted with VEC 1e to give the enantiomerically enriched allylic adducts 68 with good yields and excellent enantioselectivities (Scheme 39). To access the (S)-isomers, the reactions were performed in the presence of a bulky tertiary aminocatalyst (catalyst A)/TfOH (20 mol\%), $\mathrm{Pd}\left(\mathrm{PPh}_{3}\right)_{4}(2.5 \mathrm{~mol} \%)$, and (S)-2,2'-bis(diphenylphosphino)-1,1'-binaphthyl [(S)-BINAP] (6.25 mol\%) in acetonitrile as the solvent, at $40{ }^{\circ} \mathrm{C}$ over 36 to $96 \mathrm{~h}$. (R)-Isomers were produced from (catalyst B)/TfOH $(20 \mathrm{~mol} \%), \mathrm{Pd}_{2} \mathrm{dba}_{3}(2.5 \mathrm{~mol} \%)$, and tris(4-methoxyphenyl)phosphine [(PMP) $\left.{ }_{3} \mathrm{P}\right](10 \mathrm{~mol} \%)$ in acetonitrile at room temperature for 16-72 $\mathrm{h}$. Some of the vinylated carbonates presented better efficiency in providing the ( $R$ )-enantiomers (Scheme 40$)$. 


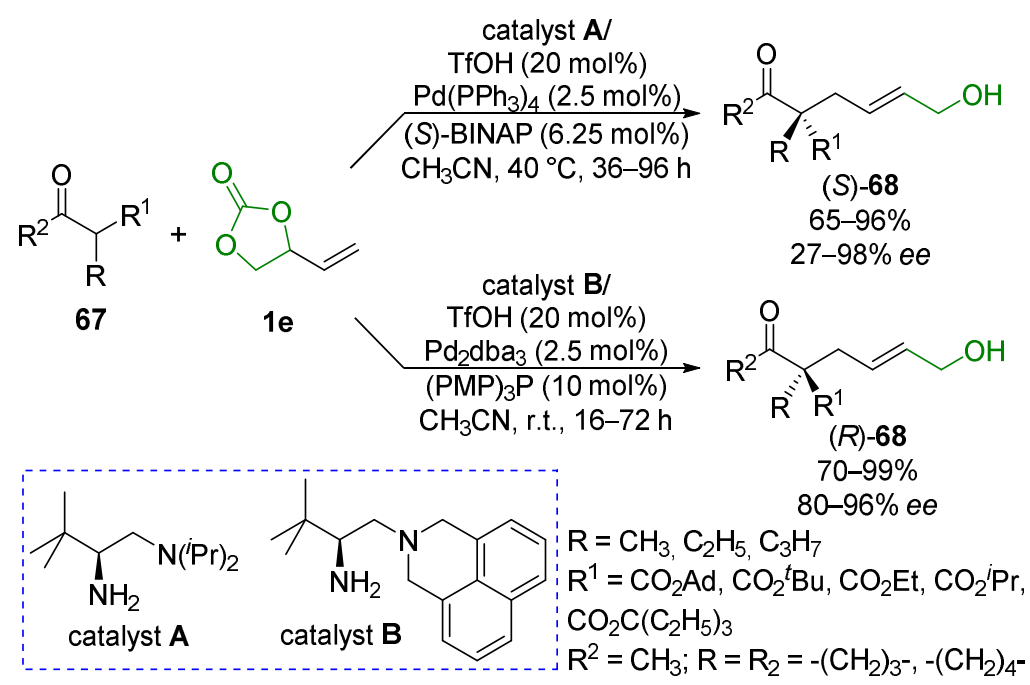

Scheme 39. Synthesis of enantiomerically enriched allylic adducts 68.
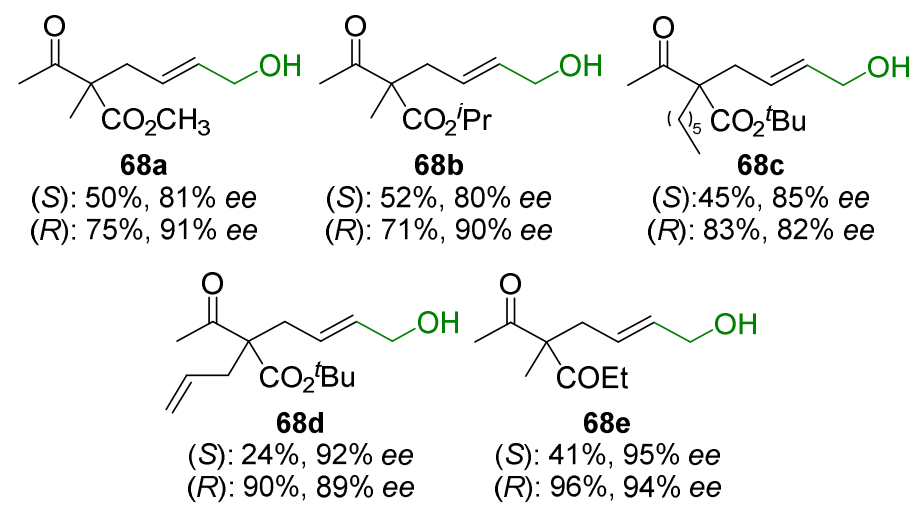

Scheme 40. Selected examples.

\subsection{Alkene Polymerization}

The synthesis of different monomers with at least two reactive groups for further polymerization is an attractive approach, especially from the point of view of the polymer industry. While one of the reactive groups can be used for copolymerization, the other one can be set aside for further transformations, namely for crosslinking [106]. In this sense, the presence of an unsaturated site on the monomer facilitates subsequent polymerization. On the other hand, the presence of a cyclic carbonate moiety as a second reactive site results in polymers with low reactivity, which allows better control of crosslinking compared with isocyanate or epoxide functions, for example. It is worth noting that the reactions on the double bond of the monomer, which can keep the cyclic carbonate unit intact, are critical for later functionalization of these monomers [19].

In this sense, Lapinte and co-workers [107] described the efficient synthesis of glycerolbased co-oligomers functionalized with alcohol, cyclocarbonate, or acetal pendant groups. The process involves free radical chain transfer polymerization using 2-mercaptoethanol (ME) as the chain transfer agent and glycerol-derived acrylate monomers. Initially, GC 1a was reacted with acryloyl chloride 69 in the presence of $\mathrm{Et}_{3} \mathrm{~N}$ to provide glycerol carbonate acrylate (GCA) 1k with $80 \%$ yield (Scheme 41 ). The free radical telomerization of GCA to oligoGCAs was performed in the presence of AIBN and $\mathrm{ME}$ at $80{ }^{\circ} \mathrm{C}$. During the telomerization process, the decomposition of AIBN causes the formation of a thiyl radical from $\mathrm{ME}$, which further reacts with a monomer unit to form radical species, resulting in the product carrying a hydroxyl head group. A similar procedure was conducted using solketal instead of GC. Those materials did not exhibit branching or gelation and were 
totally soluble in the tested solvents. Additionally, the carbonate ring or acetal protective groups on oligomers can be selectively removed under basic or acidic conditions.<smiles>O=C1OCC(CO)O1</smiles>

1a

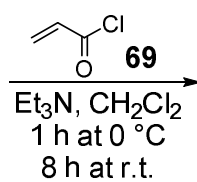<smiles>C=CC(=O)OCC1COC(=O)O1</smiles>

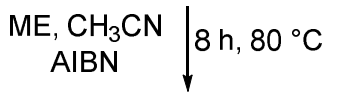<smiles>[2H]C(CSCCO)C(=O)OCC1COC(=O)O1</smiles>

Scheme 41. Synthesis of glycerol carbonate 1k and 70 .

Seeking to obtain amphiphilic polymers, Robin and co-workers [108] have prepared thiol monomers $\mathbf{7 1}$ by the esterification of oleic and lauric acids with 2-mercaptoethanol. These intermediates were employed in AIBN-induced free-radical polymerization with glycerin carbonate acrylate (GCA) $1 \mathrm{k}$ in acetonitrile solution at $80^{\circ} \mathrm{C}$. In this telomerization process, two oleate polymers 72 were obtained with $65 \%$ (for $n=27$ ) and $73 \%$ (for $n=65$ ) yield, together with one laurate polymer with $62 \%$ yield (for $n=24$ ), as shown in Scheme 42 . The fatty acid fragment is responsible for the hydrophobic character of the polymer; in order to prepare amphiphilic derivatives $\mathbf{7 3}$ from telomers $\mathbf{7 2}$, the base-catalyzed hydrolysis of the cyclic carbonate unit was used to unmask hydroxyl groups. In aqueous media, the hydrolyzed polymers 73 were able to form aggregates with different numbers of micellar units, with critical micellization concentrations in the range of 10 to $60 \mathrm{mg} \cdot \mathrm{L}^{-1}$. These values increase with the length of the hydrophilic moiety and decrease with the growth of the hydrophobic moiety length and the presence of double bonds, which leads to control of the diameter of the micelles.

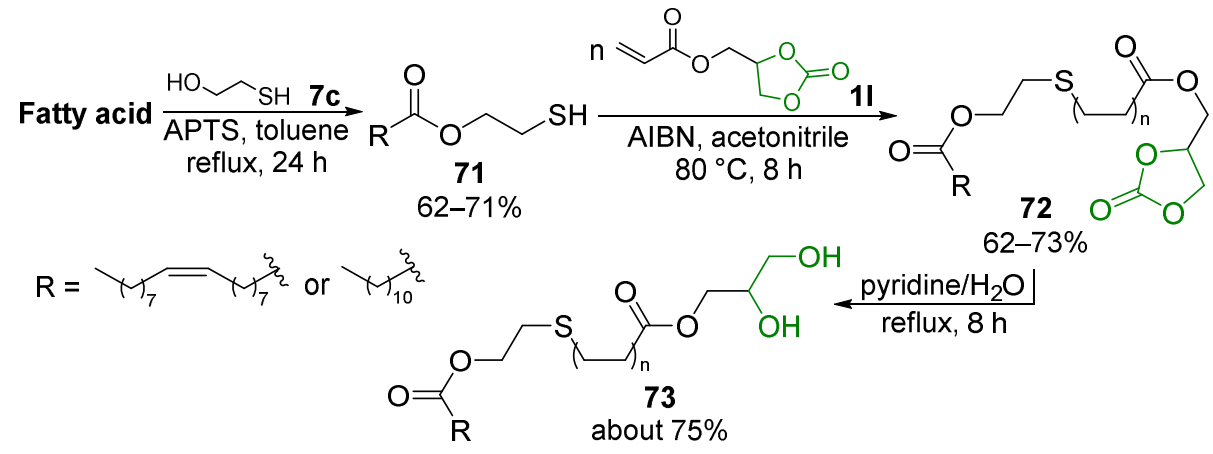

Scheme 42. Preparing amphiphilic derivatives 73 .

In order to obtain fluorinated terpolymers 74 and copolymers 75, Carpentier and coworkers [109] reacted glycerol carbonate vinyl ether $\mathbf{1 1}$ with either chlorotrifluoroethylene $\mathbf{7 6}$ and vinyl ether $\mathbf{7 7}$ or with $\mathbf{7 6}$ alone, respectively, in the presence of tert-butylperoxypivalate (TBPPi) in 1,1,1,3,3-pentafluorobutane at $74^{\circ} \mathrm{C}$ in an autoclave, in the presence of $3 \mathrm{~mol} \%$ of potassium carbonate (Scheme 43). The combined presence of fluorine atoms and the GC unit in a polymer led to several possibilities for posterior functionalization. This versatility was explored by the authors via the synthesis of fluorinated polymers bearing hydroxyurethane moieties PFHU 78a-b and 79a-b through the ring-opening of the GC unit with isopropylamine in DCM at $50{ }^{\circ} \mathrm{C}$. Complete conversion of the terpolymers 74 
to PFHU 78a-b derivatives was achieved using a large excess (20-30 equivalent) of base, while full conversion of 75 into $\mathbf{7 9 a}-\mathbf{b}$ only required 1.2 equivalent of base.

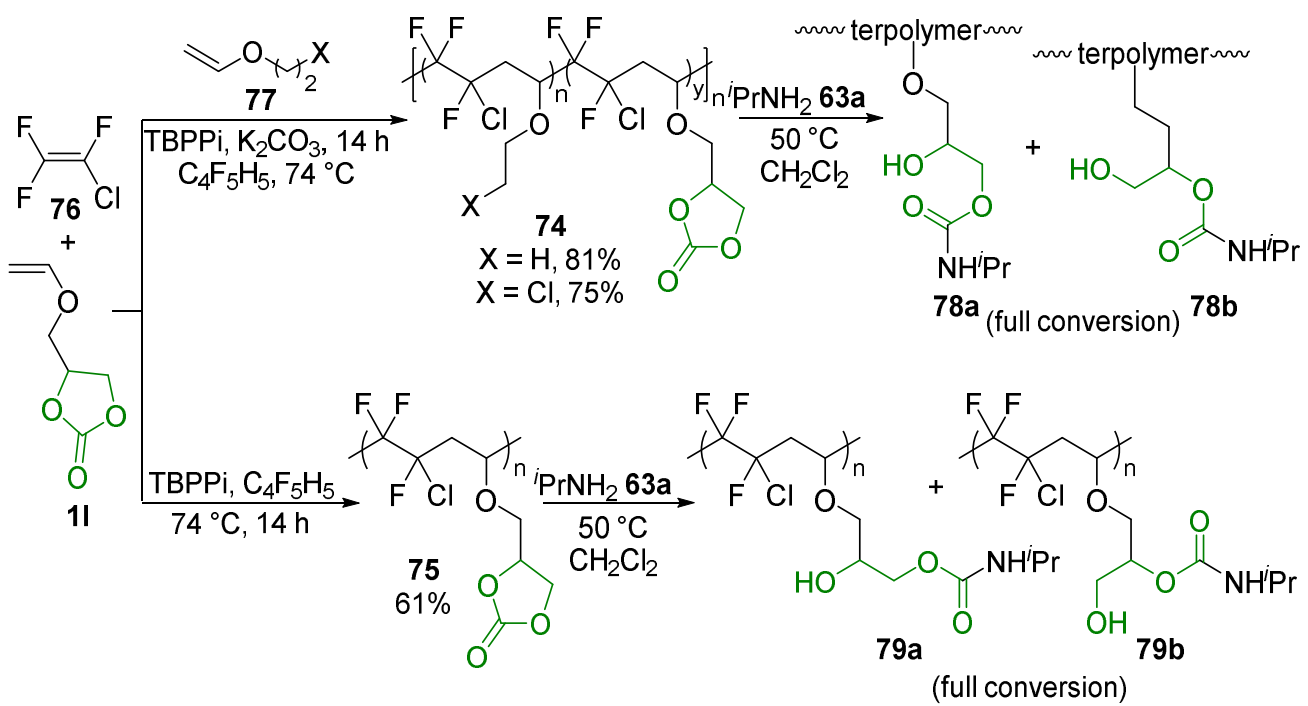

Scheme 43. Synthesis of fluorinated terpolymers 74-75 and 78-79.

Patti and co-workers [110] promoted the reaction of the double bond of polystyrene polymers bearing pendant cyclic carbonate groups BMD 80a and BBD 80b via radical photopolymerization to develop new alternative materials for application in nanocomposites of sodium smectite, such as the one used in saline leachates, keeping the cyclic carbonate unit intact in the polymerization step. The synthesis of BMD 80a was performed via the reaction between GC 1a and 4-vinylbenzyl bromide 81a in the presence of sodium hydride in THF (Scheme 44). The analog BBD $\mathbf{8 0 b}$ was similarly synthesized by reacting 4-(4-hydroxybutyl)-1,3-dioxolan-2-one with 81a. The monomers $80 \mathrm{a}$ and $80 \mathrm{~b}$ were photopolymerized over $24 \mathrm{~h}$ under nitrogen atmosphere using AIBN and a 12-cm-high UV lamp. The corresponding polymers were obtained with 93\% (PBMD 82a) and 74\% yields (PBBD 82b). On treatment of 82a with a saline solution ( $3 \mathrm{M} \mathrm{NaCl})$, a nanocomposite with disordered intercalation was formed. Alternatively, 82a and $\mathbf{8 2 b}$ were intercalated in the presence of the same saline solution, providing partially disordered intercalates nanocomposites.

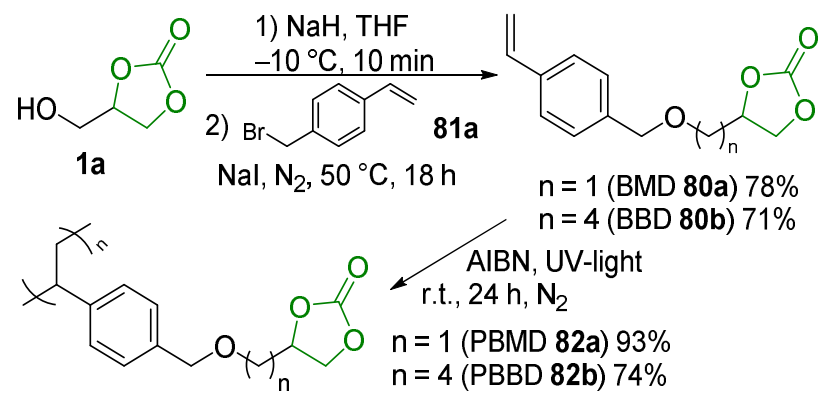

Scheme 44. Obtaining the polymers 80 and 82 .

Plasseraud and co-workers [111] prepared monoglycerides 83 by reacting CG 1a or glycidol 2a with carboxylic acids $\mathbf{6 1}$. These intermediates 83 were converted into the corresponding monoglyceride bis-acrylates 84 , which underwent polymerization under UV irradiation in the presence of 2-hydroxy-2-methyl-1-phenyl-propan-1-one (Darocur $1173^{\circledR}$ ) at room temperature (Scheme 45). When GC 1a was employed (step 1), the desired product was isolated with $14 \%$ yield only (even after $24 \mathrm{~h}$ of reaction) due to side-reactions. In 
contrast, when glycidol 2a was used in excess (carboxylic acid $\mathbf{6 1 : 2 a}=1: 2$ ), the intermediate 83 was obtained in yields above $80 \%$ after only $50 \mathrm{~min}$.

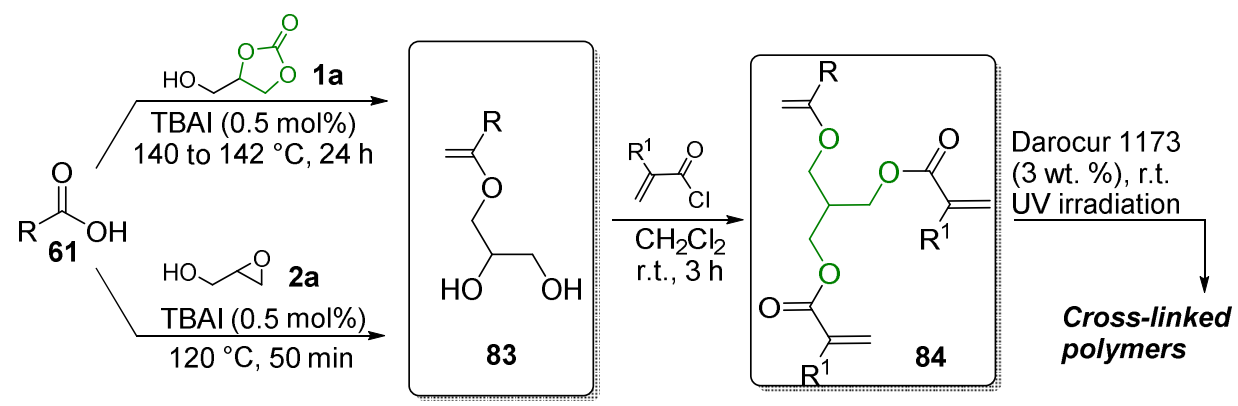

$\mathrm{R}=\mathrm{C}_{3} \mathrm{H}_{7}, \mathrm{C}_{9} \mathrm{H}_{19}, \mathrm{C}_{10} \mathrm{H}_{19}, \mathrm{C}_{17} \mathrm{H}_{35}$ $\mathrm{R}^{1}=\mathrm{H}, \mathrm{CH}_{3}$

Scheme 45. Synthesis of monoglycerides 83 and subsequent conversion to monoglyceride bisacrylates 84 .

\subsection{Ring-Opening Polymerization}

The class of five- and six-membered cyclic alkylene carbonates is large and varied, offering a wide range of monomeric systems for ring-opening polymerization (ROP), leading to new polymers [112-114]. Gnaneshwar and co-workers [115] reported the synthesis of a $\alpha$ (cyclic carbonate), $\omega$-Hydroxyl/Itaconic acid asymmetric telechelic poly( $\varepsilon$-caprolactone), by ROP followed by modification of the cyclic carbonates with 2-phenylethylamine (Scheme 46). Firstly, compound 86 was prepared with $96 \%$ yield by reacting GC 1 a as a functional biobased initiator with $\varepsilon$-caprolactone 27 in the presence of tin 2-ethylhexanoate $\left(110^{\circ} \mathrm{C}\right.$, argon flow). The authors reported that the ROP technique allows control of the molecular weights, as well as a linear correlation of the molecular weight vs. monomer conversion. The reactivity of compound $\mathbf{8 6}$ was demonstrated through the modification with 2-phenylethylamine to give hydroxylurethane 87 using a non-isocyanate route.

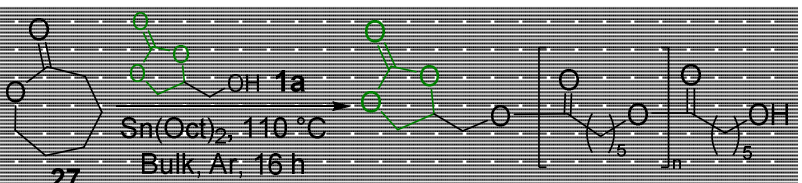

27 Bulk, Ar, $16 \mathrm{~h}$

$8696 \%$

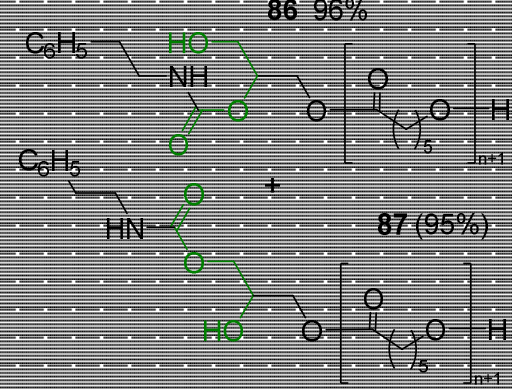

Scheme 46. Synthesis of compound 86 and subsequent modification to give hydroxylurethane 87 using a non-isocyanate route.

In 2016, Möller and co-workers developed an anionic ring-opening copolymerization technique for cyclic carbonate $\mathbf{1} \mathbf{c}$ and tert-butyl glycidyl ether $\mathbf{2 c}$, followed by the removal of the protective group (Scheme 47) [116]. The hydroxy-functionalized PEG derivatives were submitted to sequential transcarbonylation, transalkylation, and fragmentation, aiming to replace carbonate groups with ether linkages. Poly(ethylene oxide-co-tert-butyl glycidyl ether)hydroxyl telechelic copolymer $\mathbf{8 8 a}$ was synthetized via the reaction between $\mathbf{1 c}$ and $2 \mathrm{c}$ under mono-mode microwave irradiation, using $\mathrm{CsOH}$ as an initiator. After $15 \mathrm{~h}$ at $180{ }^{\circ} \mathrm{C}$, 1c was totally consumed, and the product $88 \mathrm{a}$, with molecular weight values 
of $750-1700$ g.mol ${ }^{-1}$, was obtained. Further, poly(ethylene oxide-co-glycidyl ether) $88 \mathrm{~b}$ was obtained after the removal of the tert-butyl protective group, generating hydrophilic reactive hydroxyl sites in the copolymer.

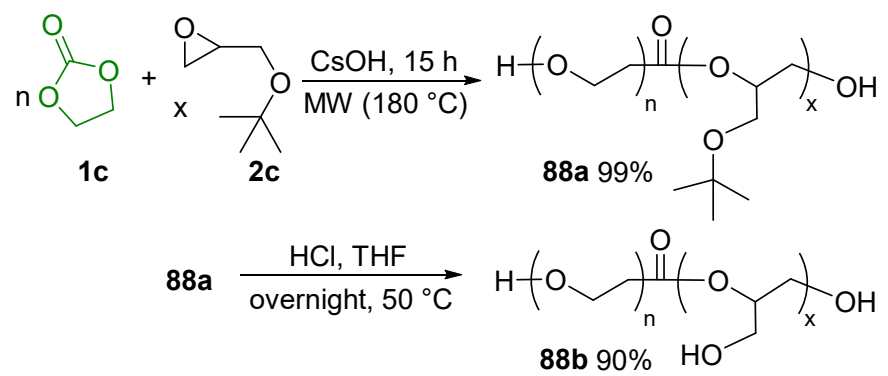

Scheme 47. Anionic ring-opening copolymerization.

The synthesis of a new polyether by cationic and anionic ROP of a cyclic carbonatecontaining epoxide $1 \mathrm{~m}$ under different conditions was achieved by Gnaneshwar and co-workers [115] to improve the hydraulic barrier properties of Na-smectite liners to saline leachates (Scheme 48). By using a strong non-nucleophilic base, it was possible to perform concomitant ring-opening of both the epoxide and the cyclic carbonate, providing the respective poly[oxy(ethane-1,2-diyl)] 89 with $87 \%$ yield. In cationic conditions, poly[oxy(ethane-1-\{[(methyloxy)methyl $]$ oxirane $\}-1,2$-diyl)] 90 was obtained with $52 \%$ yield by selective ring-opening of the cyclic carbonate functionality. In contrast, the treatment under nitrogen of the monomer with boron trifluoride resulted in ring-opening of the epoxide to give the poly(oxy\{-ethane-1-[(4-methoxymethyl)-1,3-dioxolan-2-one]-1,2-diyl\}) 91 with $63 \%$ yield. Thereafter, nanocomposites of sodium smectite were formed from those polymers via clay polymerization in situ and solution intercalation methods. The resulting nanocomposite 91 was shown to be more resistant to leaching in $3 \mathrm{M} \mathrm{NaCl}$ than its respective cyclic carbonate $1 \mathrm{~m}$.

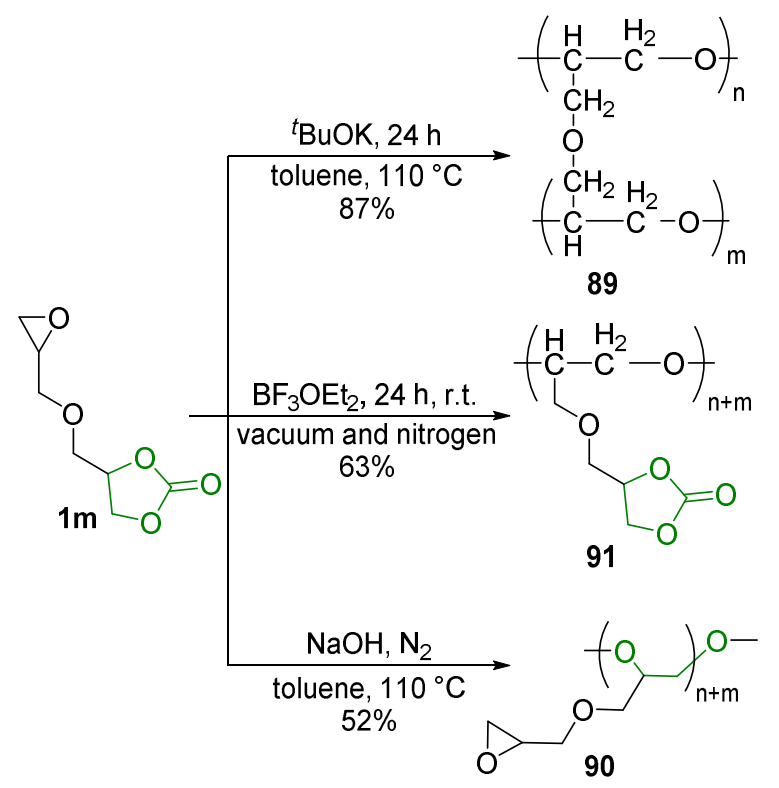

Scheme 48. Synthesis of a new polyether by cationic and anionic ROP of a cyclic carbonate-containing epoxide $1 \mathrm{~m}$.

In 2017, Marcos-Fernández and co-workers [117] described the degradation of poly(ethylene terephthalate) by ethylene carbonate (EC) in the presence of potassium hydroxide, a low-cost catalyst. Degradation of PET at $130{ }^{\circ} \mathrm{C}$ produced short-chain oligomers with approximately $33 \%$ of carbonate units inserted in their structure, resulting from 
the ring-opening of EC with partial decarboxylation. Furthermore, the reaction of bis(2hydroxyethyl) terephthalate (BHET) with EC in the absence of $\mathrm{KOH}$ produced difunctional oligomers with hydroxyl terminal groups, bearing aromatic rings esterified with polyether short chains. Generally, such oligomers could be applied as macroglycols for the preparation of thermoplastic polyurethanes.

\section{Potential Applications in Biological Studies}

\subsection{Raw Material Derivatives}

A raw material is a basic material that is used for the generation of a new material with greater application potential. Currently, glycerol represents one of the most versatile and available raw materials due to the large production of biodiesel, from which large tonnages of glycerol co-product are obtained [118]. Another highly abundant raw material is xylan, a major biopolymer associated with plant hemicelluloses [119]. Taking into account their abundance, it is interesting to explore ecologically sound applications for these raw materials.

In 2016, two methodologies describing the functionalization of xylan through reaction with cyclic carbonate 1e were reported. Saake and co-workers [120] first described the functionalization of xylan 92 to deliver modified polysaccharides 93 (Scheme 49A) through a DBU-catalyzed reaction in DMSO at $140^{\circ} \mathrm{C}$. Two different xylans were evaluated, with a special focus on the effects of the reaction time, temperature, and amount of xylan in the reaction mixture. Samples were analyzed mainly using NMR spectroscopy regarding their degree of substitution (DS) and molar substitution (MS). The products were further characterized by FTIR spectroscopy, mass spectrometry, and SEC, and also regarding their water solubility.

A few months later, the same group [121] reported that differences in temperature and time were determining factors in the synthesis of xylan derivatives. Considering the decarboxylation process that occurs in the reaction medium, the authors observed a significant difference between reactions performed at $140{ }^{\circ} \mathrm{C}$ and at $160^{\circ} \mathrm{C}$. When the reaction proceeds at $140^{\circ} \mathrm{C}$, derivatives with low substitution levels are preferably obtained, with longer reaction times being required to obtain highly substituted xylanes $\mathbf{9 2}$. Moreover, as DMSO undergoes degradation at high temperatures, a reaction proceeding at $140{ }^{\circ} \mathrm{C}$ is preferred. The remaining hydroxyl group on the hydroxyvinylethyl appendage of xylan 93 then reacts with another vinyl carbonate molecule, leading to product 94 (Scheme 49B).

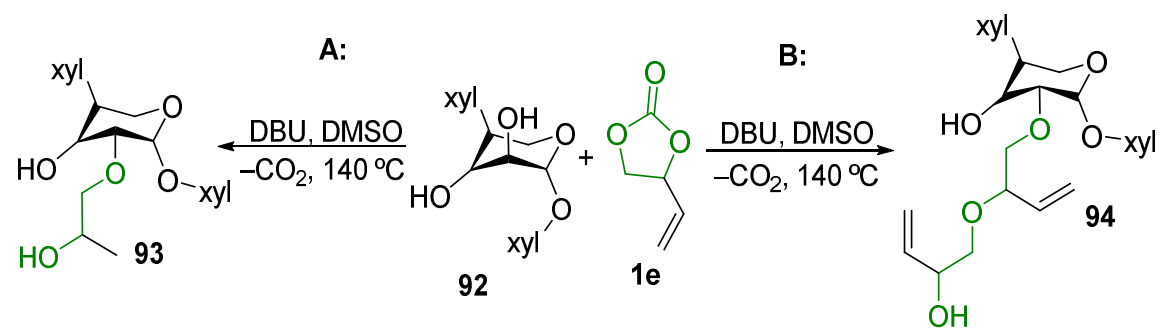

Scheme 49. Synthesis of xylan derivatives by route (A) or (B).

In 2016, Oliveira and co-workers [122] used two renewable materials for the synthesis of the glyceryl glycoside 95. The Ferrier allylic rearrangement involving GC 1a and tri$O$-acetyl-D-glucal 96 provided a mixture of diastereomers 95 with $31 \%$ yield, together with degradation products (Scheme 50). Considering their possible effects on the reaction, both the reaction time and the quantity of Lewis acid were reduced, resulting in a modest increase in the yield to $40 \%$. Finally, an optimized set of mild conditions was establishedby stirring a mixture of glucal, GC $1 \mathbf{a}$ (1.2 equivalent), $\mathrm{BF}_{3} \cdot \mathrm{Et}_{2} \mathrm{O}$ (0.1 equivalent). and $4 \AA$ molecular sieves in $\mathrm{CH}_{2} \mathrm{Cl}_{2}$ at -40 to $-20^{\circ} \mathrm{C}$ for 10 min provided glycoside 95 with $84 \%$ yield (diastereoisomeric mixture) after flash column chromatography. This protocol was used to prepare the starting material for a CuAAC reaction to induce the formation of glucoglycerol-1,2,3-triazole derivatives. 


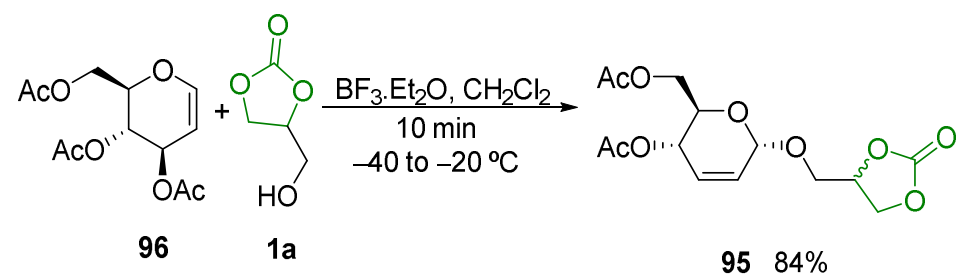

Scheme 50. Synthesis of the glyceryl glycoside 95 .

\subsection{Heterocyclic Compounds}

Heterocyclic systems represent the most general structural unit of many natural compounds; they have valuable biologically properties and a wide range of applications in the pharmaceutical industry $[123,124]$. Oxa- and aza-heterocycles atoms are the most representative, which have been used to access new compounds in chemical industries [125]. In the following sections, we mention studies from recent years that have shown efficient synthetic methodologies for the functionalization of heterocycles via the insertion of different substituents in the chemical structure.

The oxazolidin-2-ones 62 were prepared through the reaction between cyclic carbonates 1 and aryl amines 63 in the presence of 1-butyl-3-methylimidazolium acetate ([bmim]OAc) as an eco-efficient catalyst (Scheme 51) [126]. NMR spectroscopy and DFT calculations demonstrated that both the anion and the cation of the ionic liquid catalyst cooperatively activate the starting materials via formation of hydrogen bonds. Thus, several compounds 62 were obtained with good to excellent yields after $9 \mathrm{~h}$ at $130^{\circ} \mathrm{C}$. Ethylene-, propylene-, and 4-phenoxymethylethylene carbonates 1 were reacted with a range of arylamines 63. The carbonylation reaction using different cyclic carbonates showed that steric hindrance negatively influenced the reactivity in the following order: ethylene carbonate > propylene carbonate $>4$-phenoxymethylethylene carbonate.
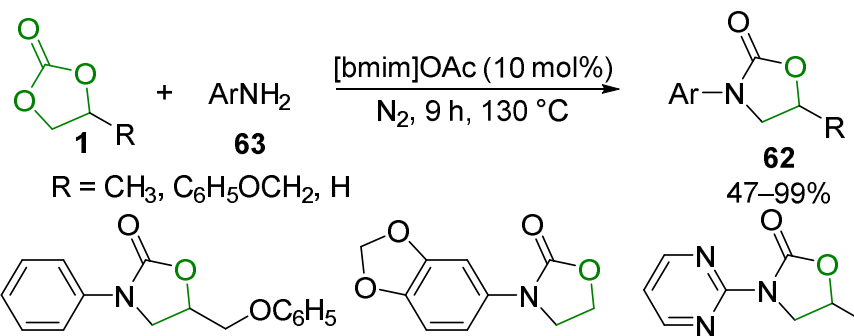
62b $80 \%$ 62c $93 \%$

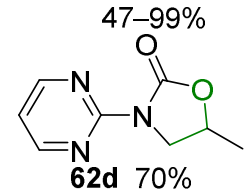<smiles>C#Cc1cccc(N2CCOC2=O)c1</smiles><smiles>CCOC(=O)c1ccc(N2CCOC2=O)cc1</smiles><smiles>CC1CN(c2ccccc2)C(=O)O1</smiles>

Scheme 51. Obtaining oxazolidin-2-ones 62 from cyclic carbonates 1 and aryl amines 63.

In the same work, a [bmim]OAc-catalyzed synthesis approach for aryl bis-oxazolidin2-ones 97 from cyclic carbonates 1 and aryl-or heteroaryldiamines 98 was devised. Ethyleneand propylene carbonate smoothly reacted with aromatic diamines to form the corresponding bis-oxazolidin-2-ones 97 in good yields (Scheme 52). In addition, the imidazoliumbased ionic liquids also exhibited high catalytic activity to prepare 3-aryl-[1,3]-oxazinan-2ones from trimethylene carbonate and [1,3]-dithiolan-2-ylidene-arylamines from ethylene trithiocarbonate [126].

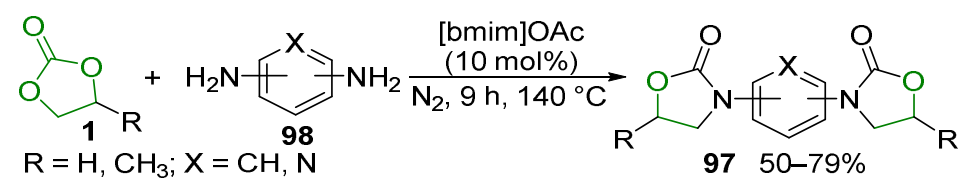

Scheme 52. [bmim]OAc-Catalyzed synthesis approach for aryl bis-oxazolidin-2-ones 97. 
Due to the versatility of glycerol carbonates, several investigations have been conducted, aiming to develop protocols for the introduction of the GC unit in heterocyclic systems. In 2012, Sackus and co-workers [127] reported the functionalization of 1-phenyl$1 \mathrm{H}$-pyrazol-3-ol 99 with TGC $\mathbf{1 h}$. The synthesis of phenylpyrazole derivatives has attracted the attention of synthetic organic chemists because of their broad spectrum of biological activities. In this protocol, $\mathbf{1 h}$ reacts with compound $\mathbf{9 9}$ in DMF at room temperature in the presence of $\mathrm{K}_{2} \mathrm{CO}_{3}$ to provide chemoselectively for 4-\{[(1-phenyl-1H-pyrazol-3yl)oxy]methyl\}-1,3-dioxolan-2-one $\mathbf{1 0 0}$ with 71\% yield (Scheme 53).<smiles>Oc1ccn(-c2ccccc2)n1</smiles>

99<smiles>O=C1OCC(C[OH2+])O1</smiles>

$1 \mathrm{~h}$

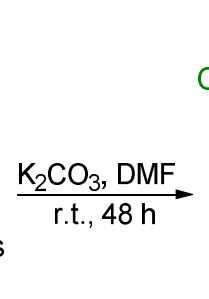

100

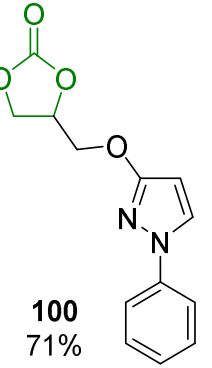

Scheme 53. Obtaining pyrazole derivatives $\mathbf{1 0 0}$.

The same group [14] reported the use of $\mathbf{1 h}$ as a bis-electrophile for the $N$-glyceryl functionalization of diverse aza-aromatic systems 101-106 (Scheme 54). The ambident benzimidazole 101 was converted into the carbonate 107 with $76 \%$ yield after $5 \mathrm{~h}$, whereas under the same conditions, benzotriazole 102 provided a mixture of 1- and 2-substituted regioisomers ( $85 \%$ global yield). For less acidic aza-heterocyclic systems, a decrease in the yield was observed, e.g., $1 H$-indole 108 led to the $N$-alkylated compound 109 with only $34 \%$ yield. Comparatively, methyl $1 \mathrm{H}$-indole-3-carboxylate 104 , with the $\mathrm{N}-\mathrm{H}$ bond under the influence of the electron-withdrawing group, was more reactive than unsubstituted indoles, providing the expected product with $48 \%$ yield. Carbazole 105 reacted in a solventdependent way to provides mixtures with $60 \%$ yield for $\mathrm{N}$-alkylated product $\mathbf{1 1 0}$ and the isomeric glycidyl carbamate. When reacting 1,2,3,4-tetrahydrocyclopenta[b]indole as the substrate in DMF, the corresponding glycidyl carbamate was obtained exclusively with $51 \%$ yield.

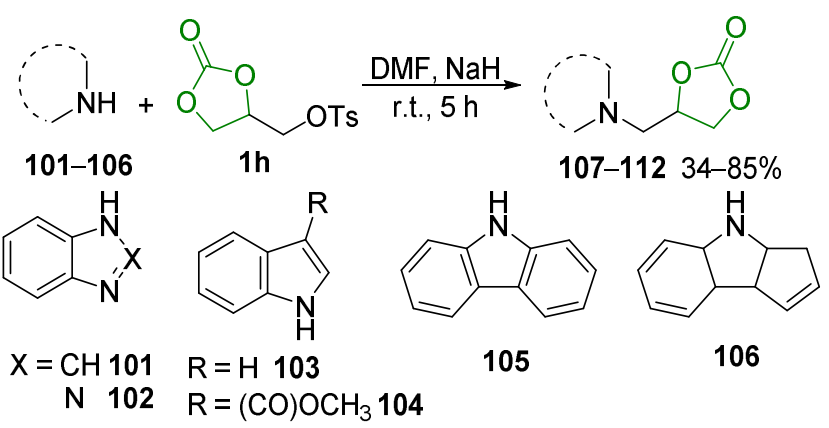

Scheme 54. Use of $1 \mathrm{~h}$ as a bis-electrophile for the $N$-glyceryl functionalization of diverse aza-aromatic systems 101-106.

Various chemistshave evaluated the performance of benzimidazole-derived carbonates as building blocks for useful transformations. The synthetic potential of the prepared compounds was evaluated in reductive or hydrolytic conditions, involving selective carbonate ring-cleavage using diverse nucleophiles (Figure 6) [14]. 

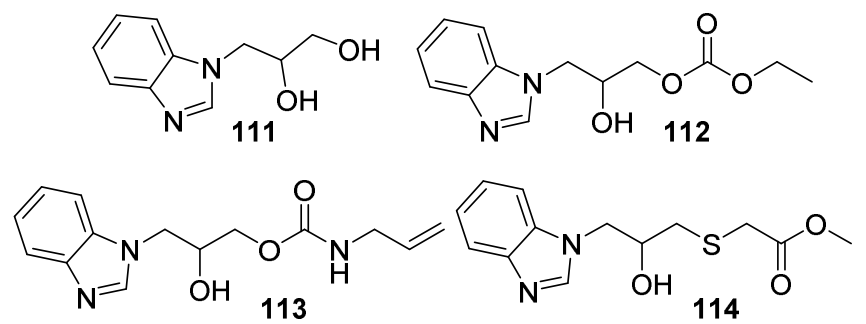

Figure 6. Products obtained from benzimidazole-derived carbonate 107.

A new series of $N$-phenyl-4,5-dibromopyrrolamides and $N$-phenylindolamides was synthetized and a selected set of compounds was evaluated against the enzyme DNA gyrase from Escherichia coli and Staphylococcus aureus [128]. Zidar and co-workers used ethylene carbonate to prepare $\mathrm{N}$-aryloxazolidin-2-ones according to Scheme 55. Initially, 3(4-nitrophenyl)oxazolidin-2-one $\mathbf{6 2 a}$ was obtained with $81 \%$ yield by reacting 4 -nitroaniline $63 \mathrm{c}$ with ethylene carbonate $1 \mathrm{c}$ at $100^{\circ} \mathrm{C}$ in the presence of DBU. Subsequent reduction of the nitro group of 62a provided the corresponding arylamine, which was further coupled with 4,5-dibromo-pyrrole-2-carboxylic acid or indole-2-carboxylic acid to give the target arylcarboxamides $\mathbf{1 1 5}$ and 116, respectively. However, these compounds showed weaker activities against both E. coli and S. aureus DNA gyrase compared to the reference molecule 2-\{[4-(4,5-dibromo-1H-pyrrole-2-carboxamido)phenyl]amino\}-2-oxoacetic acid.
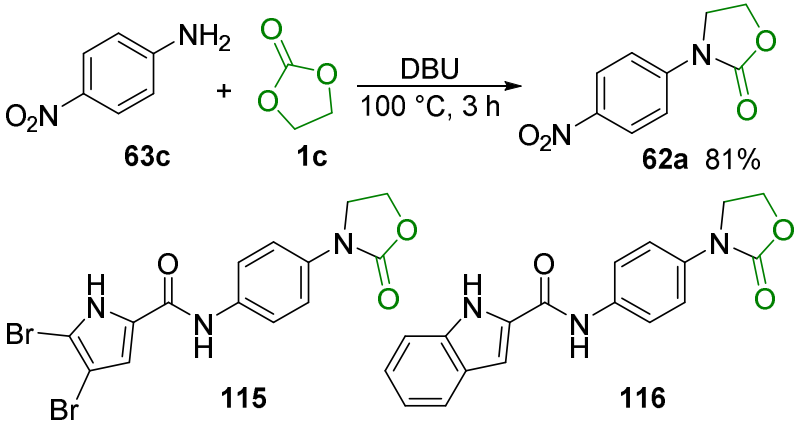

Scheme 55. Synthesis of a new series of $N$-phenyl-4,5-dibromopyrrolamides and $N$-phenylindolamides.

In 2016, Kim and co-workers [129] described a rhodium(III)-catalyzed, heteroatomdirected $\mathrm{C}-\mathrm{H}$ allylation process with allylic phosphonates and allylic carbonates. Specifically, the mild and site-selective C-H allylation of 2-arylbenzo[d]thiazole 117 with vinyl carbonate 1e provided the allylic alcohol 118 (90\% yield) with an $E / Z$ ratio of 7.5:1 (Scheme 56). This protocol was suitable for a wide range of substrates and may be applicable for accessing new bioactive heterocyclic compounds.

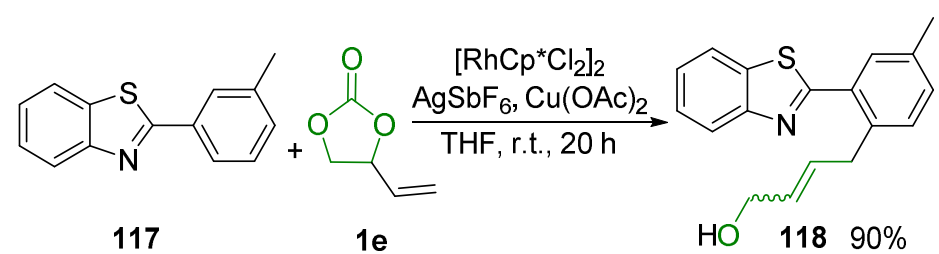

Scheme 56. C-H Allylation of 2-arylbenzo[d]thiazole 117 with vinyl carbonate $1 \mathrm{e}$ to afford the allylic alcohol 118.

A one-pot synthesis method for new N-3-substituted 2-thiohydantoins 119 was reported starting from GC (Scheme 57) [130]. In this study, a tandem Staudinger reaction was devised to convert primary azides into isothiocyanates, which were further reacted with $\alpha$-amino esters. Namely, glycerol carbonate azide $\mathbf{1 n}$ led to isothiocyanate $\mathbf{1 0}$, which 
was reacted without isolation with $\alpha$-amino ester $\mathbf{1 2 0}$ to provide the $N$-3-glycerylated compound 119 with $68 \%$ overall yield.

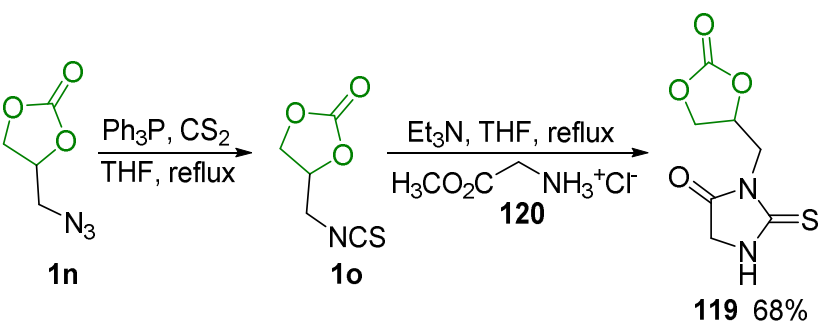

Scheme 57. One-pot synthesis method for new N-3-substituted 2-thiohydantoins 119.

In 2017, Zhao and co-workers [131] described the construction of nine-membered heterocycles via a $[5+4]$ cycloaddition reaction between $N$-tosyl azadienes 31 and substituted vinylethylene carbonates 6 under Pd catalysis, involving highly diastereoselective functionalization (Scheme 58). The benzofuran-fused heterocycles 30 were isolated with $85-92 \%$ yields after $15 \mathrm{~h}$ of reaction. This strategy was applied with high efficiency to various carbonates and azadienes bearing para-, meta-, or ortho- substituents at the aryl ring with both electron-withdrawing and electron-donating characters. When the unsubstituted vinyl carbonate $1 \mathbf{e}$ was reacted with various $N$-tosyl azadienes 31 , the kinetically preferred five-membered ring structure was formed through [3+2] cyclization, and the spirocyclic products $\mathbf{1 2 1}$ were isolated in good yields and with high diastereoselectivity.

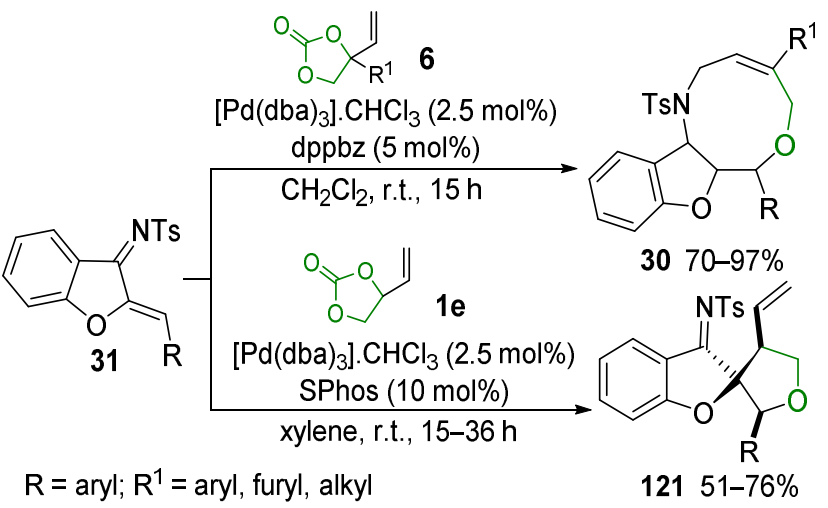

Scheme 58. Synthesis of benzofuran-fused heterocycles 30 and spirocyclic products 121.

The same group [132] reported the synthesis of [5,5]- and [6,5]-spiro-heterocycles 123 and 124 through the reaction of aurones 122 with vinylethylene carbonates 6 under Lewisacid-assisted Pd catalysis (Scheme 59). Using a simple approach and using commercially available catalysts, the scope of the [3+2] cycloaddition was extended to several enones $\mathbf{1 2 2}$ and carbonates 6 bearing electron-donating or electron-withdrawing substituents at either para- or ortho-positions on the aryl group, as well as to naphthyl- and furyl derivatives. Under the optimized conditions, substituted [5,5] products $\mathbf{1 2 3}$ were obtained in high yields, except when alkyl vinylethylene carbonates $\mathbf{6}$ were used. Additionally, the protocol was applied in [4+2] cycloadditions, targeting the formation of [6,5] spirocyclic structures 124. A range of substrates bearing different functionalities was examined, as well as other thia- or aza-heterocyclic-based enones. Generally, the expected products were obtained in very good yields and uniformly excellent diastereoselectivity (>20:1) was observed for all prepared compounds. 


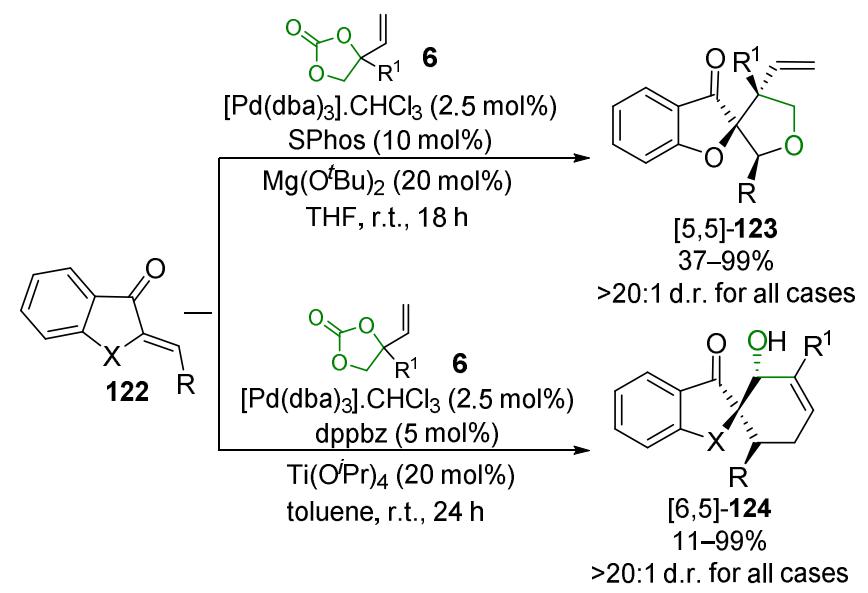

$\mathrm{R}=$ aryl, furyl, allyl, $\mathrm{CO}_{2} \mathrm{C}_{2} \mathrm{H}_{5} ; \mathrm{R}^{1}=$ aryl, furyl, alkyl; $\mathrm{X}=\mathrm{O}, \mathrm{S}, \mathrm{NH}, \mathrm{NTs}$

Scheme 59. Synthesis of [5,5]- and [6,5]-spiro-heterocycles 123 and 124.

Guo and co-workers developed an efficient Pd-catalyzed formal [5+3] cycloaddition process to prepare $\mathrm{N}, \mathrm{O}$-containing eight-membered heterocycles 126 (Scheme 60) [133]. In this work, zwitterionic allylpalladium intermediates were generated in situ from vinylethylene carbonates 6, which acted as 1,3-dipolarophiles in the cycloaddition. Under this Pd-catalyzed protocol, the reaction between $\mathrm{N}$-iminoquinazolinium ylides $\mathbf{1 2 5}$ and carbonates $\mathbf{6}$ provided tricyclic compounds $\mathbf{1 2 6}$ in high yields with excellent regioselectivities. The optimal conditions were applied to alkyl- or aryl-substituted vinylethylene carbonates and different azomethine imines, including $N$-quinazolinium and $N$-isoquinolinium ylides, providing the expected [5+3] cycloadducts. The reaction mechanism involves the formation of the zwitterionic allylpalladium intermediate $\mathbf{A}$, which adds to the azomethine imine. The allylpalladium intermediate $\mathbf{B}$ formed subsequently undergoes $\mathrm{N}$-alkylation, leading to the [5+3] cycloaddition product $\mathbf{1 2 6}$ (Scheme 60).
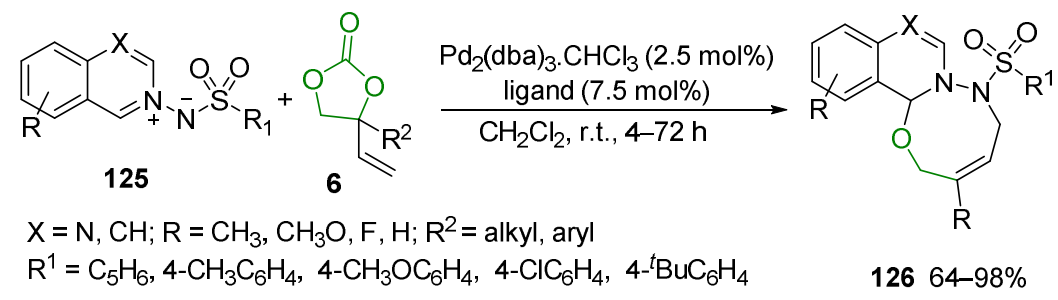

Mechanism

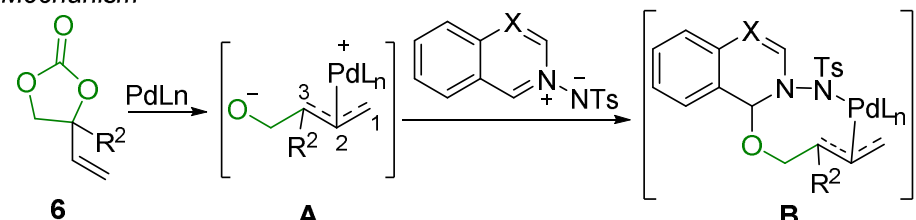

6

A<smiles>CCCCOc1ccccc1Oc1ccccc1F</smiles>

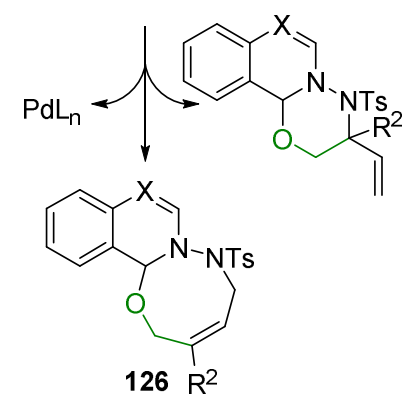

Scheme 60. Pd-catalyzed formal [5+3] cycloaddition process to prepare $\mathrm{N}, \mathrm{O}$-containing eightmembered heterocycles 126. 
Ackermann and co-workers developed an air- and water-tolerant manganese(I) catalyst to perform the $\mathrm{C}-\mathrm{H}$ allylation of heteroarenes $\mathbf{1 2 7}$ and arenes 128 with vinyl carbonates 14 through "in-water" decarboxylative C-H/C-O cleavages (Scheme 61) [134]. In a typical procedure, aromatic compounds were reacted at $100{ }^{\circ} \mathrm{C}$ for $16 \mathrm{~h}$ with an excess of carbonate 14 in the presence of $\mathrm{MnBr}(\mathrm{CO})_{5}(10 \mathrm{~mol} \%)$ and $\mathrm{NaOAc}(20 \mathrm{~mol} \%)$, using trifluoroethanol (TFE) or water as the solvent. C-H Allylations of indoles 127, for instance, proceeded with good yields and high levels of chemo-, site-, and regioselectivity.

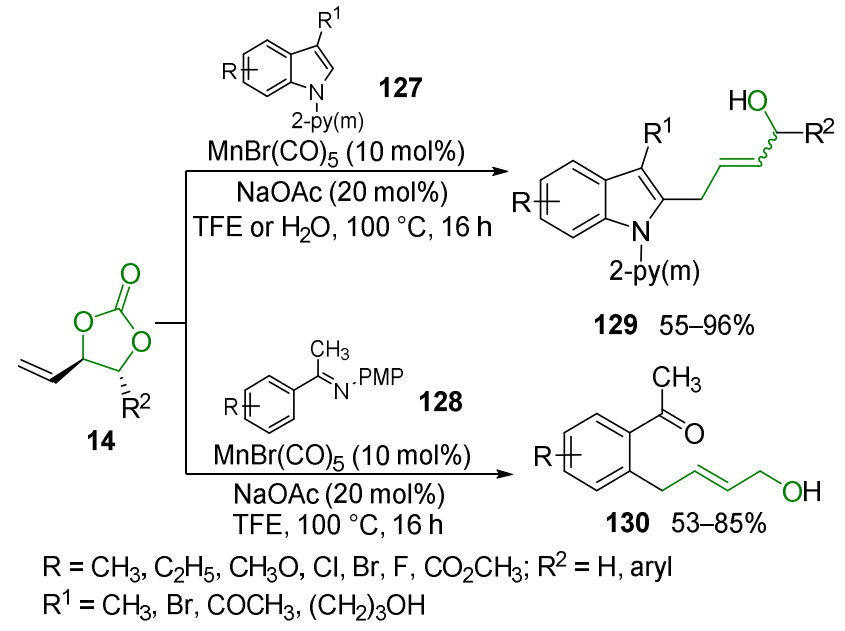

Scheme 61. C-H allylation of heteroarenes 127 and arenes 128 with vinyl carbonates 14.

In 2017, Wang and co-workers [135] explored the domino $\mathrm{C}-\mathrm{H} / \mathrm{N}-\mathrm{H}$ allylation of arylimidates under cobalt(III) catalysis (Scheme 62). In this work, the combined $\mathrm{C}-\mathrm{H}$ and $\mathrm{N}-\mathrm{H}$ allylation was reported for the one-step synthesis of isoquinolines. The reaction between different vinyl carbonates $\mathbf{1 4}$ and substituted arylimidates $\mathbf{1 3 1}$ delivered the desired decorated vinyl isoquinolines $\mathbf{1 3 2}$ in good yields. The protocol was extended to arylimidates $\mathbf{1 3 1}$ bearing electron-donating or electron-withdrawing groups, such as fluorine, chlorine, ester, ketone, and amide groups. The method was also suitable for carbonates 14 bearing aryl groups.

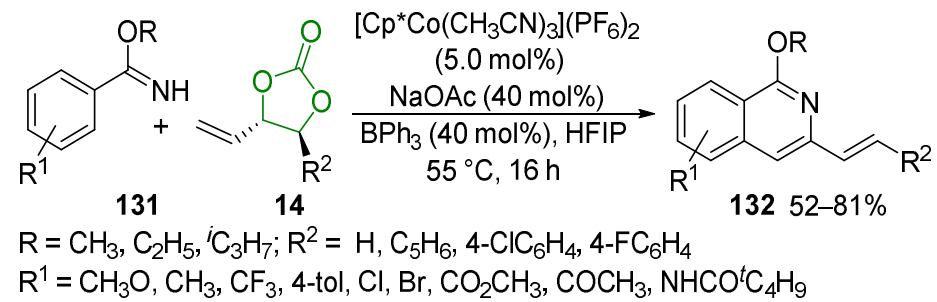

Scheme 62. Domino $\mathrm{C}-\mathrm{H} / \mathrm{N}-\mathrm{H}$ allylation of arylimidates.

In 2019, He and co-workers reported the synthesis of oxazolidinones 133 through the carboxylative cyclization of anilines 63 and cyclic carbonates 1 (Scheme 63) [136]. The protic ionic liquid 1,8-diazobicyclo[5.4.0]-7-undecenium imidazoline [HDBU][Im] was used as a bifunctional catalyst under mild reaction conditions and without the addition of conventional solvents. Using this new protocol, a total of seventeen oxazolidinones 133 with different functional groups were obtained, such as $\mathrm{Cl}, \mathrm{Br}, \mathrm{CH}_{3}, \mathrm{OCH}_{3}$, and $\mathrm{NO}_{2}$, with yields in the range of $61-92 \%$ after $6 \mathrm{~h}$ of reaction. Some of the advantages of this protocol are the low catalyst load, the wide functionality tolerance, and the convenient recycling of the catalyst. 


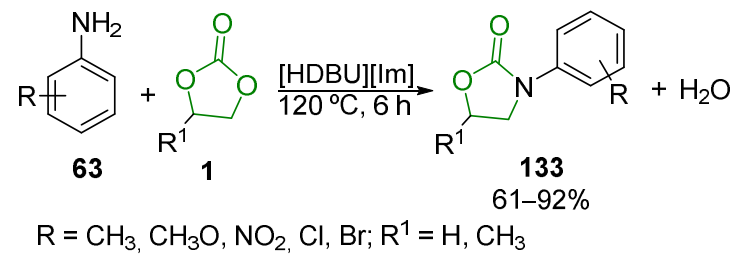

Scheme 63. Carboxylative cyclization of anilines 63 and cyclic carbonates 1 .

In the same year, Ji and co-workers described the synthesis of a new heterogeneous catalyst, the ionic liquid 1-butyl-3-methylimidazolium acetate ([bmim][OAc]) immobilized on MIL-101- $\mathrm{NH}_{2}$, denoted as IL(OAc $\left.{ }^{-}\right)-\mathrm{MIL}-101-\mathrm{NH}_{2}$. This catalyst was used in the reaction between phenylamine 63 and propylene carbonate $1 \mathrm{~b}$ to generate the oxazolidinones of interest 133 (Scheme 64) [137]. The method was extended to several anilines, allowing the synthesis of ten new oxazolidinones 133 with yields that varied from 68 to $94 \%$ after $9 \mathrm{~h}$ of reaction.

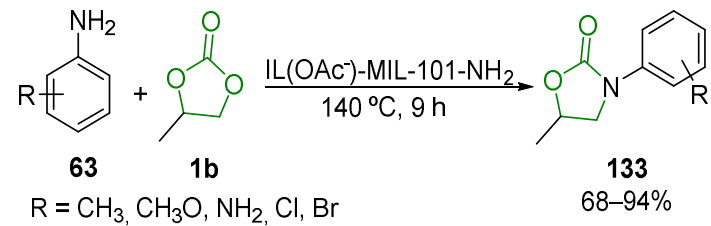

Scheme 64 . Reaction between phenylamine 63 and propylene carbonate $\mathbf{1 b}$.

\subsection{Bioactive Urethanes and Derivatives}

Carbamates or urethanes have attracted much attention due to their biological relevance as mimic fragments of pharmaceutical compounds, such as efavirenz [138] and retigabine (Figure 7) [139]. In other respects, urethanes are monomers that are largely used in the synthesis of polyurethanes, one of the most used raw materials in global industry [10]. Polyurethanes are also versatile thermoplastic elastomers employed in the preparation of biocompatible components, including artificial hearts, feeding tubes, catheters, surgical drains, and others [140].<smiles>C[C@]1(C#CC2CC2)OC(=O)Nc2ccc(Cl)cc21</smiles>

Efavirenz<smiles>CCOC(=O)Nc1ccc(NCc2ccc(F)cc2)cc1N</smiles>

Retigabine

Figure 7. Structures of efavirenz (component of first-line antiretroviral therapy) [138] and retigabine (anticonvulsant medication) [139].

In 2012, Endo and co-workers [141] reported the synthesis of a branched cationic polyurethane 134 via the polycondensation of 4-chloromethyl-1,3-dioxolan-2-one 10 with diethylenetriamine (DETA) 63d in ionic liquid as the solvent (Scheme 65). The reaction of 10 and DETA 63d was achieved using a 2:1 molar ratio for the monomers. When carried out in molten imidazolium salts, the polymerization yields were significantly higher than those obtained using conventional solvents. The authors reported that due to its ammonium group, the polymer can serve as a catalyst and a capsule for DNA, whereby it can be used as a gene delivery carrier. The complexation with DNA was confirmed by dynamic light scattering (DLS) experiments. 


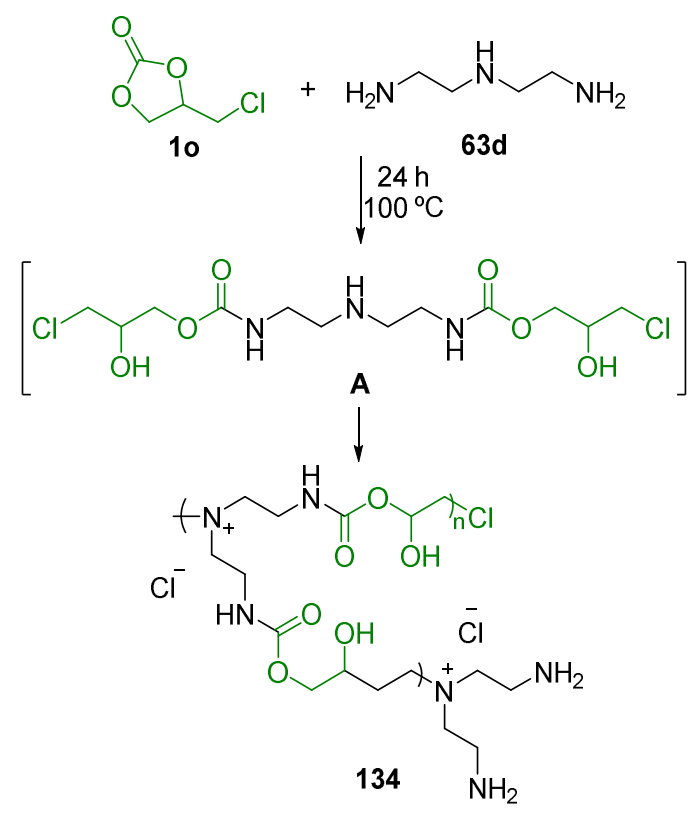

Scheme 65. The synthesis of a branched cationic polyurethane 134.

By reacting primary amines 63e, alkyl halides, and diverse carbonates 1 bearing cationic, hydrophobic, or amphiphilic groups, Möller and co-workers [142] prepared poly(ethyleneimine)s (PEI) and amphiphilic monodisperse compounds (Scheme 66). These compounds were assayed for their ability to inhibit the proliferation of microorganisms ( $E$. coli, S. aureus, and B. subtilis) and for their hemolytic activity, which was influenced by the microstructure and length of the PEI alkyl chain. The results led to the conclusion that the microstructure of the amphiphilic monodisperse compounds has a significant influence on their antibacterial properties and the hemolytic activity. Compounds with alkyl chains directly linked to cationic groups have high antibacterial efficiency for long (C-14 to C-18) alkyl chains.

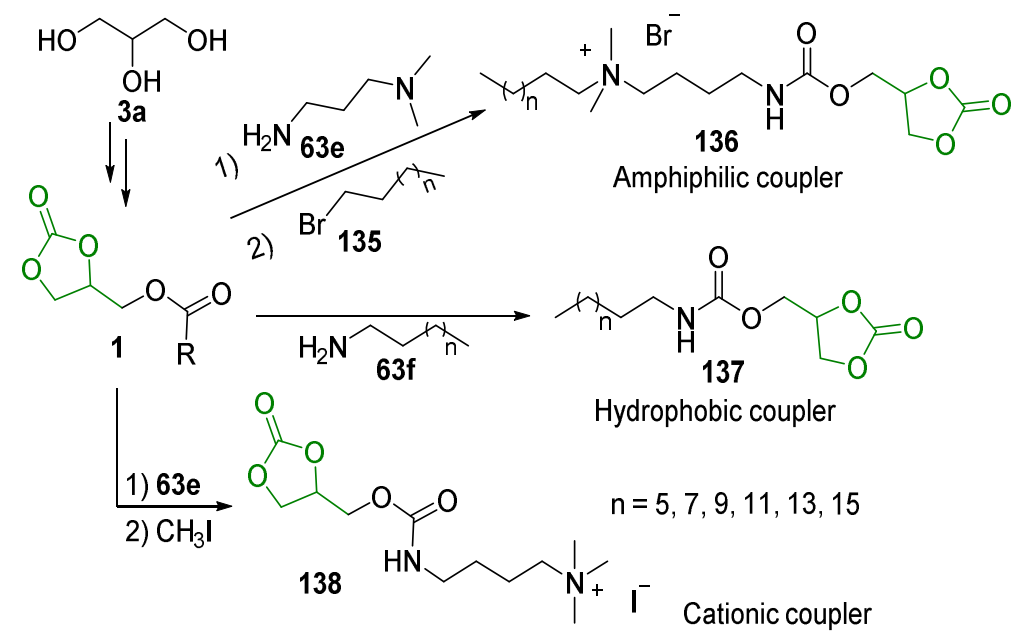

Scheme 66. Preparation of poly(ethyleneimine)s (PEI) and amphiphilic monodisperse compounds.

\subsection{Other Compounds with Biological Activity}

Several reactions have been explored for the synthesis of glycerol carbonate derivatives with interesting biological activities. In this sense, Sebastiano and co-workers [143] investigated the condensation of ferrocenemethanol 139 with glycerol derivatives and related amines in the absence of solvent and catalyst. The reactions were performed under neat homogenous conditions and eleven novel compounds were described. Among the 
tested alcohols, GC 1a was reacted with 139 in the presence of catalytic $\mathrm{CO}_{2}$ or without any catalyst, leading to the corresponding ferrocenylmethyl ether $\mathbf{1 4 0}$ with $92 \%$ and $97 \%$ yields, respectively (Scheme 67). Ferrocenylmethyl ether $\mathbf{1 4 0}$ three other ferrocenyl analogues were tested in vitro as fungicides and were shown to inhibit fungi growth against Botrytis cinerea and Penicillium spp.

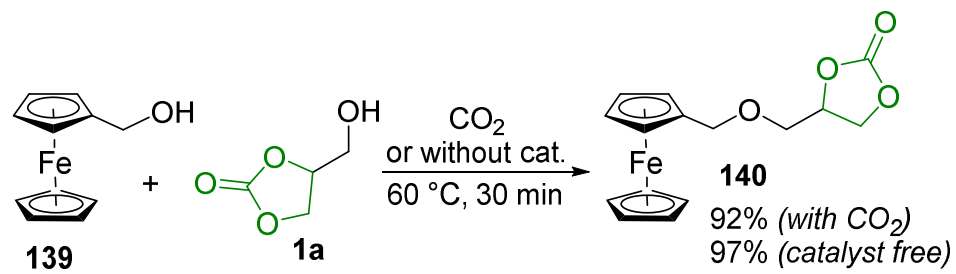

Scheme 67. The condensation of ferrocenemethanol 139 with glycerol derivatives.

Recently, Zhang and co-workers [144] described the copper-catalyzed enantioselective synthesis of highly substituted $\beta$-amino alcohols 141 starting from ethynylated carbonates 6 and arylamines 63 . The reaction was performed at $-20^{\circ} \mathrm{C}$ in toluene and in the presence of triethylamine and $(S, S)$-L as a copper ligand (Scheme 68 ). Using this procedure, fourteen novel $\beta$-amino- $\beta$-ethynyl alcohols 141 were obtained with $65-99 \%$ yields. When reacting ethynylated carbonates bearing naphthyl or heterocyclic groups under the optimal conditions, the efficacy of the method was maintained, giving the desired products with $93 \%$ and $98 \%$ yields, respectively. In contrast, the only aliphatic amine tested, ${ }^{t}$ butylamine, yielded the respective $\beta$-amino alcohol with only $75 \%$ yield. The reaction enantioselectivity (determined by HPLC) presented er ratios varying from 77:23 to 94:6.

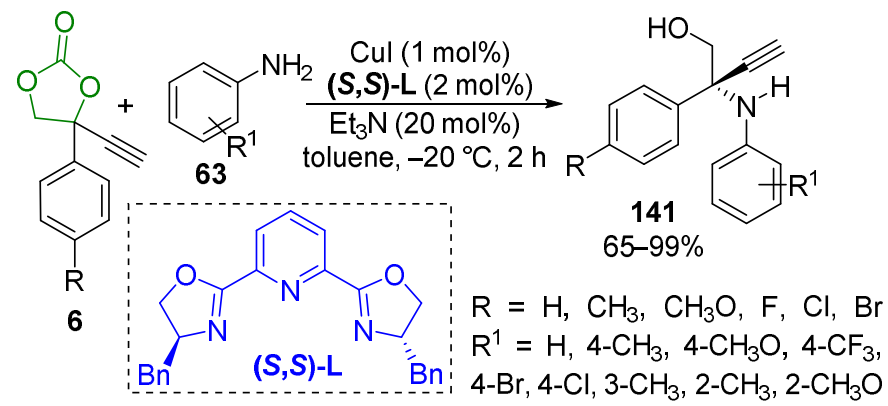

Scheme 68. The copper-catalyzed enantioselective synthesis of highly substituted $\beta$-amino alcohols 141.

In order to illustrate the potential usefulness of the $\beta$-amino- $\beta$-ethynyl alcohols 141, the authors tested several reactions, such as hydrogenation or Sonogashira coupling. They also performed a click reaction between 141a and antiretroviral Zidovudine 142 to efficiently prepare a triazolyl derivative of $\mathbf{1 4 2}$ (85\% yield; 92:8 er) (Scheme 69). Zidovudine, a FDAapproved drug used for preventing and treating AIDS, is included in the World Health Organization's List of Essential Medicines [145].

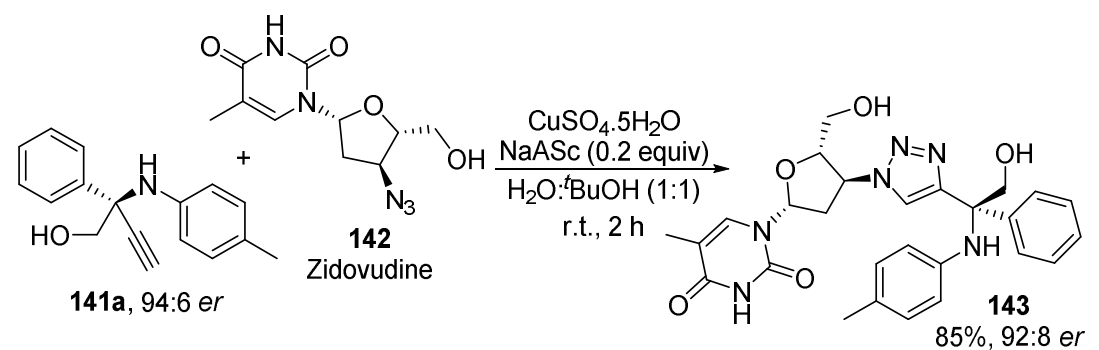

Scheme 69. Click reaction between 141a and antiretroviral Zidovudine 142. 


\section{Precursors to Materials}

\subsection{Urethanes and Polyurethanes}

As already mentioned in Section 2.3, polyurethanes (PUs) are a valuable group of materials that have applications in a range of industrial segments, in competition with other plastics, ceramics, metals, and rubbers, both in domestic and industrial fields [146]. Due to their multiple applications and high global consumption, the production of polyurethanes (24 Mtons by 2020) represents around 6\% of all the plastics produced every year. Many different kinds of polyurethanes, such as flexible and rigid foams, elastomers, adhesives, and coatings, are broadly manufactured and applied, namely as rollers, shoe soles, seals, and engineering components for electrical encapsulation and in the mining industry $[147,148]$. They also have important applicability as components of medical implants in surgery [146].

The traditional route for the synthesis of PUs involves the reaction of isocyanates with alcohols (Scheme 70) [147]. Despite the versatility of isocyanates as building blocks, these compounds are carcinogenic, mutagenic, and reprotoxic and are classified as "very harmful" chemicals by the European Union. Additionally, the synthesis of isocyanates themselves involves a reaction between the lethal phosgene gas and an amine salt [148]. For these reasons, the development of new routes to access PUs involving less toxic reagents became synonymous with the synthesis of non-isocyanate polyurethanes. The main alternative methods developed so far are (i) the cyclic carbonate pathway (polyaddition), (ii) transurethanization (polycondensation), and (iii) ring-opening polymerization and rearrangements $[146,147,149,150]$. In particular, the synthesis of PUs via the polyaddition of amines on cyclic carbonates has been explored in recent years as an environmentally friendly route (Scheme 70).

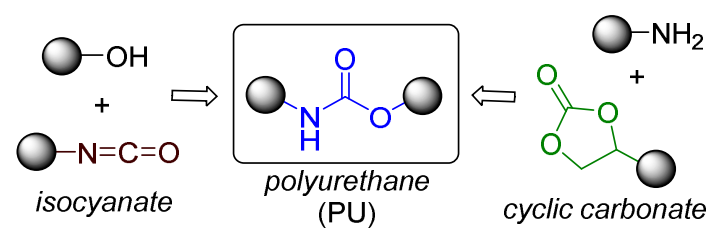

Scheme 70. The routes for the synthesis of PUs.

The studies published between 2012 and 2020 on the isocyanate-free construction of the urethane nucleus (the carbamate function) can be grouped according to the structure of the cyclic carbonate reacting with the amine: glycerol carbonate 1a, polycyclic carbonate (poly-1), ethylene carbonate 1c, and ethylene carbonate derivatives (deriv-1) (Scheme 71).

The reported studies include the preparation of polymeric and non-polymeric materials, for which the synthesis has been described [151-166], as well as studies on the properties [167-170] and structural characterization [171-175]. With regard to the materials prepared from cyclic carbonate building blocks 1, the properties observed so far include thermal stability [176], stiffness [177], elongation and tensile strength [178], rheological qualities [179-181], resistance to corrosion [182], water absorption [183], and optical resistance [184]. These diverse properties are compatible with applications in interesting fields, such as adhesives [185-188]. 


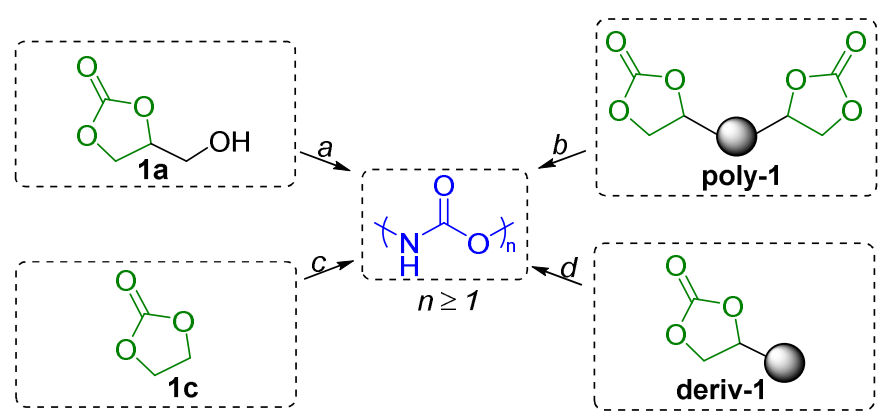

Scheme 71. The isocyanate-free construction of the urethane nucleus. ${ }^{\text {a }}$ Please, check references [151153,167-171,176]; ${ }^{\mathrm{b}}$ Please, check references [154-158,173,178,179]; ' Please, check references [159,160, 183]; ${ }^{\mathrm{d}}$ Please, check reference [161-166,172,182,186].

\subsection{Flame Retardants}

Reducing the occurrence and severity of fire is a major issue, which has fostered the development of new products able to deter or stop flame propagation. Flame retardants are chemicals added into a combustible material in order to increase the ignition temperature, reduce the rate of burning, limit the spread of flames, and minimize, if not eliminate, the generation of smoke. The most important active species in flame-retardant families are halogens (chlorine and bromine), phosphorus, and water [189,190].

In 2014, Morgan and co-workers [191] evaluated the heat release of polyurethanes modified with boron- and phosphorus-containing flame retardants using pyrolysis combustion flow calorimetry (PCFC). The observed results demonstrated that both the flame retardant's structure and its environment in the polymer greatly affect the flammability behavior. Among the tested potential flame retardants, the phosphorylated glycerol carbonate $\mathbf{1 4 5}$ (Scheme 72) did not inhibit melt flow in the polyurethane during decomposition, thus reflecting the low flame retardant potential of $\mathbf{1 4 5}$ when incorporated in a PU.

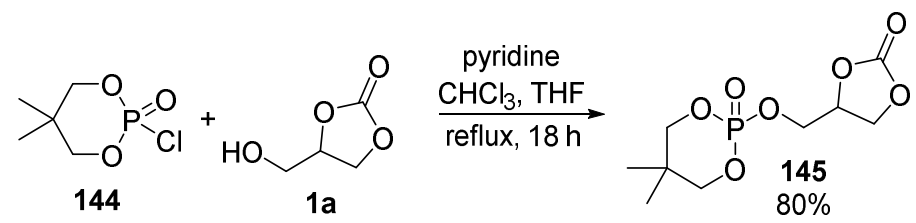

Scheme 72. Synthesis of the phosphorylated glycerol carbonate $\mathbf{1 4 5}$.

In a subsequent study, the same group [192] reported the synthesis and flammability testing of a new class of phosphorus-containing flame-retardant molecules incorporated into a PU. A new mixed phosphate ester $\mathbf{1 4 8}$ was prepared in two steps, by first converting GC 1a into its dichlorophosphate 147, which was further reacted with glycidol 2 a (2 equivalent) to give 148, containing two epoxide units and a glycerol carbonate moiety (Scheme 73). The fire-retardant performance of $\mathbf{1 4 8}$ as an additive was evaluated using PCFC, showing middling levels of flame-retardant potency. 


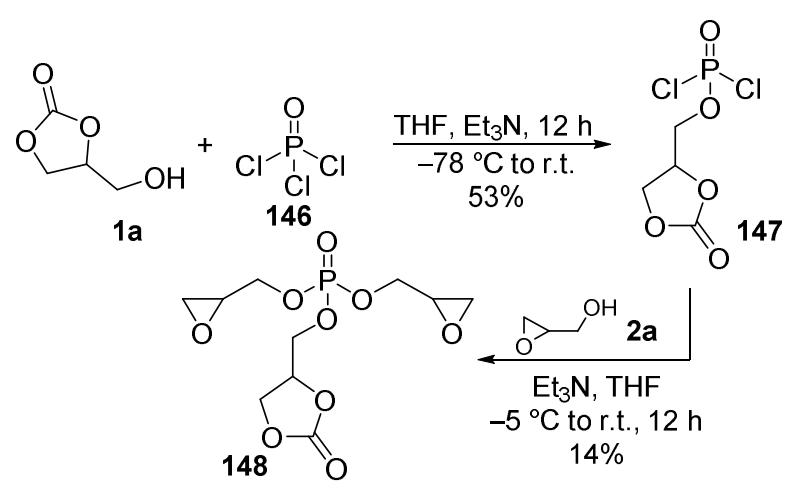

Scheme 73. Conversion of GC 1a into its dichlorophosphate 147, which was further reacted with glycidol 2a to give 148 .

In 2016, Sonnenschein and co-workers reported the alkoxylation of bisphenols S and A by propylene carbonate to prepare new hydroxylated polymerizable building blocks 149-159 (Scheme 74) [193]. The thermo-oxidative evaluation of these useful low molecular weight molecules showed significantly better thermo-oxidative stability for sulfone polyols compared to other bisphenol-A derivatives, as measured by gas evolution and pyrolysis GCmass spectrometry techniques. Moreover, bisphenol-S polyols possess higher viscosities than their non-sulfone counterparts of similar molecular weight-a property which is presumably linked to the increased interchain hydrogen bonding potential provided by the sulfone moiety.
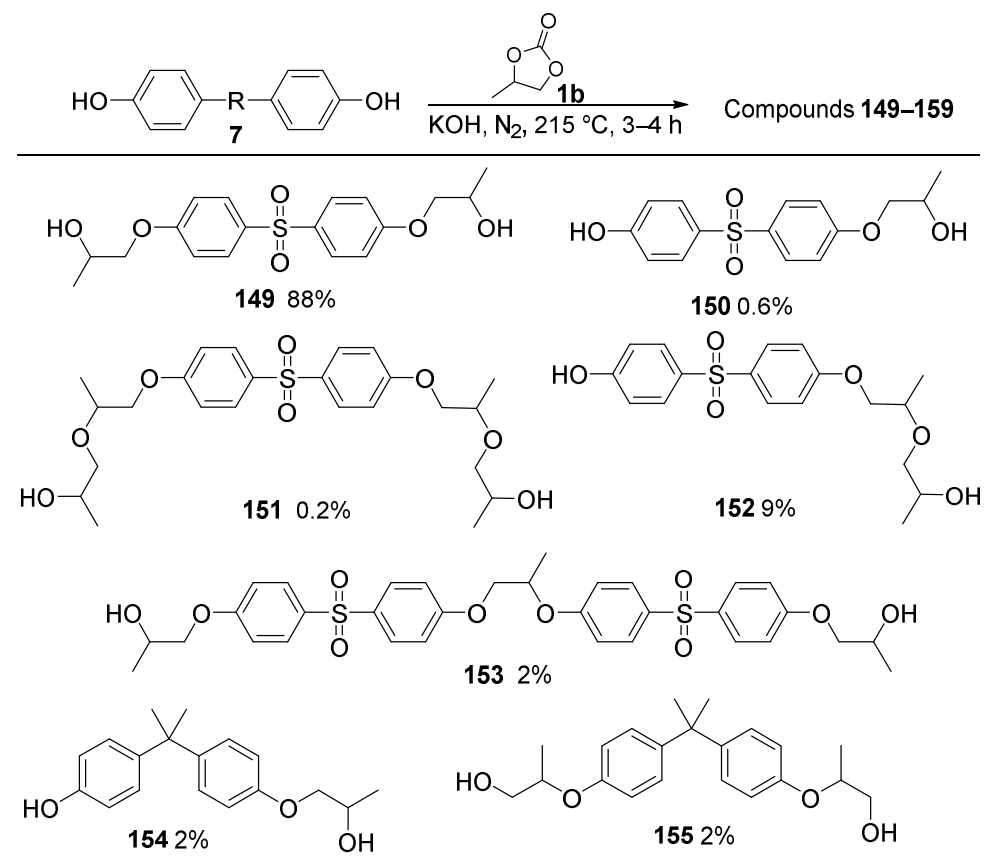<smiles>CC(O)COc1ccc(C(C)(C)c2ccc(OC(C)CO)cc2)cc1</smiles><smiles>CC(=O)OCC(C)Oc1ccc(C(C)(C)c2ccc(OC(C)CO)cc2)cc1</smiles>

Scheme 74. Alkoxylation of bisphenols $\mathrm{S}$ and A by propylene carbonate. 


\subsection{Energy and Electronics}

For further development of lithium-ion batteries, it is essential to prepare less flammable and easily processable materials. In this sense, Rieger and co-workers [194] studied the structure and ionic conductivity of liquid crystals containing propylene carbonate units (Schemes 75 and 76). The interest in this class of compounds is due to their thermal stability, high dielectric constant, and good lithium ion conductivity at room temperature [195]. The authors prepared type $\mathbf{1 6 0}$ liquid crystalline molecules bearing a cyclic carbonate endpoint (Scheme 75). The ionic conductivity of the tetrafluorinated compound 160a was compared with that of the non-fluorinated analogue 161a (Scheme 76), while 160b was compared to the tetra(ethylene oxide) (TEO) analogue 162a (Scheme 75), which bears the same fluorinated mesogenic core. The fluorinated precursor 163 was obtained in 2 steps from 2,3,5,6-tetrafluorophenol, while the non-fluorinated precursor 164a was prepared from 4-hydroxybenzoic acid. Liquid crystals 160a and 161a were obtained with satisfactory yields via the esterification with GC 1a under mild reaction conditions. The TEO analogue 162 was synthesized with $65 \%$ yield via a sequential $\mathrm{BH}_{3}$-THF reduction of $163 \mathrm{c}$, followed by the $\mathrm{Cs}_{2} \mathrm{CO}_{3}$-catalyzed etherification of the benzylic alcohol 166 using the TEO tosylate 167 .

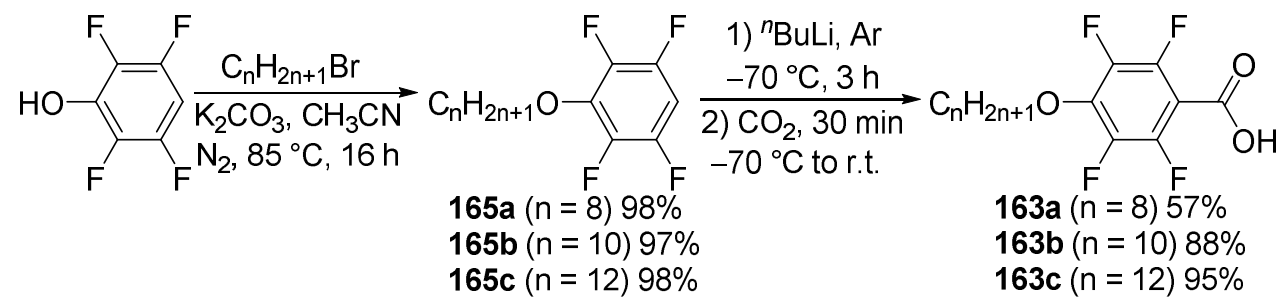

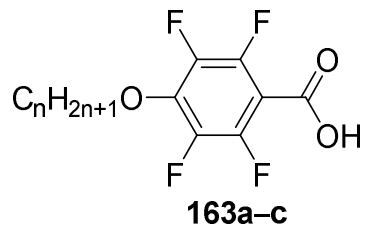

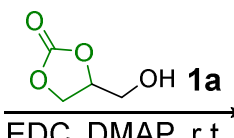

$$
\mathrm{CH}_{2} \mathrm{Cl}_{2}, 48 \mathrm{~h}
$$

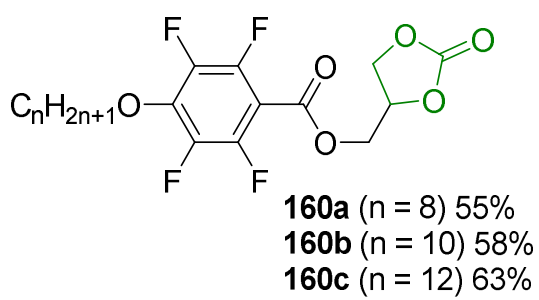

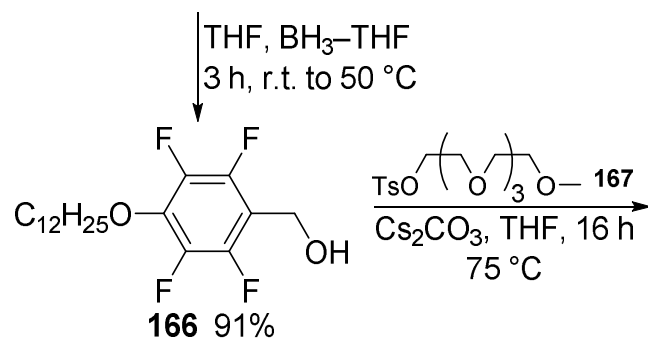<smiles>CCCCCOC(C)(C)CC(C)(C)C(C)OCc1c(F)c(F)c(OCC)c(F)c1F</smiles>

Scheme 75. Synthesis of liquid crystalline molecules bearing a cyclic carbonate endpoint $\mathbf{1 6 0}$.
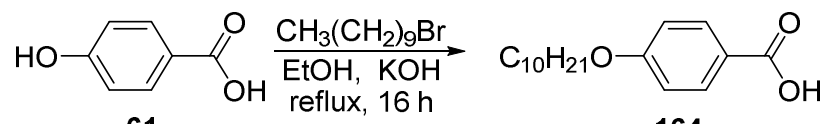

61

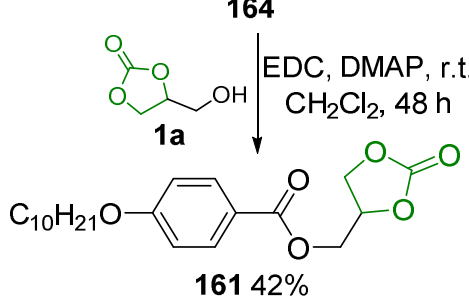

Scheme 76. Synthesis of the non-fluorinated analogue 161. 
After mixing the synthesized compounds with lithium bis(trifluoro-methanesulfonyl)imide (LiTFSI), the authors observed that $\mathrm{Li}^{+}$self-assembly was driven by the interaction with the carbonate units via coordination with the free electron pairs of oxygen. Furthermore, the cyclic carbonate moiety present in $\mathbf{1 6 0}$ and 161 enhanced the lithium salt dissociation as compared to the TEO derivative 162. Measurements by small- and wide-angle X-ray scattering (SAXS/WAXS) demonstrated that the compounds align spontaneously in the smectic phase when cooled from the isotropic melt. The formation of a smectic layer improves the ionic conductivity by enhancing the ion mobility parallel to the layer plane.

Another interesting study involving GC 1a was reported by Kim and co-workers in 2016 [196]. In this work, 1a was reacted with furfuryl amine $\mathbf{6 3 g}$ to provide the urethanes 168a-b (Scheme 77). After a few more reaction steps, a surface of polydimethylsiloxanebased polyurethane cross-linked by Diels-Alder adducts 169 was prepared. In the sequence, silver nanowire $(\mathrm{AgNW})$ was deposited on this surface via vapor-assisted solution process, resulting in a highly flexible, transparent, and healable electrode.

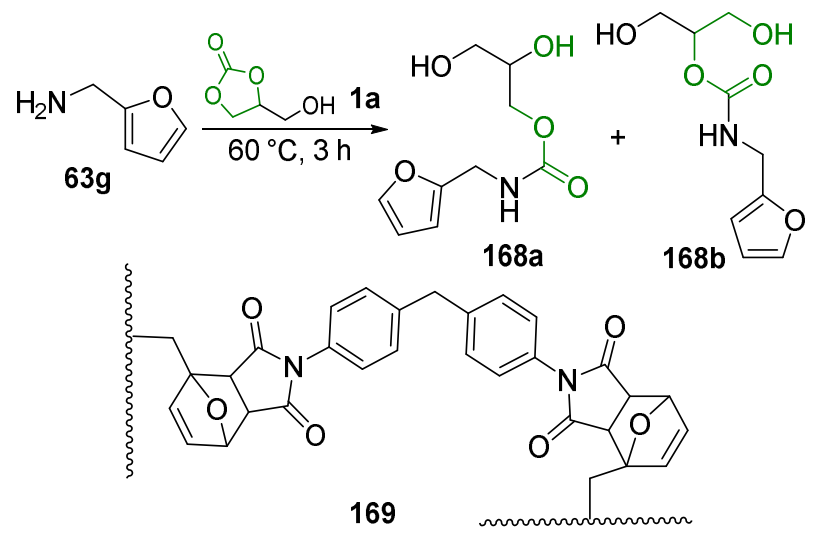

Scheme 77. Synthesis of urethanes 168a-b.

In 2020, Cui and co-workers [197] synthesized several fluorescent macrocycles 171 through the iridium-catalyzed intermolecular decarboxylative coupling of vinylated carbonate 1e with readily available isatoic anhydrides $\mathbf{1 7 0}$ (Scheme 78). The best reaction conditions were obtained with $[\operatorname{Ir}(\operatorname{cod})(\mathrm{OMe})]_{2}(2.0 \mathrm{~mol} \%)$ as the catalyst, $2,2^{\prime}$-bipyridine as the chelating $\mathrm{N}, \mathrm{N}$-donor ligand, and a mixture DCM/acetone (3:1) as the solvent. The sequential allyl-amination-macrolactonization upon extrusion of $\mathrm{CO}_{2}$ provided the expected benzo-fused, 14-membered aza-macrolides 171 with moderate yields after $12 \mathrm{~h}$ of reaction. The scope was evaluated using isatoic anhydrides 170 bearing electron-donating (Me and $\mathrm{CH}_{3}$ ) and electron-withdrawing groups (halides and $\mathrm{CF}_{3}$ ). Azamacrolides $\mathbf{1 7 1}$ showed favorable fluorescence emission in the $397-430 \mathrm{~nm}$ range.<smiles>O=c1[nH]c2ccccc2c(=O)o1</smiles>

170

$\mathrm{R}=\mathrm{CH}_{3}, \mathrm{CH}_{3} \mathrm{O}, \mathrm{F}, \mathrm{Cl}, \mathrm{Br}, \mathrm{I}, \mathrm{CF}_{3}, \mathrm{H}$
$[\operatorname{Ir}(\mathrm{cod})(\mathrm{OMe})]_{2}(2 \mathrm{~mol} \%)$ 2-2'-bipyridine $(4.5 \mathrm{~mol} \%)$

DCM/acetone $\mathrm{N}_{2}, 60^{\circ} \mathrm{C}, 12 \mathrm{~h}$<smiles>[R]c1cccc(NC(C=C)COC(=O)c2ccccc2N[C@@H](C=C)COC)c1</smiles>

$36-66 \%$

Scheme 78. Iridium-catalyzed intermolecular decarboxylative coupling of vinylated carbonate 1e with readily available isatoic anhydrides $\mathbf{1 7 0}$.

The proposed reaction mechanism starts with the $\operatorname{Ir}(\mathrm{I})$-catalyzed decarboxylation of 1e to generate the zwitterionic $p$-allyl iridium intermediate A. After tautomerization of A, 
an electrophilic six-membered iridacyclic species B is formed. Then, the intermediate B is trapped by the nucleophilic amino group of $\mathbf{1 7 0 a}$, giving the intermediate $C$ and the active $\operatorname{Ir}(\mathrm{I})$ catalyst for the next catalytic cycle. Lastly, intermediate $\mathrm{C}$ undergoes intermolecular ester exchange with a second molecule of $\mathrm{C}$ to deliver product 171a after $\mathrm{CO}_{2}$ elimination (Scheme 79).

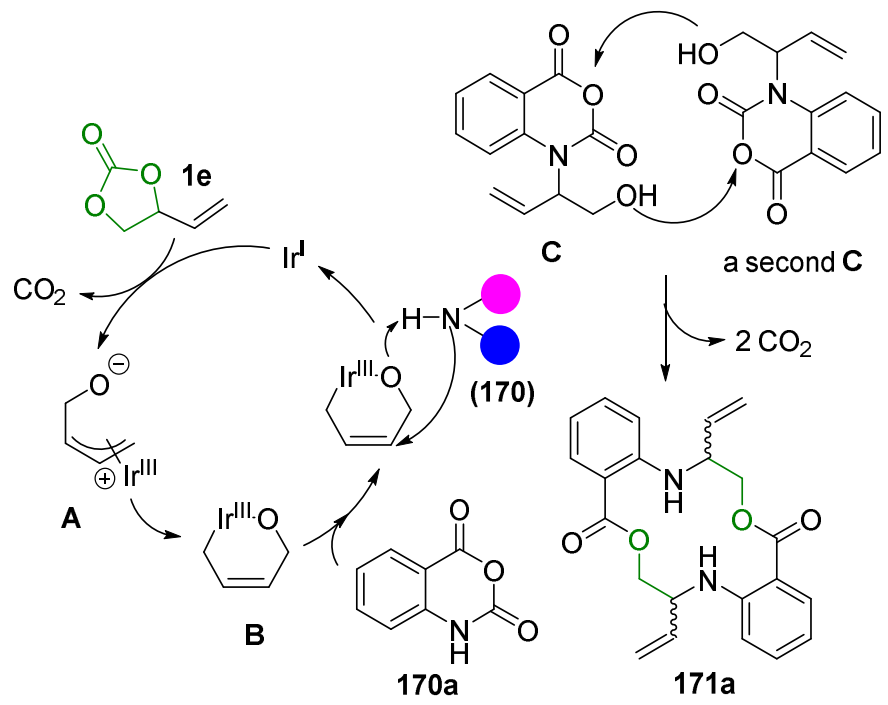

Scheme 79. The proposed reaction mechanism.

An online Raman analysis technique for monitoring of the production of biofuels was developed to study the transesterification reaction of canola oil with dimethyl carbonate [198]. The reaction was monitored by measuring the height of the $C=C$ stretching mode of the unsaturated fatty acids present in the oil. The transesterification of the triglycerides was catalyzed using a triazabicyclodecene-modified, $\mathrm{Mg}$-Al layered double hydroxide (TBD-LDH). The methyl fatty esters $\mathbf{1 7 2}$ were obtained together with esterified glycerol carbonates, which further reacted with dimethyl carbonate to form additional $\mathbf{1 7 2}$ and the bis-carbonate 1p (Scheme 80).

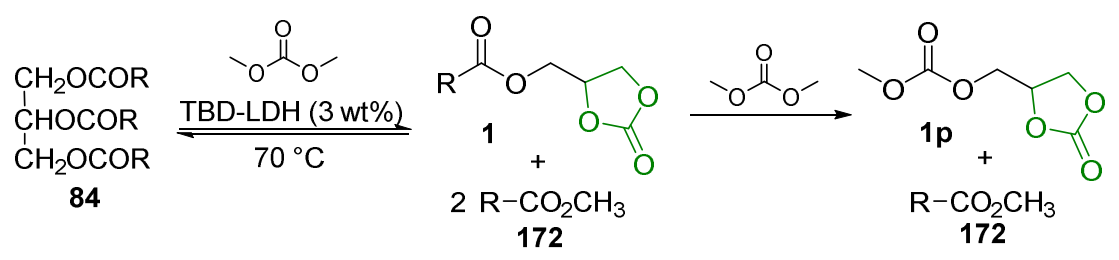

Scheme 80. The transesterification reaction of canola oil with dimethyl carbonate.

\subsection{Non-Ionic Surfactants}

Surface-active agents (surfactants) are a class of compounds that present outstanding physical properties as solubilizers, with a wide range of application in the most varied industry sectors, for example being used in the soap industry, in cosmetics, and in the food area [199]. Among the range of surfactants, non-ionic structures are used in diverse areas, such as in cleaning products, textile processing, pulp and paper processing, emulsion polymerization, and agrochemicals. An important characteristic of these materials is the absence of a hydrophilic group with filler bound to their hydrophobic chain [200,201].

In this regard, Corma, Iborra, and co-workers [202] prepared glycerol-carbonatederived fatty esters 1q using a hybrid Nafion-silica composite (Nafion SAC-13) as an acid catalyst in the absence of solvent [203]. In this work, the desired compounds were prepared through direct esterification of GC 1a with carboxylic acids of different chain lengths; the protocol led to the formation of several side-products, such as monoglycerides $\mathbf{1 2}$ and $\mathbf{1 7 3}$, 
as well as the triglyceride $\mathbf{1 7 4}$. Two different possible reaction routes were proposed by the authors:

- GC 1a and the acid $\mathbf{6 1}$ firstly react under acid catalysis to give the GC carboxylate 1q; this intermediate is subsequently decarbonylated to form two isomeric monoglycerides, 12 and 173, which can further undergo stepwise esterification to provide diglycerides $\mathbf{1 7 3}^{\prime}$ and $\mathbf{1 7 4} \mathbf{4}^{\prime \prime}$ and the triglyceride $\mathbf{1 7 4}$ (Scheme 81, route I);

- Firstly, 1a undergoes hydrolysis to glycerol, which similarly reacts with 58 to yield monoglycerides 174 and $\mathbf{1 2}$, diglycerides $\mathbf{1 7 3}^{\prime}$ and $\mathbf{1 7 3} \mathbf{3}^{\prime \prime}$, and triglyceride $\mathbf{1 7 4}$ (Scheme 81, route II).

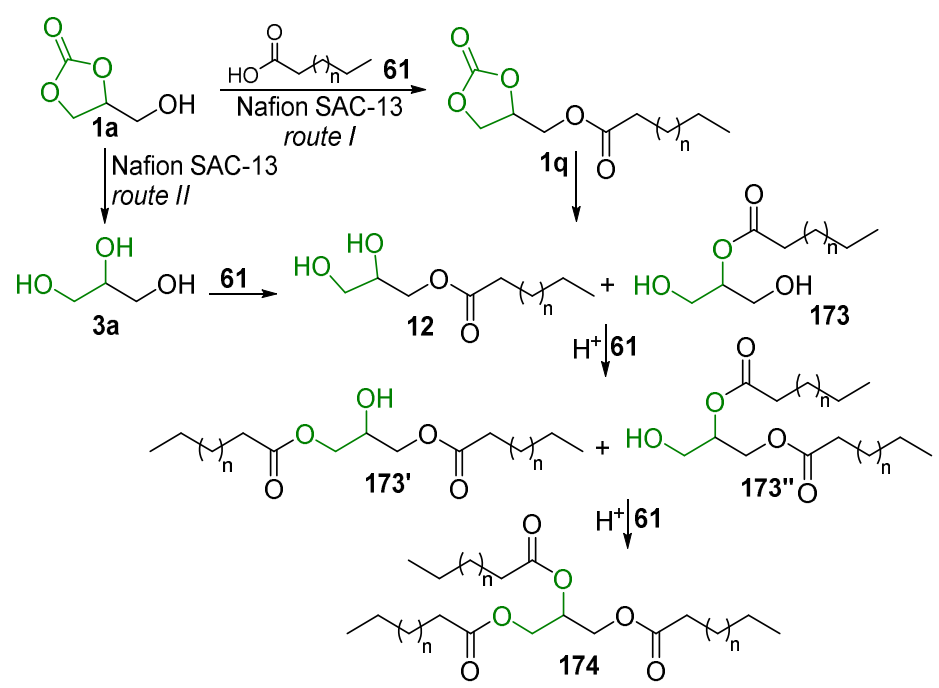

Scheme 81. Prepared glycerol-carbonate-derived fatty esters.

Several parameters were evaluated in this reaction, such as the solvent, heterogeneous catalysts, zeolites, and hybrid organic-inorganic acids. The best results for the esterification of GC 1a were obtained by using $3.5 \mathrm{wt} \%$ of Nafion-silica (with respect to the total weight of the reactants) at $100{ }^{\circ} \mathrm{C}$. The highest activity was exhibited by the Nafion SAC-13 nanocomposite, which proved to be an excellent esterification catalyst, while other ion exchange resins showed lower activity and selectivity. It has to be pointed out that when increasing the chain length in $\mathbf{6 1}$ from hexanoic to lauric and palmitic acids, the conversion rate decreased considerably from $98 \%$ to $71 \%$ and $31 \%$, respectively.

Being interested in the synthesis of an important non-ionic surfactant, glycerol monostearate $\mathbf{1 2 f}$ (GMS), Han and Wang [204] devised a solvent-free esterification approach for GC 1a with stearic acid 61a catalyzed by copper 4-toluenesulfonate (CPTS) to prepare the intermediate (2-oxo-1,3-dioxolan-4-yl)methyl stearate (ODOMS) 1r. This compound presents good thermal and oxidative stability, in addition to surfactant properties. Using $\mathrm{Et}_{3} \mathrm{~N}$-catalyzed hydrolysis at $140{ }^{\circ} \mathrm{C}$, ODOMS $1 \mathrm{r}$ was converted into GMS $12 \mathrm{f}$ with $64 \%$ yield (Scheme 82). 

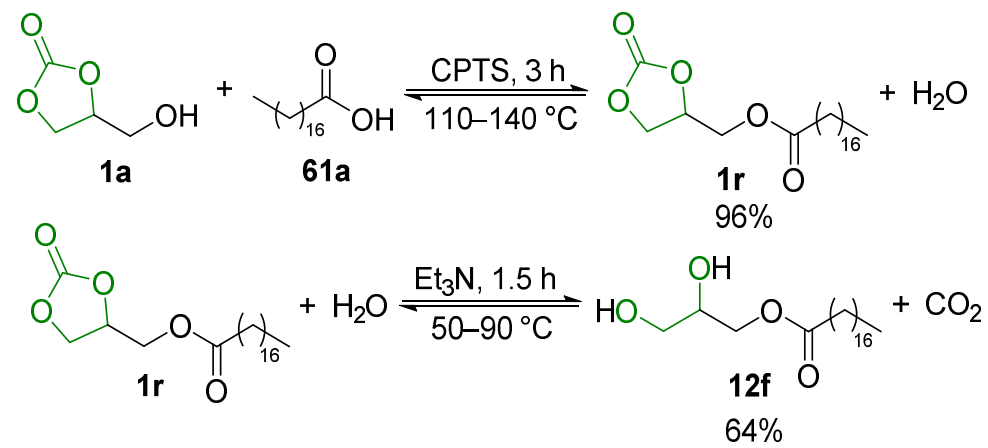

Scheme 82. Esterification approach for GC 1a with stearic acid 61a and ODOMS 1r conversion into GMS $12 f$.

\subsection{Miscellaneous}

In addition to the plethora of chemical transformations presented in the previous sections in which glycerol carbonate is involved, the versatility of this glycerol derivative has allowed it to be employed in singular polymerization reactions, leading to diversified products with significant potential for application in various materials. In this line, the synthesis of new fluorinated terpolymers bearing cyclocarbonate pendant groups to ensure the crosslinking of the polymer chains was reported [205]. The new cyclocarbonateand triazole-functionalized fluorinated terpolymer $\mathbf{1 7 6}$ was obtained in three steps from chlorotrifluoroethylene 76, as shown in Scheme 83. The glycerol carbonate vinyl ether monomer 11 was obtained with $45 \%$ yield via a transetherification reaction between GC 1a and ethoxyethylene $\mathbf{1 7 7}$ under palladium catalysis. The key co-polymerization step involving 11, 76, and 2-chloroethyl vinyl ether 178 was catalyzed by ${ }^{n}$ butylperoxypivalate and proceeded in a HFP solution at $74{ }^{\circ} \mathrm{C}$, leading to the terpolymer 179. After two more steps, the triazolyl-modified terpolymer $\mathbf{1 7 6}$ was obtained as a membrane, which was removable from the glassy substrate via immersion in $1 \mathrm{M}$ aqueous hydrochloric acid. After the final conditioning process, it was verified that the developed semi-interpenetrating polymer network (semi-IPN) blended membranes presented lower water uptake and better mechanical properties compared to non-crosslinked membranes.

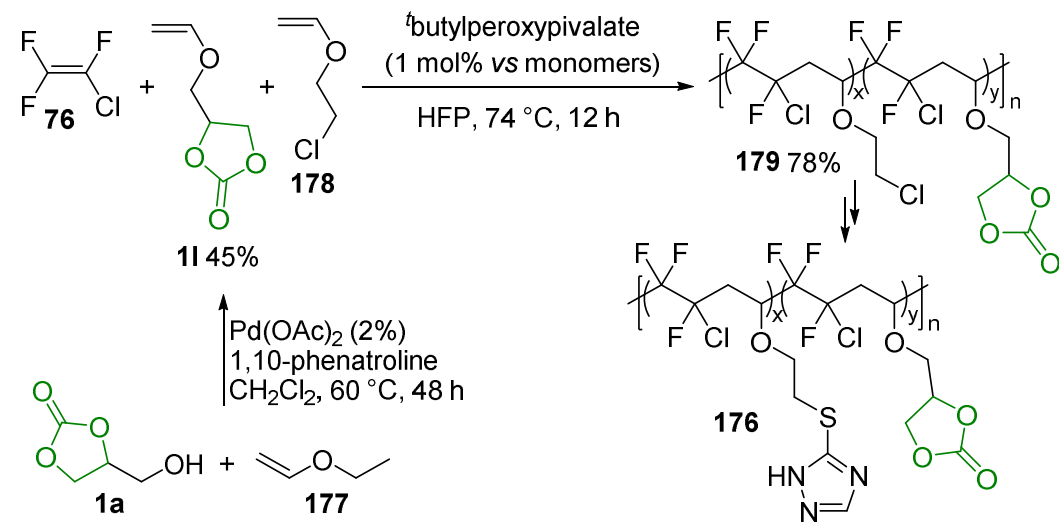

Scheme 83. Synthesis of cyclocarbonate- and triazole-functionalized fluorinated terpolymer 176.

In the same year, Sacripante and co-workers [206] described the preparation of polyester resins derived from rosin acids for application as a xerographic toner. Rosin acids obtained from pulp byproduct (tall oil), gum, or wood rosins are more sustainable monomers than those from food biomass. Reacting renewable dehydroabietic acid 180 with GC 1a (3.3 equivalent) in the presence of catalytic tetraethylammonium iodide at $150{ }^{\circ} \mathrm{C}$ provided a mixture of dehydroabietates 11e, 181, and 182. After adding more 180, the reaction was continued for $8 \mathrm{~h}$ at the same temperature to deliver a mixture of the monoesters 12e and 181 (61.9\% yield) and 182 (12.5\%), together with the isomeric diesters 
$183(12.4 \%)$ and $184(5.3 \%)$. This mixture of $182,183,184$, and 12 e rosin adducts was reacted with various organic diacids to provide novel polyester resins with a glass transition of 35-53.9 ${ }^{\circ} \mathrm{C}$, which is the suitable temperature range for toner applications (Scheme 84).

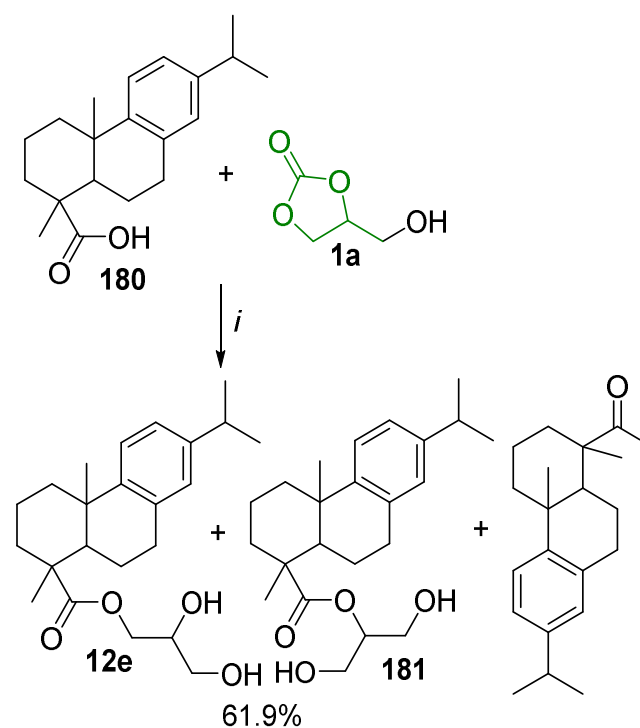

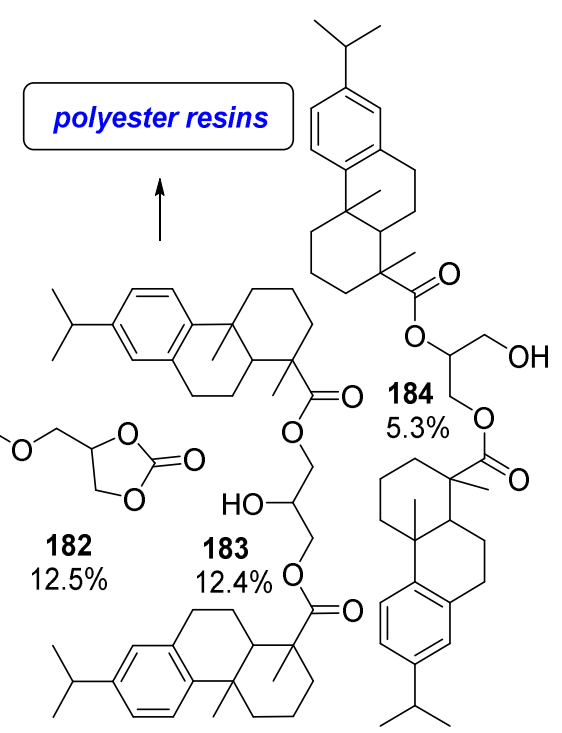

Scheme 84. Preparation of polyester resins. Conditions for $i$ : 180 (0.330 mol), $\mathrm{Et}_{4} \mathrm{NI}(0.005 \mathrm{~mol})$ and 1a $(1.1 \mathrm{~mol})$ were reacted in a $1 \mathrm{~L}$ Parr 4020 reactor at $150{ }^{\circ} \mathrm{C}$ under $\mathrm{N}_{2}$ atmosphere for $2 \mathrm{~h}$; then, more acid $180(0.670 \mathrm{~mol})$ was added and the reaction was maintained at $150{ }^{\circ} \mathrm{C}$ for $8 \mathrm{~h}$ ( $>99 \%$ conversion).

A promising approach in green and sustainable chemistry is the direct use of $\mathrm{CO}_{2}$ by combining the coupling reaction and free-radical polymerization to efficiently produce polyacrylates bearing cyclic carbonate groups. In 2016, Zhang, Du. and co-workers [207] described the use of a new nano-lamellar double-metal cyanide complex, $\mathrm{Zn}-\mathrm{Co}$ (III) $\mathrm{DMCC} / \mathrm{CTAB}$, a catalyst that allows the preparation of highly transparent polyacrylates with specific UV absorption. The reaction of $\mathrm{CO}_{2}$ with glycidyl methacrylate $\mathbf{1 8 5}$ followed by free radical polymerization (FRP) of the resulting alkenyl carbonate ester DOMA 1s provided new polyacrylates, known as PDOMAs (Scheme 85). AIBN (1.5 mol\% related to 1s) was used as the radical initiator in the FRP, which was conducted in DMF at $80^{\circ} \mathrm{C}$. The resulting polymer, poly(2-oxo-1,3-dioxolane-4-yl)methyl methacrylate (PDOMA) 186, which is soluble in strong polar solvents, has tunable number-average molecular weights (12.0-132.0 $\left.\mathrm{kg} \cdot \mathrm{mol}^{-1}\right)$, high glass transition temperatures $\left(121.0-140.4{ }^{\circ} \mathrm{C}\right)$, and a high thermal decomposition temperature $\left(5 \mathrm{wt} \%, 257^{\circ} \mathrm{C}\right)$. PDOMAs 186 presented excellent visible light transmittance (93\%) and nearly $100 \%$ UV absorbance in the wavelength range of 200-313 nm.

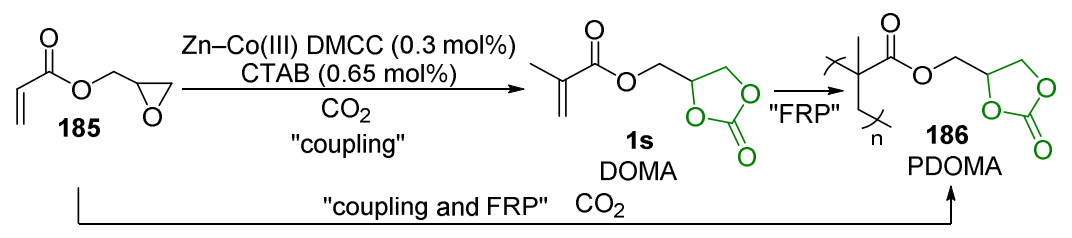

Scheme 85. Preparation of highly transparent polyacrylates.

In 2016, Carbonnier and co-workers [208] designed a synthetic route involving GC methacrylate 1s and glycol bis-methacrylate 189 for an FRP preparation of monolithic columns. Further surface modification with allylamine and thiols provided functionalized polymeric monoliths through a cyclic carbonate opening and thiol-ene click addition (Scheme 86). Subsequent possible immobilization of metallic nanoparticles allowed these materials to be successfully used as supports for chromatographic applications or as microreactors for flow catalysis. 


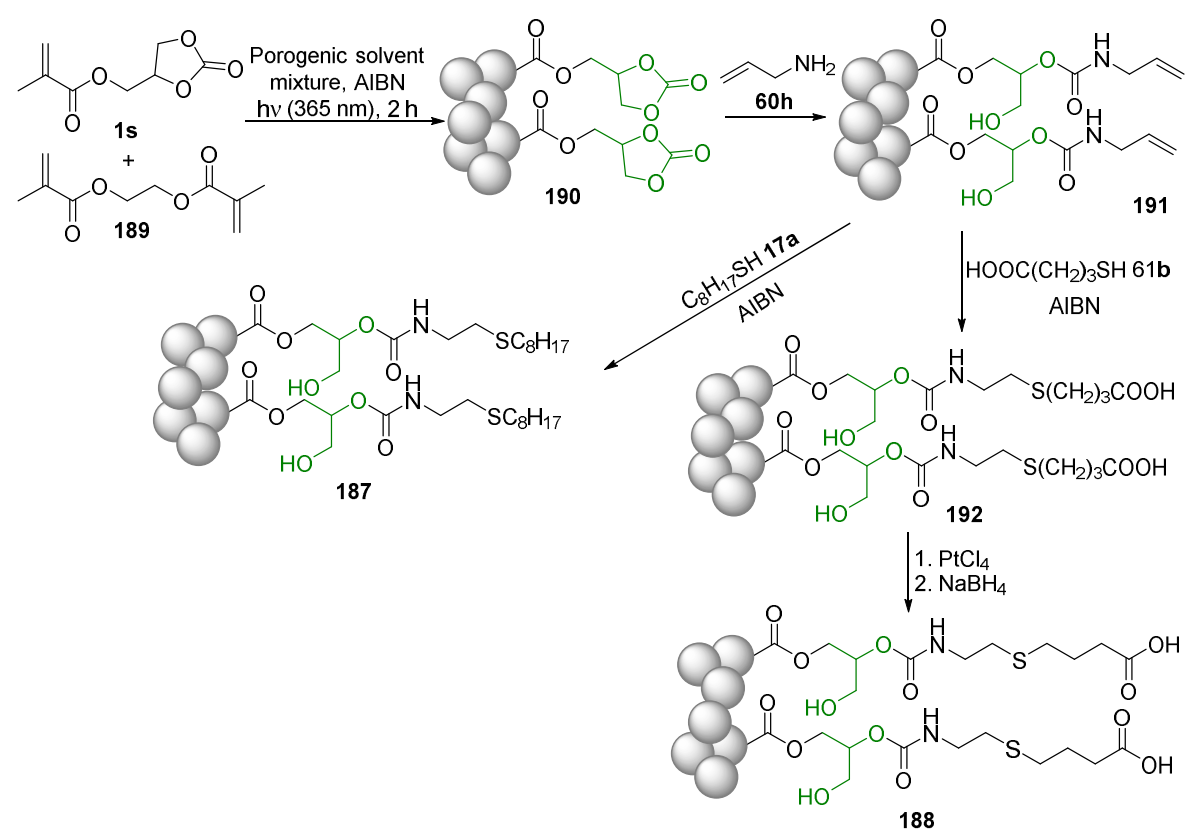

Scheme 86. Synthetic route involving GC methacrylate 1s and glycol bis-methacrylate $\mathbf{1 8 9}$ for an FRP preparation of monolithic columns.

\section{Conclusions}

The versatility of five-membered cyclic carbonates in organic synthesis and materials science has been recognized for years, as demonstrated in a number of papers. In this review, the studies reported from 2012 to the present were covered as an update of previously published contributions [5,15-21].

The cyclic carbonate nucleus has attracted considerable attention among researchers in different areas since it can be implemented as a substrate to access several classes of compounds with broad functional diversity. Our review covers miscellaneous uses of this structural unit as a starting material for the preparation of biologically active compounds, attractive molecules for the materials industry, and versatile building blocks in organic synthesis. In particular, the preparation of urethanes and polyurethanes should be highlighted as one of the most important applications of five-membered cyclic carbonates, since this represents an isocyanate-free and environmentally friendly route to these valuable polymers.

The possibility of using glycerol and $\mathrm{CO}_{2}$ (as demonstrated more recently) as readily available, cheap, renewable starting materials to prepare cyclic carbonates reinforces the role of such versatile motifs in the chemical industry. It is expected that investigating the reactivity and the physicochemical properties of cyclic carbonates will continue to attract the attention of synthetic and organic materials chemists for years to come. There are still some challenges to be overcome in the comprehensive development about cyclic carbonates, namely increases in the range and selectivity of the reactions involved in polymer synthesis and the greenness of most of the protocols engaged in the functionalization of this building block.

We hope the present review can awaken in the reader an interest in the development of new reactions and applications for the well-established range of cyclic carbonates, especially those derived from glycerol. This might well become a viable way to add value to glycerol issued from regrowing resources, with nobler applications for chemicals, pharmaceuticals, agrochemicals, and materials.

Author Contributions: Conceptualization, P.R. and G.P.; methodology, P.R., E.J.L., and G.P.; formal analysis, L.K.S., A.M.B., and D.R.A.; resources, E.J.L., R.G.J., and G.P.; writing-original draft preparation, L.K.S., A.M.B., and D.R.A.; writing-review and editing, P.R., E.J.L., R.G.J., and G.P.; 
visualization, P.R., E.J.L., R.G.J., and G.P.; supervision, P.R. and G.P.; project administration, G.P. All authors have read and agreed to the published version of the manuscript.

Funding: This research received no external funding.

Institutional Review Board Statement: Not applicable.

Informed Consent Statement: Not applicable.

Acknowledgments: We are grateful to Conselho Nacional de Desenvolvimento Científico e Tecnológico (CNPq), and Fundação de Amparo à Pesquisa do Estado do Rio Grande do Sul (FAPERGS) for financial support. CNPq is also acknowledged for fellowships for G.P., R.G.J., and E.J.L. This study was financed in part by the Coordenação de Aperfeiçoamento de Pessoal de Nível Superior Brasil (CAPES) Finance Code 001.

Conflicts of Interest: The authors declare no conflict of interest.

\section{References}

1. Ricapito, N.G.; Ghobril, C.; Zhang, H.; Grinstaff, M.W.; Putnam, D. Synthetic Biomaterials from Metabolically Derived Synthons. Chem. Rev. 2016, 116, 2664-2704. [CrossRef] [PubMed]

2. Guo, W.; Gómez, J.E.; Cristòfol, À.; Xie, J.; Kleij, A.W. Catalytic Transformations of Functionalized Cyclic Organic Carbonates. Angew. Chem. Int. Ed. 2018, 57, 13735-13747. [CrossRef]

3. Schäffner, B.; Schäffner, F.; Verevkin, S.P.; Borner, A. Organic Carbonates as Solvents in Synthesis and Catalysis. Chem. Rev. 2010, 110, 4554-4581. [CrossRef] [PubMed]

4. Gérardy, R.; Estager, J.; Luis, P.; Debecker, D.P.; Monbaliu, J.-C.M. Versatile and Scalable Synthesis of Cyclic Organic Carbonates under Organocatalytic Continuous Flow Conditions. Catal. Sci. Technol. 2019, 9, 6841-6851. [CrossRef]

5. Pescarmona, P.P. Cyclic Carbonates Synthesised from $\mathrm{CO}_{2}$ : Applications, Challenges and Recent Research Trends. Curr. Opin. Green Sustain. Chem. 2021, 29, 100457. [CrossRef]

6. Marciniak, A.A.; Lamb, K.J.; Ozorio, L.P.; Mota, C.J.A.; North, M. Heterogeneous Catalysts for Cyclic Carbonate Synthesis from Carbon Dioxide and Epoxides. Curr. Opin. Green Sustain. Chem. 2020, 26, 100365. [CrossRef]

7. Okoye, P.U.; Hammed, B.H. Review on Recent Progress in Catalytic Carboxylation and Acetylation of Glycerol as a Byproduct of Biodiesel Production. Renew. Sust. Energ. Rev. 2016, 53, 558-574. [CrossRef]

8. Samoilov, V.O.; Ramazanov, D.N.; Nekhaev, A.I.; Maximov, A.L.; Bagdasarov, L.N. Heterogeneous Catalytic Conversion of Glycerol to Oxygenated Fuel Additives. Fuel 2016, 172, 310-319. [CrossRef]

9. Rokicki, G.; Rakoczy, P.; Parzuchowski, P.; Sobiecki, M. Hyperbranched Aliphatic Polyethers Obtained from Environmentally Benign Monomer: Glycerol Carbonate. Green Chem. 2005, 7, 529-539. [CrossRef]

10. Maisonneuve, L.; Lamarzelle, O.; Rix, E.; Grau, E.; Cramail, H. Isocyanate-Free Routes to Polyurethanes and Poly(hydroxy Urethane)s. Chem. Rev. 2015, 115, 12407-12439. [CrossRef] [PubMed]

11. Simão, A.-C.; Lynikaite-Pukleviciene, B.; Rousseau, C.; Tatibouët, A.; Cassel, S.; Šačkus, A.; Rauter, A.P.; Rollin, P. 1,2-Glycerol Carbonate: A Versatile Renewable Synthon. Lett. Org. Chem. 2006, 3, 744-748. [CrossRef]

12. Rousseau, J.; Rousseau, C.; Lynikaitè, B.; Šačkus, A.; de Leon, C.; Rollin, P.; Tatibouët, A. Tosylated Glycerol Carbonate, a Versatile Bis-electrophile to Access New Functionalized Glycidol Derivatives. Tetrahedron 2009, 65, 8571-8581. [CrossRef]

13. Balieu, S.; Zein, A.E.; Sousa, R.; Jèrôme, F.; Tatibouët, A.; Gatard, S.; Pouilloux, Y.; Barrault, J.; Rollin, P.; Bouquillon, S. OneStep Surface Decoration of Poly(propyleneimines) (PPIs) with the Glyceryl Moiety: New Way for Recycling Homogeneous Dendrimer-Based Catalysts. Adv. Synth. Catal. 2010, 352, 1826-1833. [CrossRef]

14. Vilkauskaitè, G.; Krikštolaitytė, S.; Paliulis, O.; Rollin, P.; Tatibouët, A.; Šačkus, A. Use of Tosylated Glycerol Carbonate to Access N-Glycerylated Aza-aromatic Species. Tetrahedron 2013, 69, 3721-3727. [CrossRef]

15. Pham, P.D.; Monge, S.; Lapinte, V.; Raoul, Y.; Robin, J.J. Various Radical Polymerizations of Glycerol-based Monomers. Eur. J. Lipid Sci. Technol. 2013, 115, 28-40. [CrossRef]

16. Zhang, H.; Grinstaff, M.W. Recent Advances in Glycerol Polymers: Chemistry and Biomedical Applications. Macromol. Rapid Commun. 2014, 35, 1906-1924. [CrossRef]

17. Ochoa-Gómez, J.R.; Gómez-Jiménez-Aberasturi, O.; Ramírez-López, C.; Belsué, M. A Brief Review on Industrial Alternatives for the Manufacturing of Glycerol Carbonate, a Green Chemical. Org. Process. Res. Dev. 2012, 16, 389-399. [CrossRef]

18. Sonnati, M.O.; Amigoni, S.; Givenchy, E.P.T.; Darmanin, T.; Choulet, O.; Guittard, F. Glycerol Carbonate as a Versatile Building Block for Tomorrow: Synthesis, Reactivity, Properties and Applications. Green Chem. 2013, 15, 283-306. [CrossRef]

19. Besse, V.; Camara, F.; Voirin, C.; Auvergne, R.; Caillol, S.; Boutevin, B. Synthesis and applications of unsaturated cyclocarbonates. Polym. Chem. 2013, 4, 4545-4561. [CrossRef]

20. Duval, A.; Avérous, L. Cyclic Carbonates as Safe and Versatile Etherifying Reagents for the Functionalization of Lignins and Tannins. ACS Sustain. Chem. Eng. 2017, 5, 7334-7343. [CrossRef]

21. Tabanelli, T.; Giliberti, C.; Mazzoni, R.; Cucciniello, R.; Cavani, F. An Innovative Synthesis Pathway to Benzodioxanes: The Peculiar Reactivity of Glycerol Carbonate and Catechol. Green Chem. 2019, 21, 329-338. [CrossRef] 
22. Pagliaro, M.; Rossi, M. The Future of Glycerol, New Usages for a Versatile Raw Material; RSC Green Chemistry Book Series; RSC Publishing: Cambridge, UK, 2010; p. 108.

23. Jérôme, F.; Pouilloux, Y.; Barrault, J. Rational Design of Solid Catalysts for the Selective Use of Glycerol as a Natural Organic Building Block. ChemSusChem 2008, 1, 586-613. [CrossRef]

24. Hutchings, G.J.; Lee, D.F.; Minihan, A.R. Epoxidation of Allyl Alcohol to Glycidol Using Titanium Silicalite TS-1: Effect of the Reaction Conditions and Catalyst Acidity. Catal. Lett. 1996, 39, 83-90. [CrossRef]

25. Choi, J.S.; Simanjuntaka, F.S.H.; Oh, J.H.; Lee, K.I.; Lee, S.D.; Cheong, M.; Kim, H.S.; Lee, H. Ionic-liquid-catalyzed decarboxylation of glycerol carbonate to glycidol. J. Catal. 2013, 297, 248-255. [CrossRef]

26. Niu, X.; Wang, L.; Cao, J.; Cao, Y.; He, P.; Zhou, J.; Li, H. Efficient Synthesis of Epoxybutane from Butanediol via a Two-step Process. RSC Adv. 2019, 9, 10072-10080. [CrossRef]

27. Bolívar-Diaz, C.L.; Calvino-Casilda, V.; Rubio-Marcos, F.; Fernández, J.F.; Beñares, M.A. New Concepts for Process Intensification in the Conversion of Glycerol Carbonate to Glycidol. Appl. Catal. B Environ. 2013, 129, 575-579. [CrossRef]

28. Ha, J.H.; Kim, J.S.; Kim, M.H.; Lee, K.Y.; Lee, M.S. Synthesis of Glycidol by Decarboxylation of Glycerol Carbonate Over Zn-La Catalysts with Different Molar Ratio. J. Nanosci. Nanotechnol. 2016, 16, 10898-10902. [CrossRef]

29. Singh, D.; Reddy, B.; Ganesh, A.; Mahajani, S. Zinc/Lanthanum Mixed-Oxide Catalyst for the Synthesis of Glycerol Carbonate by Transesterification of Glycerol. Ind. Eng. Chem. Res. 2014, 53, 18786-18795. [CrossRef]

30. Endah, Y.K.; Kim, M.S.; Choi, J.; Jae, J.; Lee, S.D.; Lee, H. Consecutive Carbonylation and Decarboxylation of Glycerol with Urea for the Synthesis of Glycidol via Glycerol Carbonate. Catal. Today 2017, 293-294, 136-141. [CrossRef]

31. Zhu, J.-B.; Tang, X.; Falivene, L.; Caporaso, L.; Cavallo, L.; Chen, E.Y.-X. Organocatalytic Coupling of Bromo-Lactide with Cyclic Ethers and Carbonates to Chiral Bromo-Diesters: NHC or Anion Catalysis? ACS Catal. 2017, 7, 3929-3933. [CrossRef]

32. Xie, J.; Guo, W.; Cai, A.; Escudero-Adán, E.C.; Kleij, A.W. Pd-Catalyzed Enantio- and Regioselective Formation of Allylic Aryl Ethers. Org. Lett. 2017, 19, 6388-6391. [CrossRef] [PubMed]

33. Guo, W.; Kuniyil, R.; Gómez, J.E.; Maseras, F.; Kleij, A.W. A Domino Process toward Functionally Dense Quaternary Carbons through Pd-Catalyzed Decarboxylative C $\left(\mathrm{sp}^{3}\right)-\mathrm{C}\left(\mathrm{sp}^{3}\right)$ Bond Formation. J. Am. Chem. Soc. 2018, 140, 3981-3987. [CrossRef] [PubMed]

34. Balaraman, E.; Fogler, E.; Milstein, D. Efficient Hydrogenation of Biomass-derived Cyclic Di-esters to 1,2-Diols. Chem. Commun. 2012, 48, 1111-1113. [CrossRef] [PubMed]

35. Balaraman, E.; Gunanathan, C.; Zhang, J.; Shimon, L.J.W.; Milstein, D. Efficient Hydrogenation of Organic Carbonates, Carbamates and Formates Indicates Alternative Routes to Methanol Based on $\mathrm{CO}_{2}$ and CO. Nat. Chem. 2011, 3, 609-614. [CrossRef]

36. Han, Z.; Rong, L.; Wu, J.; Zhang, L.; Wang, Z.; Ding, K. Catalytic Hydrogenation of Cyclic Carbonates: A Practical Approach from $\mathrm{CO}_{2}$ and Epoxides to Methanol and Diols. Angew. Chem. Int. Ed. 2012, 51, 13041-13045. [CrossRef]

37. Wu, X.; Ji, L.; Ji, Y.; Elageed, E.H.M.; Gao, G. Hydrogenation of Ethylene Carbonate Catalyzed by Lutidine-bridged N-Heterocyclic Carbene Ligands and Ruthenium Precursors. Catal. Commun. 2016, 85, 57-60. [CrossRef]

38. Chen, J.; Zhu, H.; Chen, J.; Le, Z.-G.; Tu, T. Synthesis, Characterization and Catalytic Application of Pyridine-Bridged NHeterocyclic Carbene-Ruthenium Complexes in the Hydrogenation of Carbonates. Chem. Asian J. 2017, 12, 2809-2812. [CrossRef]

39. Liu, H.; Huang, Z.; Han, Z.; Ding, K.; Liu, H.; Xia, C.; Chen, J. Efficient Production of Methanol and Diols via the Hydrogenation of Cyclic Carbonates using Copper-Silica Nanocomposite Catalysts. Green Chem. 2015, 17, 4281-4290. [CrossRef]

40. Sun, J.; Yao, X.; Cheng, W.; Zhang, S. 1,3-Dimethylimidazolium-2-carboxylate: A Zwitterionic Salt for the Efficient Synthesis of Vicinal Diols from Cyclic Carbonates. Green Chem. 2014, 16, 3297-3304. [CrossRef]

41. Li, F.; Wang, L.; Han, X.; He, P.; Cao, Y.; Li, H. Influence of Support on the Performance of Copper Catalysts for the Effective Hydrogenation of Ethylene Carbonate to Synthesize Ethylene Glycol and Methanol. RSC Adv. 2016, 6, 45894-45906. [CrossRef]

42. Li, F.; Wang, L.; Han, X.; Cao, Y.; He, P.; Li, H. Selective Hydrogenation of Ethylene Carbonate to Methanol and Ethylene Glycol over $\mathrm{Cu} / \mathrm{SiO}_{2}$ Catalysts Prepared by Ammonia Evaporation Method. Int. J. Hydrog. Energy 2017, 42, 2144-2156. [CrossRef]

43. Zhou, M.; Shi, Y.; Ma, K.; Tang, S.; Liu, C.; Yue, H.; Liang, B. Nanoarray Cu/SiO2 Catalysts Embedded in Monolithic Channels for the Stable and Efficient Hydrogenation of $\mathrm{CO}_{2}$-Derived Ethylene Carbonate. Ind. Eng. Chem. Res. 2018, 57, 1924-1934. [CrossRef]

44. Fu, J.; Jiang, N.; Ren, D.; Song, Z.; Li, L.; Huo, Z. Hydrothermal Conversion of Ethylene Carbonate to Ethylene Glycol. Int. J. Hydrog. Energy 2016, 41, 9118-9122. [CrossRef]

45. Nakatake, D.; Yazaki, R.; Matsushima, Y.; Ohshima, T. Transesterification Reactions Catalyzed by a Recyclable Heterogeneous Zinc/Imidazole Catalyst. Adv. Synth. Catal. 2016, 358, 2569-2574. [CrossRef]

46. Perin, G.; Silva, C.M.; Borges, E.L.; Goulart, H.A.; Silva, R.B.; Jacob, R.G.; Silva, M.S.; Alves, D.; Schumacher, R.F. Selective Synthesis of 4-Chalcogenylmethyl-1,3-dioxolan-2-ones and 1,3-Bis(organylchalcogenyl)propan-2-ols from 3-O-Tosyl Glycerol 1,2-Carbonate. ChemistrySelect 2016, 1, 6238-6242. [CrossRef]

47. Pongrácz, P.; Kollár, L. Asymmetric Hydroformylation of 4-Vinyl-1,3-dioxolan-2-one. J. Heterocycl. Chem. 2017, 54, 1430-1436. [CrossRef]

48. Liu, X.; Vries, G.J.; Werner, T. Transfer Hydrogenation of Cyclic Carbonates and Polycarbonate to Methanol and Diols by Iron Pincer Catalysts. Green Chem. 2019, 21, 5248-5255. [CrossRef]

49. Huang, S.; Yan, B.; Wang, S.; Ma, X. Recent Advances in Dialkyl Carbonates Synthesis and Applications. Chem. Soc. Rev. 2015, 44, 3079-3116. [CrossRef] [PubMed] 
50. Lee, K.-H.; Lee, S.; Shin, D.; Hahm, H.-S. Dimethyl Carbonate Synthesis via Transesterification of Ethylene Carbonate and Methanol using Ionic Liquid Catalysts Immobilized on Mesoporous Cellular Foams. Res. Chem. Intermed. 2016, 42, 109-121. [CrossRef]

51. Saptal, V.B.; Bhanage, B.M. Bifunctional Ionic Liquids for the Multitask Fixation of Carbon Dioxide into Valuable Chemicals. ChemCatChem 2016, 8, 244-250. [CrossRef]

52. Jagodzinski, T.S. Thioamides as Useful Synthons in the Synthesis of Heterocycles. Chem. Rev. 2003, 103, 197-227. [CrossRef]

53. Beletskaya, I.P.; Ananikov, V.P. Transition-Metal-Catalyzed C-S, C-Se, and C-Te Bond Formation via Cross-Coupling and Atom-Economic Addition Reactions. Chem. Rev. 2011, 111, 1596-1636. [CrossRef]

54. Zeni, G.; Lüdtke, D.S.; Panatieri, R.B.; Braga, A.L. Vinylic Tellurides: From Preparation to Their Applicability in Organic Synthesis. Chem. Rev. 2006, 106, 1032-1076. [CrossRef]

55. Wirth, T. Organoselenium Chemistry in Stereoselective Reactions. Angew. Chem. Int. Ed. 2000, 39, 3740-3749. [CrossRef]

56. Santi, C.; Santoro, S.; Battistelli, B. Organoselenium Compounds as Catalysts in Nature and Laboratory. Curr. Org. Chem. 2010, 14, 2442-2462. [CrossRef]

57. Goswami, S.; Hazra, A.; Chakrabarty, R.; Fun, H.-K. Recognition of Carboxylate Anions and Carboxylic Acids by Selenium-Based New Chromogenic Fluorescent Sensor: A Remarkable Fluorescence Enhancement of Hindered Carboxylates. Org. Lett. 2009, 11, 4350-4353. [CrossRef]

58. Rasale, D.B.; Maity, I.; Das, A.K. In Situ Generation of Redox Active Peptides Driven by Selenoester Mediated Native Chemical Ligation. Chem. Commun. 2014, 50, 11397-11400. [CrossRef]

59. Ahuja, B.L.; Raykar, V.; Joshi, R.; Tiwari, S.; Talreja, S.; Choudhary, G. Electronic Properties and Momentum Densities of Tin Chalcogenides: Validation of PBEsol Exchange-Correlation Potential. Phys. B 2015, 465, 21-28. [CrossRef]

60. Trost, B.M.; Waser, J.; Meyer, A. Total Synthesis of (-)-Pseudolaric Acid B. J. Am. Chem. Soc. 2007, 129, 14556-14557. [CrossRef]

61. Wever, W.J.; Bogart, J.W.; Baccile, J.A.; Chan, A.N.; Schroeder, F.C.; Bowers, A.A. Chemoenzymatic Synthesis of Thiazolyl Peptide Natural Products Featuring an Enzyme-Catalyzed Formal [4+2] Cycloaddition. J. Am. Chem. Soc. 2015, 137, 3494-3497. [CrossRef]

62. Perin, G.; Barcellos, A.M.; Luz, E.Q.; Borges, E.L.; Jacob, R.G.; Lenardão, E.J.; Sancineto, L.; Santi, C. Green Hydroselenation of Aryl Alkynes: Divinyl Selenides as a Precursor of Resveratrol. Molecules 2017, 22, 327. [CrossRef]

63. Perin, G.; Silva, C.M.; Borges, E.L.; Duarte, J.E.G.; Goulart, H.A.; Silva, R.B.; Schumacher, R.F. Selective Synthesis of 4-Thiomethyl1,3-dioxolan-2-ones under Microwave Irradiation using an Environmentally Benign $\mathrm{KF} / \mathrm{Al}_{2} \mathrm{O}_{3} / \mathrm{PEG}-400$ System. Res. Chem. Intermed. 2016, 42, 5873-5885. [CrossRef]

64. Lenardão, E.J.; Soares, L.K.; Barcellos, A.M.; Perin, G. KF $/ \mathrm{Al}_{2} \mathrm{O}_{3}$ as a Green System for the Synthesis of Organochalcogen Compounds. Curr. Green Chem. 2016, 3, 4-17. [CrossRef]

65. Miralles, N.; Gómez, J.E.; Kleij, A.W.; Fernández, E. Copper-Mediated SN2' Allyl-Alkyl and Allyl-Boryl Couplings of Vinyl Cyclic Carbonates. Org. Lett. 2017, 19, 6096-6099. [CrossRef]

66. Khan, A.; Khan, S.; Zhao, C.; Mao, Y.; Chen, Y.; Zhang, Y.J. Enantioselective Construction of Tertiary C-O Bond via Allylic Substitution of Vinylethylene Carbonates with Water and Alcohols. J. Am. Chem. Soc. 2017, 139, 10733-10741. [CrossRef]

67. Wu, X.F.; Neumann, H.; Beller, M. Synthesis of Heterocycles via Palladium-Catalyzed Carbonylations. Chem. Rev. 2013, 113, 1-35. [CrossRef]

68. Chinchilla, R.; Najera, C. Chemicals from Alkynes with Palladium Catalysts. Chem. Rev. 2014, 114, 1783-1826. [CrossRef]

69. Musaev, D.G.; Figg, T.M.; Kaledin, A.L. Versatile Reactivity of Pd-Catalysts: Mechanistic Features of the Mono-N-protected Amino Acid Ligand and Cesium-Halide Base in Pd-Catalyzed C-H Bond Functionalization. Chem. Soc. Rev. 2014, 43, 5009-5031. [CrossRef]

70. Sperger, T.; Sanhueza, I.A.; Kalvet, I.; Schoenebeck, F. Computational Studies of Synthetically Relevant Homogeneous Organometallic Catalysis Involving Ni, Pd, Ir, and Rh: An Overview of Commonly Employed DFT Methods and Mechanistic Insights. Chem. Rev. 2015, 115, 9532-9586. [CrossRef]

71. Zuo, L.; Liu, T.; Chang, X.; Guo, W. An Update of Transition Metal-Catalyzed Decarboxylative Transformations of Cyclic Carbonates and Carbamates. Molecules 2019, 24, 3930. [CrossRef] [PubMed]

72. Fürstner, A. From Understanding to Prediction: Gold- and Platinum-Based $\pi$-Acid Catalysis for Target Oriented Synthesis. Acc. Chem. Res. 2014, 47, 925-938. [CrossRef]

73. Kakati, N.; Maiti, J.; Lee, S.H.; Jee, S.H.; Viswanathan, B.; Yoon, Y.S. Anode Catalysts for Direct Methanol Fuel Cells in Acidic Media: Do We Have Any Alternative for Pt or Pt-Ru? Chem. Rev. 2014, 114, 12397-12429. [CrossRef] [PubMed]

74. Nie, Y.; Li, L.; Wei, Z. Recent Advancements in Pt and Pt-Free Catalysts for Oxygen Reduction Reaction. Chem. Soc. Rev. 2015, 44, 2168-2201. [CrossRef] [PubMed]

75. Song, G.; Wang, F.; Li, X. C-C, C-O and C-N Bond Formation via Rhodium(III)-Catalyzed Oxidative C-H Activation. Chem. Soc. Rev. 2012, 41, 3651-3678. [CrossRef]

76. Etayo, P.; Vidal-Ferran, A. Rhodium-Catalysed Asymmetric Hydrogenation as a Valuable Synthetic Tool for the Preparation of Chiral Drugs. Chem. Soc. Rev. 2013, 42, 728-754. [CrossRef] [PubMed]

77. Ye, B.; Cramer, N. Chiral Cyclopentadienyls: Enabling Ligands for Asymmetric Rh(III)-Catalyzed C-H Functionalizations. Acc. Chem. Res. 2015, 48, 1308-1318. [CrossRef] [PubMed]

78. Cao, W.; Wang, W.; Lu, K.; Yao, W.; Xue, F.; Ma, M. Magnesium-Catalyzed Hydroboration of Organic Carbonates, carbon Dioxide and Esters. Dalton Trans. 2020, 49, 2776-2780. [CrossRef] [PubMed] 
79. Ibn El Alami, M.S.; Suisse, I.; Fadlallah, S.; Sauthier, M.; Visseaux, M.C.R. Telomerization of 1,3-Butadiene with Glycerol Carbonate and Subsequent Ring-Opening Lactone Co-polymerization. Chimie 2016, 19, 299-305. [CrossRef]

80. Liu, Q.; Liu, T.-X.; Ru, Y.; Zhu, X.; Zhang, G. Palladium-Catalyzed Decarboxylative Heterocyclizations of [60]Fullerene: Preparation of Novel Vinyl-substituted [60]Fullerene-fused Tetrahydrofurans/Pyrans/Quinolines. Chem. Commun. 2019, 55, 14498-14501. [CrossRef]

81. Singha, S.; Patra, T.; Daniliuc, C.G.; Glorius, F. Highly Enantioselective [5+2] Annulations through Cooperative N-Heterocyclic Carbene (NHC) Organocatalysis and Palladium Catalysis. J. Am. Chem. Soc. 2018, 140, 3551-3554. [CrossRef]

82. Rong, Z.-Q.; Yang, L.-C.; Liu, S.; Yu, Z.; Wang, Y.-N.; Tan, Z.Y.; Huang, R.-Z.; Lan, Y.; Zhao, Y. Nine-Membered Benzofuran-Fused Heterocycles: Enantioselective Synthesis by Pd-Catalysis and Rearrangement via Transannular Bond Formation. J. Am. Chem. Soc. 2017, 139, 15304-15307. [CrossRef] [PubMed]

83. Zhao, C.; Shah, B.H.; Khan, I.; Kan, Y.; Zhang, Y. Enantioselective Synthesis of Isoxazoline N-Oxides via Pd-Catalyzed Asymmetric Allylic Cycloaddition of Nitro-Containing Allylic Carbonates. J. Org. Lett. 2019, 21, 9045-9049. [CrossRef] [PubMed]

84. Zhao, C.; Khan, I.; Zhang, Y.J. Enantioselective Total Synthesis of Furofuran Lignans via Pd-Catalyzed Asymmetric Allylic Cycloadditon of Vinylethylene Carbonates with 2-Nitroacrylates. Chem. Commun. 2020, 56, 12431-12434. [CrossRef]

85. Das, P.; Gondo, S.; Nagender, P.; Uno, H.; Tokunaga, E.; Shibata, N. Access to Benzo-fused Nine-membered Heterocyclic Alkenes with a Trifluoromethyl Carbinol Moiety via a Double Decarboxylative Formal Ring-Expansion Process under Palladium Catalysis. Chem. Sci. 2018, 9, 3276-3281. [CrossRef]

86. Guo, W.; Martínez-Rodríguez, L.; Martin, E.; Escudero-Adán, E.C.; Kleij, A.W. Highly Efficient Catalytic Formation of (Z)-1,4-But2-ene Diols Using Water as a Nucleophile. Angew. Chem. Int. Ed. 2016, 55, 11037-11040. [CrossRef]

87. Li, C.; Breit, B. Rhodium-Catalyzed Dynamic Kinetic Asymmetric Allylation of Phenols and 2-Hydroxypyridines. Chem. Eur. J. 2016, 22, 14655-14663. [CrossRef]

88. Szewczyk, M.; Magre, M.; Zubar, V.; Rueping, M. Reduction of Cyclic and Linear Organic Carbonates Using a Readily Available Magnesium Catalyst. ACS Catal. 2019, 9, 11634-11639. [CrossRef]

89. Xue, X.; Xu, J.; Zhang, L.; Xu, C.; Pan, Y.; Xu, L.; Li, H.; Zhang, W. Rhodium(III)-Catalyzed Direct C-H Olefination of Arenes with Aliphatic Olefins. Adv. Synth. Catal. 2016, 358, 573-583. [CrossRef]

90. Lu, Q.; Klauck, F.J.R.; Glorius, F. Manganese-Catalyzed Allylation via Sequential C-H and C-C/C-Het Bond Activation. Chem. Sci. 2017, 8, 3379-3383. [CrossRef] [PubMed]

91. Tortoreto, C.; Achard, T.; Egger, L.; Guénée, L.; Lacour, J. Synthesis of Spiro Ketals, Orthoesters, and Orthocarbonates by CpRu-Catalyzed Decomposition of $\alpha$-Diazo- $\beta$-ketoesters. Org. Lett. 2016, 18, 240-243. [CrossRef]

92. Annunziata, L.; Fouquay, S.; Michaud, G.; Simon, F.; Guillaume, S.M.; Carpentier, J.-F. Mono- and Di-cyclocarbonate Telechelic Polyolefins Synthesized from ROMP Using Glycerol Carbonate Derivatives as Chain-transfer Agents. Polym. Chem. 2013, 4, 1313-1316. [CrossRef]

93. Yagci, Y.; Nuyken, O.; Graubner, V.-M. Encyclopedia of Polymer Science and Technology. In Telechelic Polymers; Wiley Online Library: Hoboken, NJ, USA, 2004. [CrossRef]

94. Kuciński, K.; Szudkowska-Frątczak, J.; Hreczycho, G. Pt-Catalyzed Synthesis of Functionalized Symmetrical and Unsymmetrical Disilazanes. Chem. Eur. J. 2016, 22, 13046-13049. [CrossRef] [PubMed]

95. Jiang, X.; Chen, J.; Zhu, W.; Zhu, W.; Cheng, K.; Liu, Y.; Su, W.-K.; Yu, C.J. Cobalt(III)-Catalyzed Fast and Solvent-Free C-H Allylation of Indoles Using Mechanochemistry. Org. Chem. 2017, 82, 10665-10672. [CrossRef]

96. Bensemhoun, J.; Condon, S. Valorization of Glycerol 1,2-Carbonate as a Precursor for the Development of New Synthons in Organic Chemistry. Green Chem. 2012, 14, 2595-2599. [CrossRef]

97. Singha, S.; Serrano, E.; Mondal, S.; Daniliuc, C.G.; Glorius, F. Diastereodivergent Synthesis of Enantioenriched $\alpha, \beta$-Disubstituted $\gamma$-Butyrolactones via Cooperative N-Heterocyclic Carbene and Ir Catalysis. Nat. Catal. 2020, 3, 48-54. [CrossRef]

98. Kargar, M.; Hekmatshoar, R.; Ghandi, M.; Mostashari, A. Use of Glycerol Carbonate in an Efficient, One-Pot and Solvent Free Synthesis of 1,3-sn-Diglycerides. J. Am. Oil Chem. Soc. 2012, 90, 259-264. [CrossRef]

99. Yuan, J.; Antonietti, M. Poly(ionic liquid)s: Polymers Expanding Classical Property Profiles. Polymer 2011, 52, 1469-1482. [CrossRef]

100. Yuan, J.; Mecerreyes, D.; Antonietti, M. Poly(ionic liquid)s: An Update. Prog. Polym. Sci. 2013, 38, 1009-1036. [CrossRef]

101. Zhang, Y.; Wang, B.; Elageed, E.H.M.; Qin, L.; Ni, B.; Liu, X.; Gao, G. Swelling Poly(ionic liquid)s: Synthesis and Application as Quasi-Homogeneous Catalysts in the Reaction of Ethylene Carbonate with Aniline. ACS Macro Lett. 2016, 5, 435-438. [CrossRef]

102. Truscello, A.M.; Gambarotti, C.; Lauria, M.; Auricchio, S.; Leonardi, G.; Shisodia, S.U.; Citterio, A. One-pot synthesis of aryloxypropanediols from glycerol: Towards valuable chemicals from renewable sources. Green Chem. 2013, 15, 625-628. [CrossRef]

103. Kao, S.-C.; Lin, Y.-C.; Ryu, I.; Wu, Y.-K. Revisiting Hydroxyalkylation of Phenols with Cyclic Carbonates. Adv. Synth. Catal. 2019, 361, 3639-3644. [CrossRef]

104. Olsén, P.; Oschmann, M.; Johnston, E.V.; Åkermark, B. Synthesis of Highly Functional Carbamates Through Ring-Opening of Cyclic Carbonates with Unprotected $\alpha$-Amino Acids in Water. Green Chem. 2018, 20, 469-475. [CrossRef]

105. Wang, Y.; Chai, J.; You, C.; Zhang, J.; Mi, X.; Zhang, L.; Luo, S. $\pi$-Coordinating Chiral Primary Amine/Palladium Synergistic Catalysis for Asymmetric Allylic Alkylation. J. Am. Chem. Soc. 2020, 142, 3184-3195. [CrossRef] 
106. Tillet, G.; Boutevin, B.; Ameduri, B. Chemical Reactions of Polymer Crosslinking and Post-crosslinking at Room and Medium Temperature. Prog. Polym. Sci. 2011, 36, 191-217. [CrossRef]

107. Pham, P.D.; Monge, S.; Lapinte, V.; Raoul, Y.; Robin, J.J. Glycerol-based Co-oligomers by Free-radical Chain Transfer Polymerization: Towards Reactive Polymers bearing Acetal and/or Carbonate Groups with Enhanced Properties. Eur. Polym. J. 2017, 95, 491-502. [CrossRef]

108. Rotta, J.; Pham, P.D.; Lapinte, V.; Borsali, R.; Minatti, E.; Robin, J.-J. Synthesis of Amphiphilic Polymers Based on Fatty Acids and Glycerol-Derived Monomers-A Study of Their Self-Assembly in Water. Macromol. Chem. Phys. 2014, 215, 131-139. [CrossRef]

109. Hamiye, R.; Alaaeddine, A.; Awada, M.; Campagne, B.; Caillol, S.; Guillaume, S.M.; Ameduri, B.; Carpentier, J.-F. From Glycidyl Carbonate to Hydroxyurethane Side-groups in Alternating Fluorinated Copolymers. Polym. Chem. 2014, 5, 5089-5099. [CrossRef]

110. Shaheen, U.; Turney, T.W.; Saito, K.; Gates, W.P.; Patti, A.F. Pendant Cyclic Carbonate-polymer/Na-Smectite Nanocomposites via In Situ Intercalative Polymerization and Solution Intercalation. J. Polym. Sci. Part A Polym. Chem. 2016, 54, 2421-2429. [CrossRef]

111. Mhanna, A.; Sadaka, F.; Boni, G.; Brachais, C.-H.; Brachais, L.; Couvercelle, J.-P.; Plasseraud, L.; Lecamp, L. Photopolymerizable Synthons from Glycerol Derivatives. J. Am. Oil Chem. Soc. 2014, 91, 337-348. [CrossRef]

112. Dubois, P.; Coulembier, O.; Raquez, J.-M. Handbook of Ring-Opening Polymerization; WILEY-VCH: Weinheim, Germany, 2009.

113. Clements, J.H. Reactive Applications of Cyclic Alkylene Carbonates. Ind. Eng. Chem. Res. 2003, 42, 663-674. [CrossRef]

114. Yadav, N.; Seidi, F.; Crespy, D.; D’Elia, V. Polymers Based on Cyclic Carbonates as Trait d'Union Between Polymer Chemistry and Sustainable $\mathrm{CO}_{2}$ Utilization. ChemSusChem 2019, 12, 724-754. [CrossRef]

115. Patil, R.M.; Hong, H.; Chai, C.L.L.; Ghanwat, A.A.; Ganugapati, S.; Gnaneshwar, R. Synthesis and Characterization of $\alpha-($ Cyclic Carbonate), w-Hydroxyl/Itaconic Acid Asymmetric Telechelic Poly(E-caprolactone). Polym. Bull. 2015, 72, 2489-2501. [CrossRef]

116. Kapiti, G.; Keul, H.; Möller, M. Functional PEG Building Blocks via Copolymerization of Ethylene Carbonate and tert-Butyl Glycidyl Ether. Polym. Chem. 2016, 7, 5050-5059. [CrossRef]

117. García, K.E.; Navarro, R.; Ramírez-Hernández, F.; Marcos-Fernández, Á. New Routes to Difunctional Macroglycols Using Ethylene Carbonate: Reaction with Bis-(2-hydroxyethyl) Terephthalate and Degradation of Poly(Ethylene Terephthalate). Polym. Degrad. Stab. 2017, 144, 195-206. [CrossRef]

118. Kong, P.S.; Aroua, M.K.; Daud, W.M.A.W. Conversion of Crude and Pure Glycerol into Derivatives: A Feasibility Evaluation. Renew. Sustain. Energy Rev. 2016, 63, 533-555. [CrossRef]

119. Cunha, A.G.; Gandini, A. Turning Polysaccharides into Hydrophobic Materials: A Critical Review. Part 2. Hemicelluloses, Chitin/Chitosan, Starch, Pectin and Alginates. Cellulose 2010, 17, 1045-1065. [CrossRef]

120. Akil, Y.; Lorenz, D.; Lehnen, R.; Saake, B. Safe and Non-toxic Hydroxyalkylation of Xylan Using Propylene Carbonate. Eur. Polym. J. 2016, 77, 88-97. [CrossRef]

121. Akil, Y.; Lehnen, R.; Saake, B. Novel Synthesis of Hydroxyvinylethyl Xylan Using 4-Vinyl-1,3-dioxolan-2-one. Tetrahedron Lett. 2016, 57, 4200-4202. [CrossRef]

122. Costa, P.L.F.; Melo, V.N.; Guimarães, B.M.; Schuler, M.; Pimenta, V.; Rollin, P.; Tatibouët, A.; Oliveira, R.N. Glycerol Carbonate in Ferrier Reaction: Access to New Enantiopure Building Blocks to Develop Glycoglycerolipid Analogues. Carbohydr. Res. 2016, 436, 1-10. [CrossRef]

123. Vitaku, E.; Smith, D.T.; Njardarson, J.T. Analysis of the Structural Diversity, Substitution Patterns, and Frequency of Nitrogen Heterocycles among U.S. FDA Approved Pharmaceuticals. J. Med. Chem. 2014, 57, 10257-10274. [CrossRef] [PubMed]

124. Neha; Dwivedi, A.R.; Kumar, R.; Kumar, V. Recent Synthetic Strategies for Monocyclic Azole Nucleus and Its Role in Drug Discovery and Development. Curr. Org. Synth. 2018, 15, 321-340. [CrossRef]

125. Eicher, T.; Hauptmann, S. The Chemistry of Heterocycles; Wiley/VCH: Weinheim, Germany, 2003.

126. Wang, B.; Yang, S.; Min, L.; Gu, Y.; Zhang, Y.; Wu, X.; Zhang, L.; Elageed, E.H.M.; Wu, S.; Gao, G. Eco-Efficient Synthesis of Cyclic Carbamates/Dithiocarbonimidates from Cyclic Carbonates/Trithiocarbonate and Aromatic Amines Catalyzed by Ionic Liquid BmimOAc. Adv. Synth. Catal. 2014, 356, 3125-3134. [CrossRef]

127. Vilkauskaitè, G.; Holzer, W.; Šačkus, A. 4-\{[(1-Phenyl-1H-pyrazol-3-yl)oxy]methyl\}-1,3-dioxolan-2-one. Molbank 2012, 2012 , M786. [CrossRef]

128. Zidar, N.; Tomašič, T.; Macut, H.; Sirc, A.; Brvar, M.; Montalvão, S.; Tammela, P.; Ilaš, J.; Kikelj, D. New N-Phenyl-4,5dibromopyrrolamides and N-Phenylindolamides as ATPase Inhibitors of DNA Gyrase. Eur. J. Med. Chem. 2016, 117, 197-211. [CrossRef]

129. Jo, H.; Han, S.; Park, J.; Choi, M.; Han, S.H.; Jeong, T.; Lee, S.-Y.; Kwak, J.H.; Jung, Y.H.; Kim, I.S. Rhodium(III)-Catalyzed Heteroatom-directed C-H Allylation with Allylic Phosphonates and Allylic Carbonates at Room Temperature. Tetrahedron 2016, 72, 571-578. [CrossRef]

130. Gosling, S.; El Amri, C.; Tatibouët, A. Staudinger Condensation for the Preparation of Thiohydantoins. Synthesis 2014, 46, 1079-1084. [CrossRef]

131. Yang, L.-C.; Rong, Z.-Q.; Wang, Y.-N.; Tan, Z.Y.; Wang, M.; Zhao, Y. Construction of Nine-Membered Heterocycles through Palladium-Catalyzed Formal [5+4] Cycloaddition. Angew. Chem. Int. Ed. 2017, 56, 2927-2931. [CrossRef] [PubMed]

132. Yang, L.-C.; Tan, Z.Y.; Rong, Z.-Q.; Liu, R.; Wang, Y.-N.; Zhao, Y. Palladium-Titanium Relay Catalysis Enables Switch from Alkoxide-pAllyl to Dienolate Reactivity for Spiro-Heterocycle Synthesis. Angew. Chem. Int. Ed. 2018, 57, 7860-7864. [CrossRef] 
133. Yuan, C.; Wu, Y.; Wang, D.; Zhang, Z.; Wang, C.; Zhou, L.; Zhang, C.; Song, B.; Guo, H. Formal [5+3] Cycloaddition of Zwitterionic Allylpalladium Intermediates with Azomethine Imines for Construction of N,O-Containing Eight-Membered Heterocycles. Adv. Synth. Catal. 2018, 360, 652-658. [CrossRef]

134. Wang, H.; Lorion, M.M.; Ackermann, L. Air-Stable Manganese(I)-Catalyzed C-H Activation for Decarboxylative C-H/C-O Cleavages in Water. Angew. Chem. Int. Ed. 2017, 56, 6339-6342. [CrossRef]

135. Wang, H.; Lorion, M.M.; Ackermann, L. Domino C-H/N-H Allylations of Imidates by Cobalt Catalysis. ACS Catal. 2017, 7, 3430-3433. [CrossRef]

136. Lang, X.-D.; Li, Z.-M.; He, L.-N. Protic Ionic Liquid-Catalyzed Synthesis of Oxazolidinones Using Cyclic Carbonates as both $\mathrm{CO}_{2}$ Surrogate and Sustainable Solvent. Catal. Today 2019, 324, 167-173. [CrossRef]

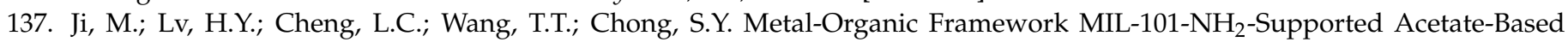
Butylimidazolium Ionic Liquid as a Highly Efficient Heterogeneous Catalyst for the Synthesis of 3-Aryl-2-oxazolidinones. Langmuir 2019, 35, 495-503. [CrossRef]

138. Rakhmaninam, N.Y.; van den Anker, J.N. Efavirenz in the Therapy of HIV Infection. Expert Opin. Drug Metab. Toxicol. 2010, 6, 95-103. [CrossRef]

139. Splinter, M.Y. Ezogabine (Retigabine) and its Role in the Treatment of Partial-onset Seizures: A Review. Clin. Ther. 2012, 34, 1845-1856. [CrossRef]

140. Cooper, S.L.; Guan, J. Advances in Polyurethane Biomaterials; Woodhead Publishing: Cambridge, UK, 2016 ; ISBN 9780081006221.

141. Ochiai, B.; Koda, K.; Endo, T. Branched Cationic Polyurethane Prepared by Polyaddition of Chloromethylated Five-Membered Cyclic Carbonate and Diethylenetriamine in Molten Salts. J. Polym. Sci. A Polym. Chem. 2012, 50, 47-51. [CrossRef]

142. He, Y.; Heine, E.; Keusgen, N.; Keul, H.; Möller, M. Synthesis and Characterization of Amphiphilic Monodisperse Compounds and Poly(Ethylene Imine)s: Influence of their Microstructures on the Antimicrobial Properties. Biomacromolecules 2012, 13, 612-623. [CrossRef] [PubMed]

143. Shisodia, S.U.; Auricchio, S.; Citterio, A.; Grassi, M.; Sebastiano, R. New Examples of Template Catalysis based Processes: Glycerol-like Units as Efficient Promoters for Dehydrative Nucleophilic Substitutions of Ferrocenylmethanol. Tetrahedron Lett. 2014, 55, 869-872. [CrossRef]

144. Tian, L.; Gong, L.; Zhang, X. Copper-Catalyzed Enantioselective Synthesis of $\beta$-Amino Alcohols Featuring Tetrasubstituted Tertiary Carbons. Adv. Synth. Catal. 2018, 360, 2055-2059. [CrossRef]

145. Kinch, M.S.; Patridge, E. An Analysis of FDA-Approved Drugs for Infectious Disease: HIV/AIDS Drugs. Drug Discov. Today 2014, 19, 1510-1513. [CrossRef]

146. Clemitson, I. Castable Polyurethane Elastomers; CRC Press: New York, NY, USA, 2008.

147. Suryawanshi, Y.; Sanap, P.; Wani, V. Advances in the Synthesis of Non-isocyanate Polyurethanes. Polym. Bull. 2018, 76, 3233-3246. [CrossRef]

148. Sonnenschein, M.F. Polyurethanes—Science, Technology, Markets and Trends; John Wiley \& Sons, Inc.: Hoboken, NJ, USA, 2015.

149. Ghasemlou, M.; Daver, F.; Ivanova, E.P.; Adhikari, B. Bio-based Routes to Synthesize Cyclic Carbonates and Polyamines Precursors of Non-isocyanate Polyurethanes: A review. Eur. Polym. J. 2019, 118, 668-684. [CrossRef]

150. Monie, F.; Grignard, B.; Thomassin, J.-M.; Mereau, R.; Tassaing, T.; Jerome, C.; Detrembleur, C. Chemo- and Regioselective Additions of Nucleophiles to Cyclic Carbonates for the Preparation of Self-Blowing Non-Isocyanate Polyurethane Foams. Angew. Chem. Int. Ed. 2020, 59, 17033-17041. [CrossRef] [PubMed]

151. Nohra, B.; Candy, L.; Blanco, J.F.; Raoul, Y.; Mouloungui, Z. Synthesis of Five and Six-membered Cyclic Glycerilic Carbonates bearing Exocyclic Urethane Functions. Eur. J. Lipid Sci. Technol. 2013, 115, 111-122. [CrossRef]

152. Bassam, N.; Laure, C.; Jean-François, B.; Yann, R.; Zephirin, M. Aza-Michael versus Aminolysis Reactions of Glycerol Carbonate Acrylate. Green Chem. 2013, 15, 1900-1909. [CrossRef]

153. Nohra, B.; Candy, L.; Blanco, J.-F.; Raoul, Y.; Mouloungui, Z. Aminolysis Reaction of Glycerol Carbonate in Organic and Hydroorganic Medium. J. Am. Oil Chem. Soc. 2012, 89, 1125-1133. [CrossRef]

154. Lombardo, V.M.; Dhulst, E.A.; Leitsch, E.K.; Wilmot, N.; Heath, W.H.; Gies, A.P.; Miller, M.D.; Torkelson, J.M.; Scheidt, K.A. Cooperative Catalysis of Cyclic Carbonate Ring Opening: Application Towards Non-Isocyanate Polyurethane Materials. Eur. J. Org. Chem. 2015, 2015, 2791-2795. [CrossRef]

155. Van Velthoven, J.L.J.; Gootjes, L.; Van Es, D.S.; Noordover, B.A.J.; Meuldijk, J. Poly(Hydroxy Urethane)s Based on Renewable Diglycerol Dicarbonate. Eur. Polym. J. 2015, 70, 125-135. [CrossRef]

156. Blain, M.; Yau, H.; Jean-Gérard, L.; Auvergne, R.; Benazet, D.; Schreiner, P.R.; Caillol, S.; Andrioletti, B. Urea- and ThioureaCatalyzed Aminolysis of Carbonates. ChemSusChem 2016, 9, 2269-2272. [CrossRef]

157. Lee, J.Y.; Saito, R. Polyurethane-Silica Nanocomposites Provided from Perhydropolysilazane: Polymerization Mechanism. Polymer (Guildf) 2018, 135, 251-260. [CrossRef]

158. Annunziata, L.; Diallo, A.K.; Fouquay, S.; Michaud, G.; Simon, F.; Brusson, J.M.; Carpentier, J.F.; Guillaume, S.M. $\alpha, \omega-D i(g l y c e r o l$ arbonate) Telechelic Polyesters and Polyolefins as Precursors to Polyhydroxyurethanes: An Isocyanate-free Approach. Green Chem. 2014, 16, 1947-1956. [CrossRef]

159. Aricò, F.; Bravo, S.; Crisma, M.; Tundo, P. 1,3-Oxazinan-2-ones via Carbonate Chemistry: A Facile, High Yielding Synthetic Approach. Pure Appl. Chem. 2016, 88, 227-237. [CrossRef] 
160. Mei, C.; Zhao, Y.; Zou, K.; Cao, C.; Pang, G.; Shi, Y. Synthesis of N-Aryl-2-oxazolidinones from Cyclic Carbonates and Aromatic Amines Catalyzed by Bio-catalyst. Res. Chem. Intermed. 2018, 44, 2179-2194. [CrossRef]

161. Blain, M.; Jean-Gérard, L.; Auvergne, R.; Benazet, D.; Caillol, S.; Andrioletti, B. Rational Investigations in the Ring Opening of Cyclic Carbonates by Amines. Green Chem. 2014, 16, 4286-4291. [CrossRef]

162. Mommer, S.; Lamberts, K.; Keul, H.; Möller, M. A Novel Multifunctional Coupler: The Concept of Coupling and Proof of Principle. Chem. Commun. 2013, 49, 3288-3290. [CrossRef] [PubMed]

163. Legros, V.; Taing, G.; Buisson, P.; Schuler, M.; Bostyn, S.; Rousseau, J.; Sinturel, C.; Tatibouët, A. Activated Glycerol Carbonates, Versatile Reagents with Aliphatic Amines: Formation and Reactivity of Glycidyl Carbamates and Trialkylamines. Eur. J. Org. Chem. 2017, 2017, 5032-5043. [CrossRef]

164. Magliozzi, F.; Chollet, G.; Grau, E.; Cramail, H. Benefit of the Reactive Extrusion in the Course of Polyhydroxyurethanes Synthesis by Aminolysis of Cyclic Carbonates. ACS Sustain. Chem. Eng. 2019, 7, 17282-17292. [CrossRef]

165. Quérette, T.; Fleury, E.; Sintes-Zydowicz, N. Non-isocyanate Polyurethane Nanoparticles Prepared by Nanoprecipitation. Eur. Polym. J. 2019, 114, 434-445. [CrossRef]

166. Quienne, B.; Kasmi, N.; Dieden, R.; Caillol, S.; Habibi, Y. Isocyanate-Free Fully Biobased Star Polyester-Urethanes: Synthesis and Thermal Properties. Biomacromolecules 2020, 21, 1943-1951. [CrossRef] [PubMed]

167. Pyo, K.-h.; Lee, D.H.; Kim, Y.; Kim, J.-W. Extremely Rapid and Simple Healing of a Transparent Conductor Based on Ag Nanowires and Polyurethane with a Diels-Alder Network. J. Mater. Chem. C 2016, 4, 972-977. [CrossRef]

168. Jaratrotkamjorn, R.; Nourry, A.; Pasetto, P.; Choppé, E.; Panwiriyarat, W.; Tanrattanakul, V.; Pilard, J.-F. Synthesis and Characterization of Elastomeric, Biobased, Nonisocyanate Polyurethane from Natural Rubber. J. Appl. Polym. Sci. 2017, 134, 45427-45439. [CrossRef]

169. Rix, E.; Grau, E.; Chollet, G.; Cramail, H. Synthesis of Fatty Acid-based Non-isocyanate Polyurethanes, NIPUs, in Bulk and Mini-Emulsion. Eur. Polym. J. 2016, 84, 863-872. [CrossRef]

170. Bao, Y.M.; Shen, G.R.; He, J.; Li, Y.S. Water-soluble Hyperbranched Poly(Ester Urethane)s Based on D,L-Alanine: Isocyanate-free Synthesis, Post-functionalization and Application. Green Chem. 2012, 14, 2243-2250. [CrossRef]

171. Besse, V.; Camara, F.; Méchin, F.; Fleury, E.; Caillol, S.; Pascault, J.P.; Boutevin, B. How to Explain Low Molar Masses in PolyHydroxyUrethanes (PHUs). Eur. Polym. J. 2015, 71, 1-11. [CrossRef]

172. Zhang, K.; Nelson, A.M.; Talley, S.J.; Chen, M.; Margaretta, E.; Hudson, A.G.; Moore, R.B.; Long, T.E. Non-isocyanate Poly(Amidehydroxyurethane)s from Sustainable Resources. Green Chem. 2016, 18, 4667-4681. [CrossRef]

173. Lambeth, R.H.; Rizvi, A. Mechanical and Adhesive Properties of Hybrid Epoxy-Polyhydroxyurethane Network Polymers. Polymer 2019, 183, 121881-121888. [CrossRef]

174. Dai, J.; Wu, Z.; Tang, L.; Qu, J. Preparation of Five-membered Bis(Cyclic Carbonate)s at Atmospheric Pressure for Polyhydroxyurethane Coatings. J. Appl. Polym. Sci. 2019, 136, 47957-47965. [CrossRef]

175. Wu, Z.; Tang, L.; Dai, J.; Qu, J. Synthesis and Properties of Aqueous Cyclic Carbonate Dispersion and Nonisocyanate Polyurethanes under Atmospheric Pressure. Prog. Org. Coat. 2019, 136, 105209-105217. [CrossRef]

176. Duval, C.; Kébir, N.; Jauseau, R.; Burel, F. Organocatalytic Synthesis of Novel Renewable Non-isocyanate Polyhydroxyurethanes. J. Polym. Sci. Part A Polym. Chem. 2016, 54, 758-764. [CrossRef]

177. Fleischer, M.; Blattmann, H.; Mülhaupt, R. Glycerol-, Pentaerythritol- and Trimethylolpropane-based Polyurethanes and their Cellulose Carbonate Composites Prepared via the Non-isocyanate Route with Catalytic Carbon Dioxide Fixation. Green Chem. 2013, 15, 934-942. [CrossRef]

178. Carré, C.; Zoccheddu, H.; Delalande, S.; Pichon, P.; Avérous, L. Synthesis and Characterization of Advanced Biobased Thermoplastic Nonisocyanate Polyurethanes, with Controlled Aromatic-Aliphatic Architectures. Eur. Polym. J. 2016, 84, 759-769. [CrossRef]

179. Tryznowski, M.; Świderska, A.; Zołek-Tryznowska, Z.; Gołofit, T.; Parzuchowski, P.G. Facile Route to Multigram Synthesis of Environmentally Friendly Non-isocyanate Polyurethanes. Polymer (Guildf) 2015, 80, 228-236. [CrossRef]

180. Benyahya, S.; Habas, J.P.; Auvergne, R.; Lapinte, V.; Caillol, S. Structure-Property Relationships in Polyhydroxyurethanes Produced from Terephthaloyl Dicyclocarbonate with Various Polyamines. Polym. Int. 2012, 61, 1666-1674. [CrossRef]

181. Lee, S.H.; Lee, D.S. Self-Healing and Rheological Properties of Polyhydroxyurethane Elastomers Based on Glycerol Carbonate Capped Prepolymers. Macromol. Res. 2019, 27, 460-469. [CrossRef]

182. Wazarkar, K.; Kathalewar, M.; Sabnis, A. Development of Epoxy-Urethane Hybrid Coatings via Non-isocyanate Route. Eur. Polym. J. 2016, 84, 812-827. [CrossRef]

183. Wang, Z.; Zhang, X.; Zhang, L.; Tan, T.; Fong, H. Nonisocyanate Biobased Poly(ester urethanes) with Tunable properties synthesized via an environment-friendly route. ACS Sustain. Chem. Eng. 2016, 4-5, 2762-2770. [CrossRef]

184. Tale, N.V.; Jagtap, R.N.; Tathe, D.S. An Efficient Approach for the Synthesis of Thermoset Polyurethane Acrylate Polymer and its Film Properties. Des. Monomers Polym. 2014, 17, 147-155. [CrossRef]

185. Mamiński, M.Ł.; Szymański, R.; Parzuchowski, P.; Antczak, A.; Szymona, K. Hyperbranched Polyglycerols with Bisphenol A Core as Glycerol-derived Components of Polyurethane Wood Adhesives. BioResources 2012, 7, 1440-1451. [CrossRef]

186. Dolci, E.; Michaud, G.; Simon, F.; Boutevin, B.; Fouquay, S.; Caillol, S. Remendable Thermosetting Polymers for Isocyanate-free Adhesives: A Preliminary Study. Polym. Chem. 2015, 6, 7851-7861. [CrossRef] 
187. Leitsch, E.K.; Heath, W.H.; Torkelson, J.M. Polyurethane/Polyhydroxyurethane Hybrid Polymers and their Applications as Adhesive Bonding Agents. Int. J. Adhes. Adhes. 2016, 64, 1-8. [CrossRef]

188. Ju, Y.H.; Lee, H.-J.; Han, C.J.; Lee, C.-R.; Kim, Y.; Kim, J.-W. Water-responsive Pressure-sensitive Adhesive with Reversibly Changeable Adhesion for Fabrication of Stretchable Devices. Mater. Des. 2020, 195, 108995. [CrossRef]

189. Weil, E.D.; Levchik, S.V. Flame Retardants for Plastics and Textiles; Hanser Publishers: Munich, Germany, 2009.

190. Dufton, P.W. Flame Retardants for Plastics Market. Report; Rapra Technology Limited: West Midlands, UK, 2003.

191. Benin, V.; Gardelle, B.; Morgan, A.B. Heat Release of Polyurethanes Containing Potential Flame Retardants Based on Boron and Phosphorus Chemistries. Polym. Degrad. Stab. 2014, 106, 108-121. [CrossRef]

192. Benin, V.; Cui, X.; Morgan, A.B.; Seiwert, K.J. Synthesis and Flammability Testing of Epoxy Functionalized Phosphorous-based Flame Retardants. Appl. Polym. Sci. 2015, 132, 42296-42305. [CrossRef]

193. Sonnenschein, M.F.; Virgili, J.M.; Babb, D.A.; Bell, B.M.; Nickless, B.C. Synthesis and Flame Retardant Potential of Polyols Based on Bisphenol-S. J. Polym. Sci. Part A Polym. Chem. 2016, 54, 2102-2108. [CrossRef]

194. Eisele, A.; Kyriakos, K.; Bhandary, R.; Schönhoff, M.; Papadakis, C.M.; Rieger, B. Structure and Ionic Conductivity of Liquid Crystals having Propylene Carbonate Units. J. Mater. Chem. A 2015, 3, 2942-2953. [CrossRef]

195. Zhu, Z.; Einset, A.G.; Yang, C.-Y.; Chen, W.-X.; Wnek, G.E. Synthesis of Polysiloxanes Bearing Cyclic Carbonate Side Chains. Dielectric Properties and Ionic Conductivities of Lithium Triflate Complexes. Macromolecules 1994, 27, 4076-4079. [CrossRef]

196. Lee, D.H.; Heo, G.; Pyo, K.; Kim, Y.; Kim, J.-W. Mechanically Robust and Healable Transparent Electrode Fabricated via Vapor-Assisted Solution Process. ACS Appl. Mater. Interfaces 2016, 8, 8129-8136. [CrossRef]

197. Fu, W.; Wang, L.; Yang, Z.; Shen, J.-S.; Tang, F.; Zhang, J.; Cui, X. Facile Access to Versatile Aza-macrolides Through IridiumCatalysed Cascade Allyl-amination/Macrolactonization. Chem. Commun. 2020, 56, 960-963. [CrossRef] [PubMed]

198. Mollaeian, K.; Wei, S.; Islam, M.R.; Dickerson, B.; Holmes, W.E.; Benson, T.J. Development of an Online Raman Analysis Technique for Monitoring the Production of Biofuels. Energy Fuels 2016, 30, 4112-4117. [CrossRef]

199. Steber, J. Handbook for Cleaning/Decontamination of Surfaces: The Ecotoxicity of Cleaning Product Ingredients; Elsevier: Amsterdam, The Netherlands, 2007.

200. Castro, M.J.L.; Ojeda, C.; Cirelli, A.F. Advances in Surfactants for Agrochemicals. Environ. Chem. Lett. 2014, 12, 85-95. [CrossRef]

201. Sorella, G.; Strukul, G.; Scarso, A. Recent Advances in Catalysis in Micellar Media. Green Chem. 2015, 17, 644-683. [CrossRef]

202. Climent, M.J.; Corma, A.; Iborra, S.; Martínez-Silvestre, S.; Velty, A. Preparation of Glycerol Carbonate Esters by using Hybrid Nafion-Silica Catalyst. ChemSusChem 2013, 6, 1224-1234. [CrossRef]

203. Mauritz, K.A.; Moore, R.B. State of Understanding of Nafion. Chem. Rev. 2004, 104, 4535-4586. [CrossRef] [PubMed]

204. Han, L.; Wang, T. Preparation of Glycerol Monostearate from Glycerol Carbonate and Stearic Acid. RSC Adv. 2016, 6, 34137-34145. [CrossRef]

205. Campagne, B.; David, G.; Améduri, B.; Jones, D.J.; Rozière, J.; Roche, I. New Semi-IPN PEMFC Membranes Composed of Crosslinked Fluorinated Copolymer bearing Triazole Groups and sPEEK for Operation at Low Relative Humidity. Int. J. Hydrog. Energy 2015, 40, 16797-16813. [CrossRef]

206. Sacripante, G.G.; Zhou, K.; Farooque, M. Sustainable Polyester Resins Derived from Rosins. Macromolecules 2015, 48, 6876-6881. [CrossRef]

207. Liu, B.; Zhang, Y.-Y.; Zhang, X.-H.; Du, B.-Y.; Fan, Z.-Q. Fixation of carbon dioxide concurrently or in tandem with free radical polymerization for highly transparent polyacrylates with specific UV absorption. Polym. Chem. 2016, 7, 3731-3739. [CrossRef]

208. Poupart, R.; Houda, D.N.E.; Chellapermal, D.; Guerrouache, M.; Carbonnier, B.; Droumaguet, B.L. Novel In-capillary Polymeric Monoliths Arising from Glycerol Carbonate Methacrylate for Flow-through Catalytic and Chromatographic Applications. RSC Adv. 2016, 6, 13614-13617. [CrossRef] 